
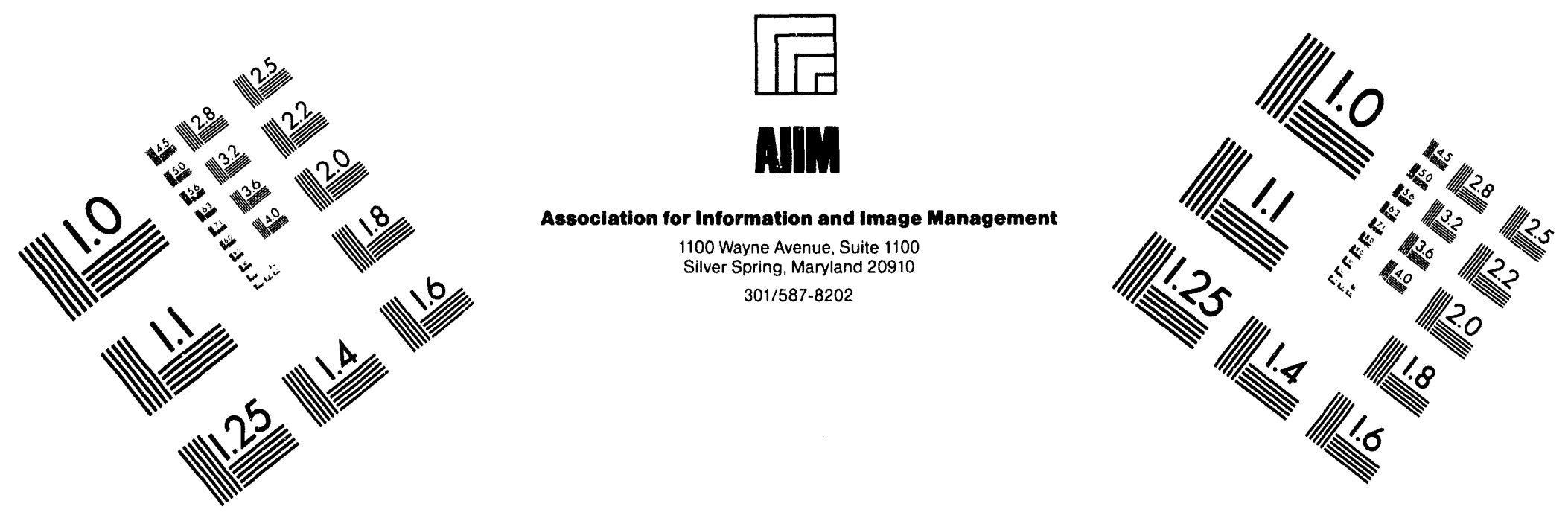

\title{
Centimeter
}

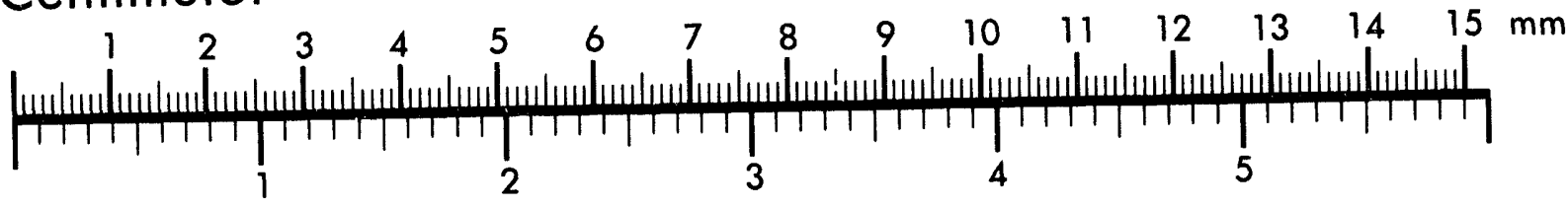
Inches
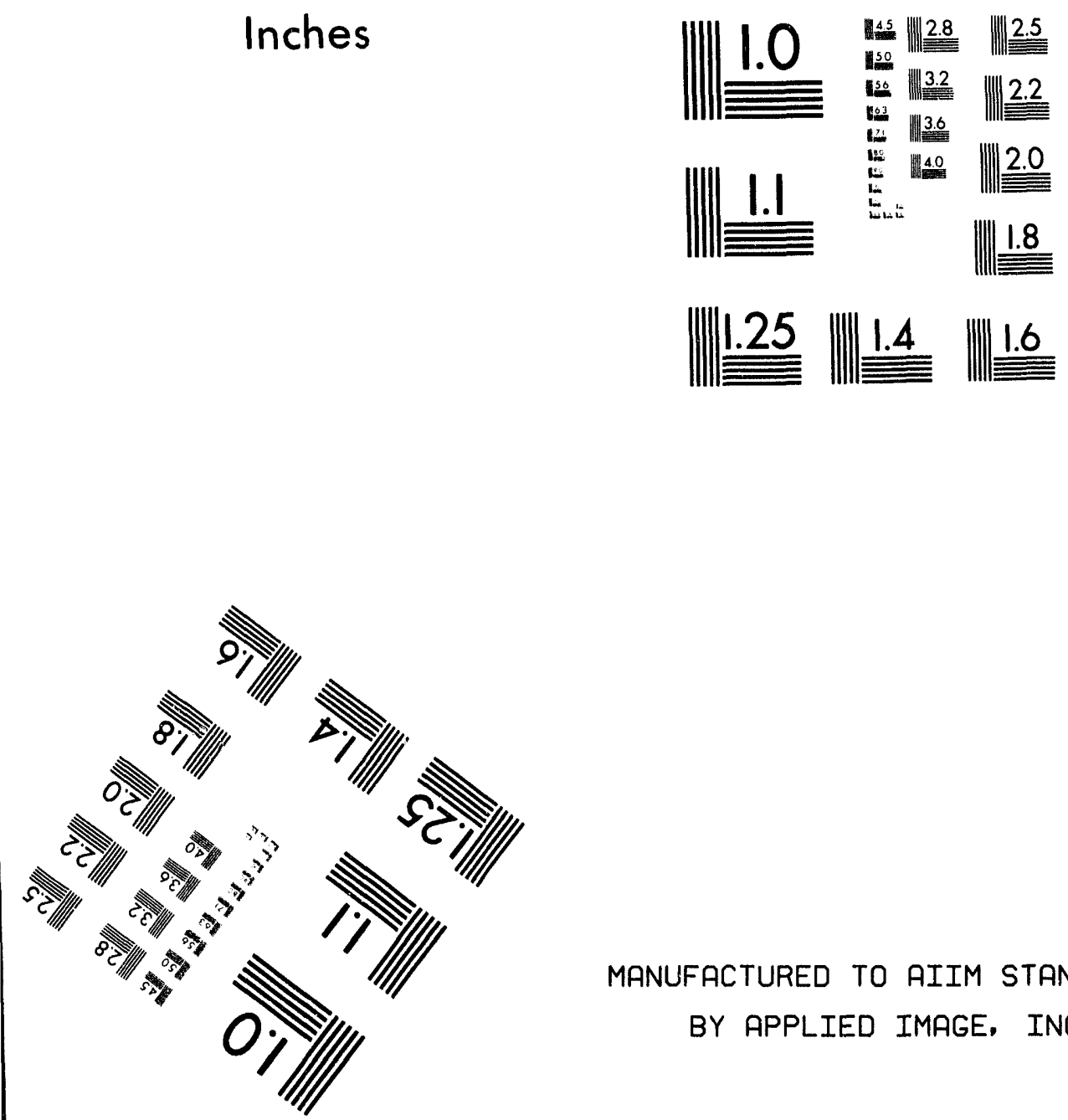

MANUFACTURED TO AIIM STANDARDS

BY APPLIED IMAGE, INC.

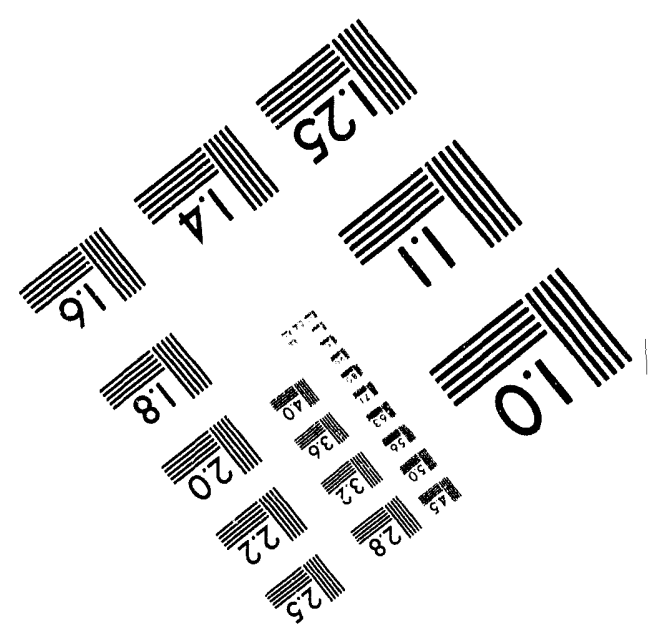



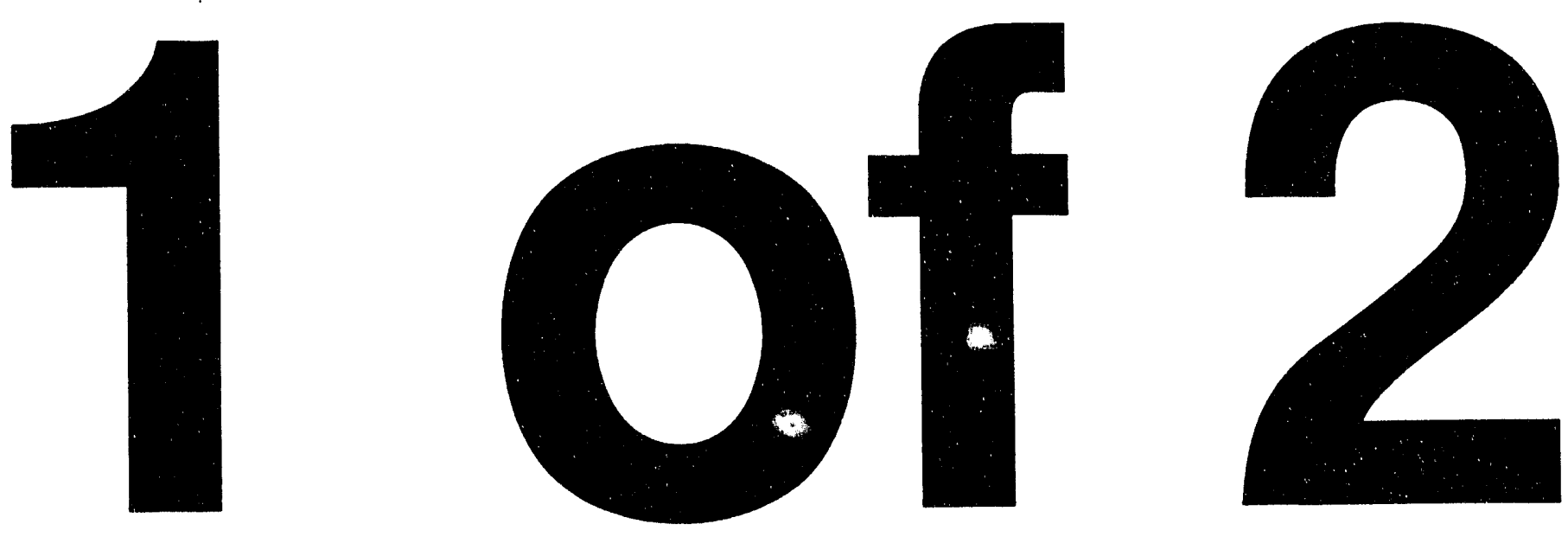


\section{SAVANNAH RIVER SITE \\ HUMAN ERROR DATA BASE DEVELOPMENT FOR NONREACTOR NUCLEAR FACILITIES (U)}

by

H. C. Benhardt

S. A. Eide*

J. E. Held

L. M. Olsen

R. E. Vail

Issued: February 28, 1994

* Los Alamos Technical Associates

Albuqurque, NM 87110

Westinghouse Savannah River Company

Savannah River Site

Alken, SC 29808

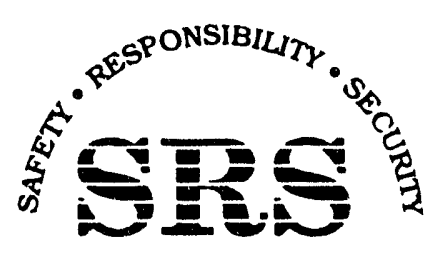

SAVANNAH RIVER SITE

PREPARED FOR THE U.S. DEPARTMENT OF ENERGY UNDER CONTRACT NO. DE-AC09-89SR18035 
This page intentionally left blank 


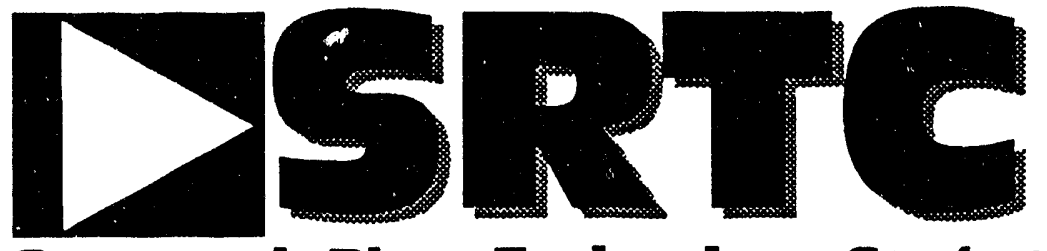

Savannah River Technology Center

Document:

Title:
WSRC-TR-93-581

Savannah River Site Human Error Data Base Development for Nonreactor Nuclear Facilities (U)

Approvals:

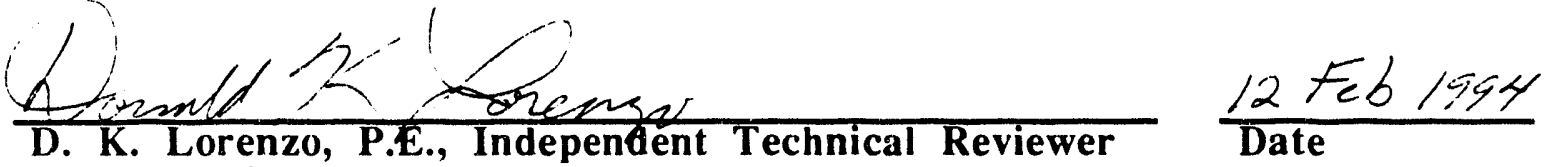
JBF Associates, Inc.

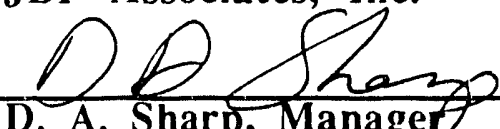

Risk Assessment Methodology Group

M. J. Hitchler, Manager

Whaste and Environmental Safety Technology Section $\frac{24 \sqrt{4 b} / 994}{\text { Date }}$

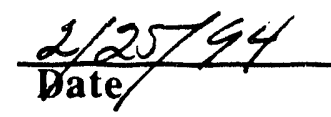


This page intentionally left blank 


\section{EXECUTIVE SUMMARY}

As part of an overall effort to upgrade and streamline methodologies for safety analyses of nonreactor nuclear facilities at the Savannah River Site (SRS), a human error data base has been developed and is presented in this report.

The data base fulfills several needs of risk analysts supporting safety analysis report (SAR) development. First, it provides a single source for probabilities or rates for a wide variety of human errors associated with the SRS nonreactor nuclear facilities. Second, it provides a documented basis for human error probabilities or rates. And finally, it provides actual SRS-specific human error data to support many of the error probabilities or rates. Use of a single, documented reference source for human errors, supported by SRS-specific human error data, will improve the consistency and accuracy of human error modeling by SRS risk analysts.

It is envisioned that SRS risk analysts will use this report as both a guide to identifying the types of human errors that may need to be included in risk models such as fault and event trees, and as a source for human error probabilities or rates. For each human error in this report, three different mean probabilities or rates are presented to cover a wide range of conditions and influencing factors. The risk analysts must decide which mean value is most appropriate for each particular application. If other types of human errors are needed for the risk models, the analyst must use other sources. Finally, if human errors are dominant in the quantified risk models (based on the values obtained from this report), then it may be appropriate to perform detailed human reliability analyses (KRAs) for the dominant events. This document does not provide guidance for such refined HRAs; in such cases experienced human reliability analysts should be involved. 
WSRC-TR-93-581

This page intentionally left blank. 


\begin{abstract}
As part of an overall effort to upgrade and streamline methodologies for safety analyses of nonreactor nuclear facilities at the Savannah River Site (SRS), a human error data base has been developed. The data base includes models and quantification results for 35 representative human errors. For 16 of the human errors, the recommended human error probabilities or rates are based solely on generic models developed from industry literature (i.e., no actual SRS data available). SRSspecific data were collected for 19 of the 35 human errors. Of these 19 human errors, the final recommended values for two errors were based solely on the actual SRS-specific data.

Recommended SRS-specific human error probabilities or rates were obtained by combining the generic models with the SRS-specific data for the remaining 17 human errors.
\end{abstract}


This page intentionally left blank 


\section{TABLE OF CONTENTS}

Executive Summary

Page

Abstract.

ES-1

Table of Contents

..i

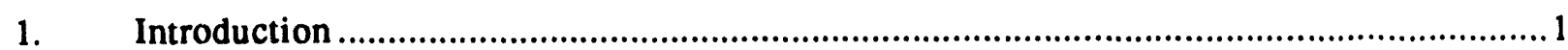

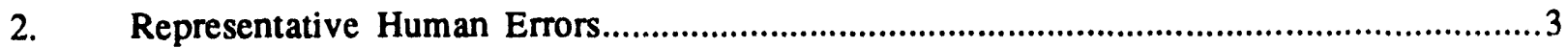

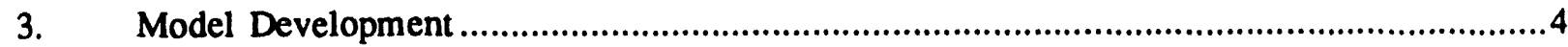

3.1 Generic Model Development ............................................................................4

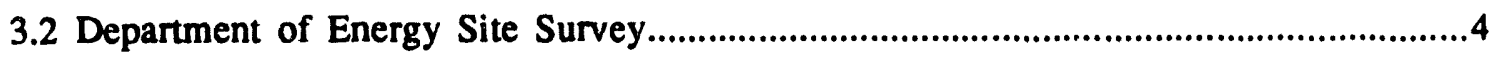

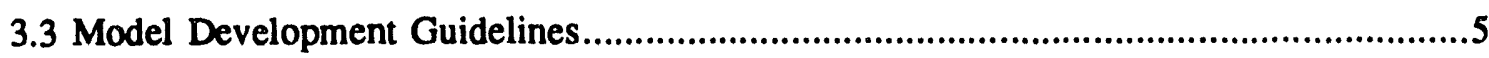

3.4 SRS-Specific Human Error Data Collection ........................................................8

3.5 Recommended SRS-Specific Model Development ................................................

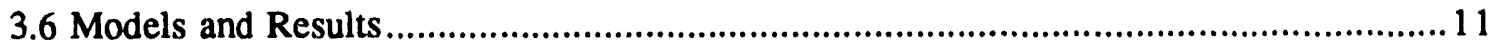

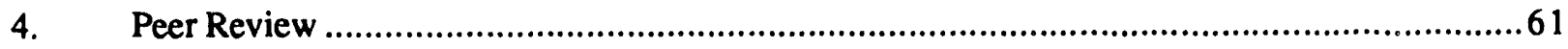

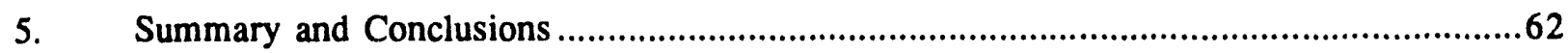

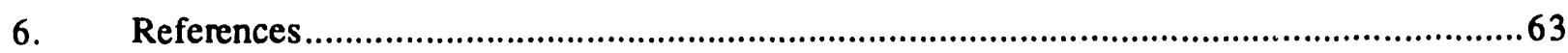


This page intentionally left blank 


\section{LIST OF TABLES}

Page

1. List of representative human errors .65

2. Guidelines for selection of Error Factors.................................................................69

3. Recommended SRS human error probabilities and rates .........................................70

4. Selection guidelines for recommended human error probabilities and rates .76

\section{LIST OF FIGURES}

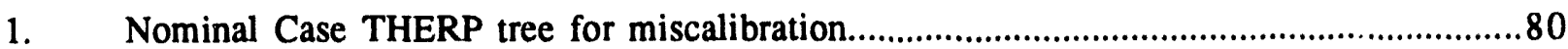

2. Nominal Case THEIRP tree for failure to restore following test ...................................8 1

3. Nominal Case THERP tree for failure to restore following maintenance..........................84

4. Nominal Case THERP tree for failure to verify parameter with calculation........................85

5. Low Case THERP tree for failure of visual inspection ..............................................86

6. Nominal Case THERP tree for long-term accident recovery .......................................87 
WSRC-TR-93-581

This page intentionally left blank. 


\section{INTRODUCTION}

As part of an overall effort to upgrade and streamline methodologies for safety analyses of nonreactor nuclear facilities at the Savannah River Site (SRS), a human error data base has been developed. The data base includes models and quantification results for 35 representative human errors. For 16 of the human errors, the recommended human error probabilities or rates are based solely on the generic models (i.e., no actual SRS-specific data available). SRS-specific data were collected for 19 of the 35 errors. Of these 19 human errors, the final recommended values for two errors were based solely on the actual SRS-specific data. Recommended SRS-specific error probabilities or rates were obtained by combining the generic models with the SRS-specific data for the remaining 17 human errors.

The data base fulfills several needs of risk analysts supporting safety analysis report (SAR) development. First, it provides a single source for probabilities or rates for a wide variety of human errors associated with the SRS nonreactor nuclear facilities. Second, it provides a documented basis for human error probabilities or rates. And finally, it provides actual SRS-specific human error data to support many of the error probabilities or rates. Use of a single, documented reference source for human errors, supported by SRS-specific human error data, will improve the consistency and accuracy of human error modeling by SRS risk analysts.

It is envisioned that SRS risk analysts will use this report as both a guide to identifying the types of human errors that may need to be included in risk models such as fault and event trees, and a source for human error probabilities or rates. For each human error in this report, three different mean probabilities or rates are presented to cover a wide range of conditions and influencing factors. These results are shown in Table 4. The risk analysts must decide which mean value is most appropriate for each particular application. If other types of human errors are needed for the risk models, the analyst must use a source other than this document to derive error frequencies and demands. It is suggested that methods should be used that are similar to those used in the Section 3.3 Model Development Guidelines. Error frequencies are best extracted from a data base reporting system (e.g., SRS Risk Assessment Fault Tree Data Banks System). Arriving at an accurate number of demands for a specific operation and time frame will require investigation into the facility's process records, interviews with subject matter experts, and interviews with facility personnel. Finally, if human errors are dominant in the quantified risk models (based on the values obtained from this report), then it may be appropriate to perform detailed human reliability analyses (HRAs) for the dominant events. This document does not provide guidance for such refined HRAs; in such cases experienced human reliability analysts should be involved. 
Steps in this project included the following:

- develop a comprehensive list of human errors used in SRS risk models of nonreactor nuclear facilities

- develop generic quantification models for the resultant list of human errors

- collect SRS-specific human error data

- develop SRS-specific human error rates based on the generic model results and the SRSspecific data using a Bayesian update process 1

- $\quad$ obtain extemal peer review and mocify results as necessary.

Each step is discussed in the following sections. 


\section{REPRESENTATIVE HUMAN ERRORS}

A representative list of human errors appropriate for risk models of SRS nonreactor nuclear facilities is presented in Table 1. This list was generated from a review of the following:

- $\quad$ existing SRS nonreactor nuclear facility risk models (I:B-Line, H-Canyon, Plutonium Storage Facility, F and H Area Waste Tanks, In-Tank Processing, Consolidated Incinerator Facility, Solid Waste Disposal Facility, Savannah River Technology Center Laboratory Facilities, and 772-F Laboratory)

- $\quad$ the Defense Waste Processing Facility (DWPF) SAR upgrade

- actual human errors that occurred at the SRS H-Canyon (1991 - present), as reported in the SRS Risk Assessment Fault Tree Data Banks System. 2

From this review approximately 25 representative human error events were identified. The list was expanded to the final 35 by the addition of transportation, container handling, and excavation events. The final list of 35 human error events is meant to be relatively complete for SRS nonreactor nuclear facility risk analyses; however, each new risk analysis may require events that have not been included.

The human error events in Table 1 have been grouped into the following types:

1. basic

2. complex
a. maintenance and testing
b. facility operations
c. mobile equipment operation
d. accident response.

This grouping is not essential for the subsequent generic model development and data collection, but is provided as a guide to risk analysts in locating and understanding the human error events.

Human error events are often grouped into pre-accident, initiator, and post-accident. A review of Table 1 indicates that almost all of the events are pre-accident or initiators, with very few in the post-accident category (events 30 through 35 in Table 1). This is typical for nonreactor nuclear facility SARs where the focus is on initiating events. 


\section{MODEL DEVELOPMENT}

\subsection{GENERIC MODEL DEVELOPMENT}

Generic human error model development involved the identification of applicable human error models for each of the events discussed in Section 2 and quantification of the models for several different sets of influence factors or situations. This is discussed in the Generic Model Section associated with each human error modeled in this report. In some cases the generic models reflect specific practices at the SRS; however, the models do not include any influence from actual SRSspecific human error data. Collection of actual SRS-specific human error data and their use in modifying the generic results are discussed in the SRS-Specific Model and Recommended SRSSpecific Model Sections.

The process of developing and quantifying the generic human error models included several steps:

1. a survey of DOE sites to identify current HRA practices and any available human error data

2. development of guidelines for generic model selection and quantification

3. actual generic model selection, application, and quantification.

Each step is described below.

\subsection{DEPARTMENT OF ENERGY SITES SURVEY}

The DOE sites survey had two main purposes:

- $\quad$ identify current and proposed methods for quantifying human errors

- $\quad$ identify any actual site human error data.

The survey included the following sites:

- Idaho National Engineering Laboratory (INEL)

- $\quad$ EG\&G Idaho, Incorporated (EGG)

- Westinghouse Idaho Nuclear Company (WINCO)

- $\quad$ Rocky Flats Plant (RFP)

- Sandia National Laboratory (SNL)

- $\quad$ Oak Ridge National Laboratory (ORNL). 
Results of the survey indicated that two main HRA models were typically used to quantify human errors: Technique for Human Error Rate Prediction (THERP) as described in the Handbook of Human Reliability Analysis with Emphasis on Nuclear Power Plant Applications 3 (hereafter referred to as the Handbook) and the Accident Sequence Evaluation Program Human Reliability Analysis Procedure 4 (hereafter referred to as ASEP). ASEP is a simplified and generally conservative derivative of the Handbook. ORNL recently published a report providing guidance for applying THERP to nonreactor facilities. 5

In addition to THERP and ASEP, the DOE sites have made more limited use of several other human reliability models. These include the following:

\author{
- human cognitive reliability (HCR) 6 \\ - INTENT 7 \\ - actual national or regional data for transportation accidents \\ - $\quad$ expert judgment elicitation. 8
}

None of the DOE sites surveyed have a site-specific human error data base. Some have records (log books, incident reports, and others) that could be reviewed to identify actual human errors. The SRS is the most advanced in this area, with its computerized SRS Risk Assessment Fault Tree Data Banks System. However, even this system has only failure event data. To convert such event data to failure probabilities or rates, information on the numbers of demands or opportunities must be collected. (Such an effort is described in Section 3.4 of this report.)

\title{
3.3 MODEL DEVELOPMENT GUIDELINES
}

Considerations for developing generic human error models involved the types of human actions and the quantification approach. The types of human actions that were considered are discussed in Section 2 The quantification approach includes several topics: level of conservatism desired in the results, distinction between mean and median values, multiple results for each event to cover a variety of situations, and rounding scheme for results. Each is discussed below.

The DOE sites survey indicated that several types of human error models are used, but with THERP and ASEP being predominant. The models considered for this project include all of those identified in the survey except for ASEP. ASEP was not considered because more detail, more 
flexibility, and less conservatism were desired than are available with this model.

In the selection and quantification of human error models, best estimate or conservatively high results can be obtained, depending upon the structure of the model, the allowance for extra recoveries, and the basic human error probabilities or rates chosen to insert into the model. In this project, the goal was to strive for results that leaned more towards best estimate than towards conservatively high.

Risk analysis models are often quantified in two ways. The first involves using mean values for all of the basic events in the models to obtain a best estimate (interpreted to be a mean) result. The second involves determining the uncertainty distribution for the complex event by propagating error factors for the basic events through the THERP models to obtain an uncertainty distribution for the result. In order to fulfill both quantification needs, the generic models were quantified to obtain both mean failure probabilities and uncertainty distribution information for each of the human errors. Therefore, when sources such as the Handbook were used for basic human error rates, all values interpreted to be medians were first converted to means before use in the models. Assuming a lognormal distribution, the relationship of the mean to the median is the following:

$$
\text { mean } / \text { median }=\exp \left\{0.5[(\operatorname{lnEF}) / 1.645]^{2}\right\}
$$

where $E F=$ error factor (95th percentile / 50th percentile)

ln = natural logarithm.

Given human error models for each event, each model was quantified to obtain three mean failure probabilities: low, nominal, and high. Each value represents a mean error probability or rate for a different set of conditions. The low mean value is representative of instances where most influencing factors such as training, quality of procedures, environment, and others are better than average. The nominal mean value is representative of instances where most influencing factors are average, while the high mean value is appropriate where most influencing factors are worse than average.

The risk analyst's choice of high, nominal, or low human error probability values is determined by making subjective assessments of the significant influences on human actions. Some of the more prominent influences on human actions are the quality of administrative controls, procedures, training, organizational culture, situational stress, and the design of the man-machine interface. Department of Energy and commercial nuclear industry orders, regulations, standards, and guidelines provide the detailed information for evaluating the influences on human actions. The Handbook can be consulted for guidance on evaluating human actions traditionally associated 
with nuclear facility operation. Fire fighting, excavating, mobile crane operations, and transport vehicle operations have their own industry standards that must be consulted.

Qualitative assessments of excellent, very good, good, fair, and poor are determined by comparing the appropriate influences on the human action being evaluated to the appropriate regulations, standards, and/or guidelines. If the influences are positive-contribute to lower error probabilities-they would be rated good, very good, or excellent based on the degree to which they meet or exceed regulations, standards, and/or guidelines. If the influences fall below requirements, a fair or poor rating would be assigned. This results in higher error probabilities. Information on the quality of the influencing factors can be obtained by reviewing evaluation reports and abnormal event data bases or by conducting interviews with subject matter experts.

Situational stress depends on the scenario that is being modeled. Perception of personal safety, external stimuli (e.g., alarms, flashing lights, voices, etc.), training and experience are major contributors in determining stress levels. Low or nominal human error probabilities are used in situations of normal operation, planned process transients (process startup, shutdown, batch process operations including material transfers, etc.) and frequent minor off normal occurrences. Nominal or high stress probabilities apply for less frequent, more significant off normal occurrences (loss of offsite power, environmental releases, material leaks and spills, etc.), and post major event situations ( $\geq 2$ hours after earthquake, tornado, explosions, etc.). High stress probabilities apply to situations where effects are direct on personnel (e.g., personal well-being threatened). Situations of this nature are earthquakes where major structural or equipment damage has occurred, tornadoes that strike the facility where personnel are located, explosions/fires where personnel are close enough to perceive a loud noise, flame or smoke, and criticality accidents where personnel are at or near the scene.

Each resulting human error probability or rate was considered to have lognormal distribution, characterized by a mean and an EF. Each mean value obtained from each generic human error model was rounded to 1,3 , or 5 times the appropriate power of ten.

Original Number

$7.5 \times 10^{n}>Y \times 10^{n} \geq 4.0 \times 10^{n}$

$4.0 \times 10^{n}>Y \times 10^{n} \geq 2.0 \times 10^{n}$

$2.0 \times 10^{\mathrm{n}}>\mathrm{Y} \times 10^{\mathrm{n}} \geq 7.5 \times 10^{(\mathrm{n}-1)}$
Bounded Number

$5 \times 10^{n}$

$3 \times 10^{n}$

$1 \times 10^{n}$

Where $\mathrm{Y} \times 10^{\mathrm{n}}$ represents the mean value being rounded and $\mathrm{n}$ is a negative integer. 
This rounding scheme lies between rounding to one significant figure and rounding to 1 or 3 times the appropriate power of ten, which was employed in the Reactor Risk Study, or WASH-1400. 9 Although initial estimates of EFs were obtained from the models (where sufficient information is provided), the final EFs were obtained from the guidelines $n$ Table 2. These guidelines were used because some of the generic models did not provide information on EFs and there do not appear to be strong bases for the EFs in the Handbook. The guidelines for selecting EFs in Table 2 are based on three common practices. The first is to keep the EFs simple (and somewhat consistent with the rounding scheme for the mean values). The second is to keep the 95th percentile (median times EF) below 10 . The third is to have the EF increase as the mean probability decreases. These rounding schemes are felt to be appropriate for a generic data base. The rounding schemes discussed above are consistent with the rounding schemes used in the development of the SRS generic data base for component hardware failures. 10 The rounded nominal, high, and low mean HEPs and EFs from each Generic Model section are presented in the Generic Model column of Table 3.

\subsection{SRS-SPECIFIC HUMAN ERROR DATA COLLECTION}

Many of the generic human error models in this report are based on models, data, or estimates derived for applications at commercial nuclear reactors. In order to strengthen the basis for the generic models to SRS facilities, SRS-specific human error data were collected. The SRS data was then used to adjust the generic models. Several sources for SRS human error data were used. A major source was the SRS Risk Assessment Fault Tree Data Banks System. ${ }^{2}$ This computerized data bank includes nonreactor events found in various facility log books, incident reports, and many other SRS documents. The other major source was the SRS reactor data base (REAC), covering events at the SRS reactors. 11 Finally, other sources for events included various specialized records for facilities and interviews with facility subject matter experts.

For the human error data to be useful for this project, estimates of the numbers of demands or opportunities for such errors were also needed. These estimates were obtained from interviews with facility personnel or reviews of procedures and other facility-specific documents and records.

The SRS-specific human error data are summarized in Table 3. The collection efforts or sources of the data are discussed in the SRS-Specific Model sections for each of the human errors modeled in this report. 


\subsection{RECOMMENDED SRS-SPECIFIC MODEL DEVELOPMENT}

The recommended SRS human error rates and probabilities were obtained by using the rounded generic model results as priors and the SRS-specific model results as the evidence in the Bayesian updates. For events with no SRS-specific data, the generic model results were also the recommended SRS results. Likewise, for the two events with no generic model results the SRSspecific data were used as the recommended SRS results. This process is analogous to updating generic component failure rates with facility-specific data.

For human error events that are per demand, operation, or mile, the Bayesian update process fits the prior distribution to a beta distribution and the posterior is also then a beta distribution (which is converted to a lognornal distribution). The process is the following ${ }^{1}$ :

1. Fit the prior lognormal distribution to a beta distribution

$$
\begin{aligned}
\alpha+\beta+1 & =\left(1-\mathrm{Mn}_{1}\right) /\left(\mathrm{Mn}_{1}\left[\exp \left(\left(\ln \left(\mathrm{EF}_{1}\right) / 1.645\right)^{2}\right)-1\right]\right\} \\
\alpha & =\operatorname{Mn}_{1}[(\alpha+\beta+1)-1]
\end{aligned}
$$

where $\mathrm{Mn}_{1}=$ mean of prior lognormal distribution (Generic Model)

$$
\mathrm{EF}_{1}=\mathrm{EF} \text { of prior lognormal distribution (Generic Model) }
$$

2. Identify the SRS-specific data (evidence)

$$
\begin{aligned}
& \mathrm{n}=\text { number of events (SRS-Specific Model) } \\
& \mathrm{D}=\text { number of demands (SRS-Specific Model) }
\end{aligned}
$$

3. Determine the beta distribution for the posterior

$$
\begin{aligned}
\mathrm{Mn}_{2} & =(\alpha+\mathrm{n}) /[(\alpha+\beta+1)+\mathrm{D}-1] \\
\mathrm{EF}_{2} & \left.=\exp \left(1.645\left[\left(\ln \left(1+\left(1-\mathrm{Mn}_{2}\right) /\left(\mathrm{Mn}_{2}(\alpha+\beta+1+\mathrm{D})\right)\right)\right)\right)^{0.5}\right]\right) \\
\text { where } \mathrm{Mn}_{2} & =\text { mean of posterior beta distribution } \\
\mathrm{EF}_{2} & =\mathrm{EF} \text { of posterior beta distribution }
\end{aligned}
$$

4. Convert to lognormal posterior

$$
\begin{aligned}
& \mathrm{Mn}_{3}=\mathrm{Mn}_{2} \\
& \mathrm{EF}_{3}=\mathrm{EF}_{2}
\end{aligned}
$$

where $\mathrm{Mn}_{3}=$ mean of posterior lognormal distribution

$\mathrm{EF}_{3}=\mathrm{EF}$ of posterior lognormal distribution. 
If the human error event is per hour, then a gamma prior distribution is used, resulting in a gamma posterior distribution (which is converted to a lognormal distribution). The process is the following 1 :

1. Fit the prior lognormal distribution to a gamma distribution

$$
\begin{aligned}
& \alpha=\left\{\exp \left[\left(\ln \left(\mathrm{EF}_{1}\right) / 1.645\right)^{2}\right] \cdot 1\right\}^{-1} \\
& B=\alpha / \mathrm{Mn}_{1}
\end{aligned}
$$

where $\mathrm{Mn}_{1}=$ mean of prior lognomal distribution (Generic Model)

$\mathrm{EF}_{1}=\mathrm{EF}$ of prior lognormal distribution (Generic Model)

2. Identify the SRS-specific data (evidence)

$$
\begin{aligned}
& \mathrm{n}=\text { number of events (SRS-Specific Model) } \\
& \mathrm{T}=\text { exposure time (SRS-Specific Model) }
\end{aligned}
$$

3. Determine the gamma distribution for the posterior

$$
\begin{aligned}
& \mathrm{Mn}_{2}=(\alpha+n) /(B+\mathrm{T}) \\
& \mathrm{EF}_{2}=\exp \left\{1.645[\ln ((\alpha+n+1) /(\alpha+n))]^{0.5}\right\} \\
& \text { where } \mathrm{Mn}_{2}=\text { mean of posterior gamma distribution } \\
& \mathrm{EF}_{2}=\mathrm{EF} \text { of posterior gamma distribution }
\end{aligned}
$$

4. Convert to lognormal posterior

$$
\begin{aligned}
& \mathrm{Mn}_{3}=\mathrm{Mn}_{2} \\
& \mathrm{EF}_{3}=\mathrm{EF}_{2}
\end{aligned}
$$

where $\mathrm{Mn}_{3}=$ mean of posterior lognormal distribution

$\mathrm{EF}_{3}=\mathrm{EF}$ of posterior lognormal distribution.

The results of the Bayesian updates and the recommended human error probabilities or rates for the SRS are presented in Table 3. Table 4 is the recommended table to be consulted to obtain human error probabilities or rates. 


\subsection{MODELS AND RESULTS}

\subsubsection{Failure of Administrative Control}

The failure of administrative control involves the failure of personnel to follow a policy or procedure. Factors that influence errors in following administrative controls are organizational culture, training, quality of administrative controls, accessibility of documents, and tempting shortcuts in the actions described in the controls.

\subsubsection{Generic Model}

Table 20-5 in the Handbook, "Estimated HEPs [human error probabilities] Related to Failure of Administrative Control" provides the error probabilities for this event. When following a documented policy or normal operating procedure under normal circumstances, Table 20-6, Item 1 applies and lists a mean HEP of 1.6E-2 (median =1.0E-2), with an EF of five. This is considered to be the nominal case mean value for this human error. This nominal value should also be used for emergency or abnormal operating procedures. The Handbook indicates that operators seek the assurances of these procedures during stressful situations, making their use more probable. For the same situation where documents and training are poor quality, the upper uncertainty bound from the Handbook was used to obtain a mean HEP of 8.0E-2 (median $=5.0 \mathrm{E}-2$ ), with an EF of five. This is the high mean value. Finally, for a routine, shiftly inspection or checking function, Item 2 in Table 20-6 lists a mean probability of 1.3E-3 (median $=1.0 \mathrm{E}-3$ ), with an EF of three. This is the low mean value.

\subsubsection{SRS-Specific Model}

While searching the REAC data base for potential miscalibration events, three events sets were identified involving failure to perform a periodic calibration at the required time. 12 Such failures were categorized as failures of administrative control. The event sets are: (1) For axial flux monitors, five failures were identified over the period 1971 through 1988. For this system during that period, 454 demands (requirements for calibrations) occurred. (2) For flow monitors in the primary water system, one failure was identified in 212 demands. (3) Finally, for flow monitors in the secondary water system, no failures were identified in 212 demands.

\subsubsection{Recommended SRS-Specific Model}

The three event sets discussed in section 3.6.1.2 were applied to the generic model nominal 
case in section 3.6.1.1, using the Bayesian update process. The percent change of the generic nominal case to the nominal recommended value was applied to adjust the high and low generic values to obtain high and low recommended values, respectively.

Using the Generic Model results as the prior and the SRS-Specific Model as the posterior in the Bayesian update process and rounding the results as discussed in Section 3.3, the following are the recommended SRS-Specific human error probabilities:

$\begin{array}{lllll}\text { Nominal Mean Value: } & 5.0 \mathrm{E}-3 & \mathrm{EF}=10 & \text { Use: } & \text { Typical circumstances } \\ \text { High Mean Value: } & 5.0 \mathrm{E}-2 & \mathrm{EF}=5 & \text { Use: } & \text { Unusual circumstances } \\ \text { Low Mean Value: } & 5.0 \mathrm{E}-4 & \mathrm{EF}=10 & \text { Use: } & \text { Routine, repetitive } \\ & & & & \text { circumstances }\end{array}$

The calculated results are summarized in Table 3. Table 4 should be consulted to obtain human error probabilities or rates.

\subsubsection{Failure to Respond to Compelling Signal}

Failure to notice or respond to an alarm, annunciator, or other compelling signal includes any type of visual waming device that functions in conjunction with an audible signal. The most common device of this nature is a translucent plastic tile inscribed with a message and back lit when activated. At the time the tile becomes lit an audible signal is generated to draw attention to the alarm. This event also applies to alarm messages displayed on a cathode ray tube (CRT) display. Factors that influence the ability to notice and respond to alarms are environmental factors (noise, lighting, etc.), display design (e.g., whether critical alarms are mixed with minor alarms), number of alarms or annunciators, training, and experience.

\subsubsection{Generic Model}

Tables 20-23 and 20-24 in the Handbook are applicable to this situation. Table 20-23, "The Annunciator Response Model: Estimated HEPs for Multiple Annunciators Alarming Closely in Time," is the most pertinent for this application. The mean values for all three situations presented already include stress effects and should not be increased again in consideration of stress effects. Table 20-23, Item 6k, for 4-6 alarms, represents the nominal case mean value. This nominal situation results in a mean HEP of $1.3 \mathrm{E}-2$ (median $=5.0 \mathrm{E}-3$ ), with an EF of ten. Item 10k in the same table was selected for the high case of seven or more alarms resulting in a mean HEP of $1.3 \mathrm{E}-1$ (median = 5.0E-2), with an EF of ten. This is the high mean value. Finally, Table 20-23, Item $3 \mathrm{k}$ is used to 
model one to three alarms. One to three alarms results in a mean HEP of $2.7 \mathrm{E}-3$ (median $=1.0 \mathrm{E}-3$ ), with an EF of ten. This is the low mean value.

\subsubsection{SRS-Specific Model}

No SRS-specific data were available for this human error.

\subsubsection{Recommended SRS-Specific Model}

Since no SRS-specific data were available for this human error, the generic model results, rounded as discussed in Section 3.3, are the recommended SRS results.

$\begin{array}{lllll}\text { Nominal Mean Value: } & 1.0 \mathrm{E}-2 & \mathrm{EF}=5 & \text { Use: } & \text { Several competing signals } \\ \text { High Mean Value: } & 1.0 \mathrm{E}-1 & \mathrm{EF}=3 & \text { Use: } & \text { Many competing signals } \\ \text { Low Mean Value: } & 3.0 \mathrm{E}-3 & \mathrm{EF}=10 & \text { Use: Few competing signals }\end{array}$

The calculated results are summarized in Table 3 . Table 4 should be consulted to obtain human error probabilities or rates.

\subsubsection{Failure to Verify Within Control Room}

This error involves a failure to select the correct instrument for verification, or given the correct selection, failure to verify within the control room the status of the instrument when requested or indicated by procedure. Influencing factors include the layout of instrumentation or indicators, time available, training, and experience.

\subsubsection{Generic Model}

This action is composed of an error of commission and omission. Tables 20-9, 20-10, 20-11, 20-25, and 20-26 in the Handbook all have some degree of applicability to the situation for the errors of commission. Table 20-11, "Estimated HEPs for Errors of Commission in Check-Reading Displays," Item 6, best represents the type of action intended, and the HEP is the most conservative (highest) of those for this type of action. Table 20-11 represents procedure-driven checking as well as general scanning. The commission error HEP for verifying the status of an instrument in a control room under nominal conditions is a median value of $6.0 \mathrm{E}-3$ with an EF of three. Table 20-7. "Estimated Probabilities of Errors of Omission per Item of Instruction When Use of Written Procedures is Specified" quantifies the error of omission. Table 20-7, Item 2, for correctly using a 
procedure with a long list and checkoff provisions, gives an error of omission median value of 3.0E-3 with an EF of three. The errors of omission and commission were combined by adding. The combined nominal mean HEP is $1.1 \mathrm{E}-2$ (median $=9.0 \mathrm{E}-3$ ) with an EF of three. This is considered to be the nominal case mean value.

Under very high stress conditions, multipliers from Table 20-16, "Modification of Estimated HEPs for the Effects of Stress and Experience Levels," can be used to adjust the nominal HEP for offnormal conditions. Instrument and control status verification is a procedure-guided step-by-step action, so the appropriate row of Table 20-16 was used. Also, training and qualification requirements make the "skilled operator" column the appropriate data source for this application. For very high stress, Item 6a indicates that a multiplier of five be used to adjust the nominal value, resulting in a mean HEP of 5.6E-2 (median $=4.5 \mathrm{E}-2$ ), with an EF of three. This is the high mean value. Finally, the low mean value was obtained by combining nominal conditions with the lowest HEP in Table 20-11, Items 1 or 2, and Table 20-7, Item 1, resulting in a mean HEP of 2.5E-3 (median = 2.0E-3), with an EF of three. The low case assumes excellent, easily read and interpreted displays (e.g., digital readout displays) are in use at the facility.

\subsubsection{SRS-Specific Model}

No SRS-specific data were available for this human error.

\subsubsection{Recommended SRS-Specific Model}

Since no SRS-specific data were available for this human error, the generic model results, rounded as discussed in Section 3.3, are the recommended SRS results.

$\begin{array}{lllll}\text { Nominal Mean Value: } & 1.0 \mathrm{E}-2 & \mathrm{EF}=5 & \text { Use: } & \text { Good layout, procedure-driven } \\ \text { High Mean Value: } & 5.0 \mathrm{E}-2 & \mathrm{EF}=5 & \text { Use: } & \text { Poor layout, scanning effort } \\ \text { Low Mean Value: } & 3.0 \mathrm{E}-3 & \mathrm{EF}=10 & \text { Use: } & \text { Excellent layout, procedure- } \\ & & & & \text { driven }\end{array}$

The calculated results are summarized in Table 3. Table 4 should be consulted to obtain human error probabilities or rates. 


\subsubsection{Failure to Verify Outside Control Room}

This error involves a failure to select the correct instrument for verification, or given the correct selection, failure to verify outside the control room the status of the instrument when requested or indicated by procedure. Influencing factors include the layout of instrumentation, time available, training, experience, and environmental factors (lighting, housekeeping, need for protective clothing, etc.).

\subsubsection{Generic Model}

This action is composed of an error of commission and omission. Tables 20-9, 20-10, 20-11, 20-25, and 20-26 in the Handbook all have some degree of applicability to this situation for the error of commission. As in Section 3.6.3, Table 20-11, Item 6, best represents the type of action intended for the error of commission and is the most conservative (highest value) for this type of action. Table 20-7, Item 2, is used for the error of omission. The errors of omission and commission were combined by adding. Typically, environments outside the control room are not as favorable as inside. To reflect the environmental influences that may increase the chance of error, the nominal median HEP in Section 3.6.3, 9.0E-3, was adjusted to its upper uncertainty bound by multiplying the HEP by its error factor of three. For the nominal case, the resulting mean HEP is 3.4E-2 (median = 2.7E-2), with an EF of three. As in Section 3.6.3, an adjustment for stress (a multiplier of five) was made to the nominal value to obtain the high result for this event. The high mean value is $1.8 \mathrm{E}-1$ (median $=1.4 \mathrm{E}-1$ ), with an EF of three. The low mean HEP uses values from Table 20-11, Items 1 or 2, combined with Table 20-7, Item 1, (each value increased by its EF of three). The low mean HEP is $7.5 \mathrm{E}-3$ (median $=6.0 \mathrm{E}-3$ ), with an EF of three.

\subsubsection{SRS-Specific Model}

No SRS-specific data were available for this human error.

\subsubsection{Recommended SRS-Specific Model}

Since no SRS-specific data were available for this human error, the generic model results, rounded as discussed in Section 3.3, are the recommended SRS results.

$\begin{array}{lllll}\text { Nominal Mean Value: } & 3.0 \mathrm{E}-2 & \mathrm{EF}=5 & \text { Use: } & \text { Good layout, procedure-driven } \\ \text { High Mean Value: } & 1.0 \mathrm{E}-1 & \mathrm{EF}=3 & \text { Use: } & \text { Poor layout, scanning effort } \\ \text { Low Mean Value: } & 1.0 \mathrm{E}-2 & \mathrm{EF}=5 & \text { Use: } & \begin{array}{l}\text { Excellent layout, procedure- } \\ \text { driven }\end{array}\end{array}$


The calculated results are summarized in Table 3. Table 4 should be consulted to obtain human error probabilities or rates.

\subsubsection{Error in Selecting Control Within Control Room}

This operator action failure probability involves selecting the wrong control or improperly operating a control in the control room when requested or indicated by procedure. Factors that influence control selection and operation are the layout of controls, training, experience, and time available.

\subsubsection{Generic Model}

This action is composed of an error of omission and commission. Table 20-12, "Estimated Probabilities of Errors of Commission in Operating Manual Controls," Item 2, in the Handbook addresses control selection and operation common to facilities being considered for the error of commission. For the nominal case, the median commission HEP is 3.0E-3, with an EF of three. Table 20-7, "Estimated Probabilities of Errors of Omission per Item of Instruction When Use of Written Procedures is Specified," quantifies the error of omission. Table 20-7, Item 2, for correctly using a procedure with a long list and checkoff provisions, gives an error of omission median value of 3.0E-3 with an EF of three. The errors of omission and commission were combined by adding.

The combined nominal mean HEP is 7.5E-3 (median $=6.0 \mathrm{E}-3$ ) with an EF of three. Under very high stress conditions, a multiplier from Table 20-16, "Modifications of Estimated HEPs for the Effects of Stress and Experience Levels," was used to adjust the nominal HEP for off-normal conditions. Control selection and operation is a procedure-guided step-by-step action so the appropriate row of Table 20-16 was used. Also, training and qualification requirements make the "skilled operator" column the appropriate data source for this application. For the very high stress case, Item $6 \mathrm{a}$ indicates a multiplier of five. Therefore, the high value mean HEP is $3.8 \mathrm{E}-2$ (median $=$ 3.0E-2), with an EF of three. For the low value, nominal conditions were assumed and the lowest value in Table 20-12, Item 4, was combined with Table 20-7, Item 1. This produced a low value mean HEP of $1.9 \mathrm{E}-3$ (median $=1.5 \mathrm{E}-3$ ), with an EF of three. This HEP represents easily identified and operated controls.

\subsubsection{SRS-Specific Model}

No SRS-specific data were available for this human error. 


\subsubsection{Recommended SRS-Specific Model}

Since no SRS-specific data were available for this human error, the generic model results, rounded as discussed in Section 3.3, are the recommended SRS results.

$\begin{array}{lllll}\text { Nominal Mean Value: } & 1.0 \mathrm{E}-2 & \mathrm{EF}=5 & \text { Use: } & \text { Good layout, procedure-driven } \\ \text { High Mean Value: } & 3.0 \mathrm{E}-2 & \mathrm{EF}=5 & \text { Use: } & \text { Poor layout, scanning effort } \\ \text { Low Mean Value: } & 1.0 \mathrm{E}-3 & \mathrm{EF}=10 & \text { Use: } & \begin{array}{l}\text { Excellent layout, procedure- } \\ \text { driven }\end{array}\end{array}$

The calculated results are summarized in Table 3. Table 4 should be consulted to obtain human error probabilities or rates.

\subsubsection{Error in Selecting Control or Valve Outside Control Room}

This operator action failure probability involves an error in selecting a control or a manually operated valve or damper, or improperly operating a control outside the control room when requested or indicated by procedure. Factors that influence control selection and operation are the layout of controls, training, experience, time available, and environmental factors (lighting, housekeeping, need for protective clothing, etc.).

\subsubsection{Generic Model}

This action is composed of an error of omission and commission. Tables 20-12, 20-13, 2014, and 20-15 in the Handbook all have some degree of applicability to this situation for the error of commission. Table 20-12, "Estimated Probabilities of Errors of Commission in Operating Manual Controls," Item 11 and Table 20-13, "Estimated HEPs for Selection Errors for Locally Operated Valves," Item 3, describe common field situations and both have mean HEPs of 6.3E-3 (median = 5.0E-3), with an EF of three. Since the tables used are based on field operation, no additional adjustment is required to reflect conditions experienced outside the control room. Table 20-7, Item 2 , is used for the error of omission. The errors of omission and commission were combined by adding. Therefore, the nominal case mean HEP is $1.0 \mathrm{E}-2$ (median $=8.0 \mathrm{E}-3$ ), with an EF of three. Under very high stress conditions, a multiplier from Table 20-16, "Modification of Estimated HEPs for the Effects of Stress and Experience Levels," was used to adjust the nominal HEP for off-normal conditions. Control selection and operation is a procedure-guided step-by-step action, so the appropriate row of Table 20-16 was used. Training and qualification requirements make the "skilled operator" column the correct data source for this application. For very high stress, Item 6a indicates a 
multiplier of five is appropriate. Therefore, the high mean HEP is $5.0 \mathrm{E}-2$ (median $=4.0 \mathrm{E}-2$ ), with an EF of three. The low mean HEP was determined using the nominal conditions but with a lower basic HEP value (Table 20-13, Item 1, combined with Table 20-7, Item 1). The low mean HEP is $2.5 E-3$ (median $=2.0 \mathrm{E}-3$ ), with an EF of three.

\subsubsection{SRS-Specific Model}

No SRS-specific data were available for this human error.

\subsubsection{Recommended SRS-Specific Model}

Since no SRS-specific data were available for this human error, the generic model results, rounded as discussed in Section 3.3, are the recommended SRS results.

$\begin{array}{lllll}\text { Nominal Mean Value: } & 1.0 \mathrm{E}-2 & \mathrm{EF}=5 & \text { Use: } & \text { Good layout, procedure-driven } \\ \text { High Mean Value: } & 5.0 \mathrm{E}-2 & \mathrm{EF}=5 & \text { Use: } & \text { Poor layout, scanning effort } \\ \text { Low Mean Value: } & 3.0 \mathrm{E}-3 & \mathrm{EF}=10 & \text { Use: } & \begin{array}{l}\text { Excellent layout, procedure- } \\ \text { driven }\end{array}\end{array}$

The calculated results are summarized in Table 3. Table 4 should be consulted to obtain human error probabilities or rates.

\subsubsection{Communication Error}

A communication error is any error in sending or receiving instructions, responses, or results by face-to-face conversation, by telephone, by walkie-talkie, or by a public address (PA) system. Communication is influenced by communication mode, environmental factors (noise, distance, etc.), message length, and communication procedure.

\subsubsection{Generic Model}

Table 20-8, "Estimated Probabilities of Error in Recalling Oral Instruction Items Not Written Down," in the Handbook provides human error probabilities for verbal communication. Column B of Table 20-8 provides error probabilities for communication that requires all detailed items to be recalled, but in no particular order. The second half of the table, Items 6-10, specify the HEPs for oral instructions that are general. Item $8 b$ involves recalling instructions with up to three instruction items and was used to model complex information. For complex information, the mean HEP is 
4.8E-2 (median = 3.0E-2), with an EF of five. This HEP was used for the nominal case. For very complex information, under high stress, or when communication is degraded, Item $10 \mathrm{~b}$ was used. This results in a mean HEP of $4.8 \mathrm{E}-1$ (median $=3.0 \mathrm{E}-1$ ), with an EF of five for the high value. Item $6 \mathrm{~b}$ was used to model simple information involving one instruction item or idea. The mean HEP for recalling one instruction item is $1.3 \mathrm{E}-3$ (median $=1.0 \mathrm{E}-3$ ), with an EF of three. This was used as the low HEP.

\subsubsection{SRS-Specific Model}

No SRS-specific data were available for this human error.

\subsubsection{Recommended SRS-Specific Model}

Since no SRS-specific data were available for this human error, the generic model results, rounded as discussed in Section 3.3, are the recommended SRS results.

$\begin{array}{lllll}\text { Nominal Mean Value: } & 5.0 \mathrm{E}-2 & \mathrm{EF}=5 & \text { Use: } & \text { Moderate Information } \\ \text { High Mean Value: } & 5.0 \mathrm{E}-1 & \mathrm{EF}=2 & \text { Use: } & \text { Complex Information } \\ \text { Low Mean Value: } & 1.0 \mathrm{E}-3 & \mathrm{EF}=10 & \text { Use: } & \text { Simple Information }\end{array}$

The calculated results are summarized in Table 3. Table 4 should be consulted to obtain human error probabilities or rates.

\subsubsection{Checker Verification Error}

The failure of checker verification addresses a checker failing to verify an action. For credit to be taken for verification, the action must be described in a written procedure or other document. Other influencing factors include ease of verification, time available, training, and experience. The checker verification discussed in this section is conducted under normal operating or maintenance conditions. The checker is assumed to be fully dedicated to the verification action with no other coincident responsibilities.

\subsubsection{Generic Model}

Table 20-22, "Estimated Probabilities That a Checker Will Fail 'To Detect Errors Made By Others," is applicable to this case. A checker checking an action in which he is not an active participant but will be "alerted", is modeled by Table 20-22, Item 3. For checking in an "alerted" 
situation, the mean HEP is $8.0 \mathrm{E}-2$ (median $=5.0 \mathrm{E}-2$ ) with an EF of five. This type of checking is a task that is not part of an operator's normal daily tasks, and the checker would be expected to approach the task with a higher level of alertness and attention. An operator checking restoration of an emergency diesel generator following an annual test is a specific example. This was used as the mean value for the nominal case.

Checking an action which involves routine general checking without using written materials is modeled by Table 20-22, Item 2. The mean HEP is 3.2E-1 (median = 2.0E-1) with an EF of five. Examples of this type of checking include verifying positions of locally operated valves, switches, and circuit breakers. This is the high mean value.

Whenever the checking action involves active participation by the checker, the HEP is modeled by Table 20-22, Item 4. The mean HEP is $1.6 \mathrm{E}-2$ (median $=1.0 \mathrm{E}-2$ ) with an EF of five. Examples of this type of checking are tasks that involve hands-on activities such as using an instrument for some measurement (e.g., torque wrench, calipers, gas analyzer, etc.). This is the low mean HEP.

\subsubsection{SRS-Specific Model}

No SRS-specific data were available for this human error.

\subsubsection{Recommended SRS-Specific Model}

Since no SRS-specific data were available for this human error, the generic model results, rounded as discussed in Section 3.3, are the recommended SRS results.

$\begin{array}{lllll}\text { Nominal Mean Value: } & 1.0 \mathrm{E}-1 & \mathrm{EF}=3 & \text { Use: } & \begin{array}{l}\text { Alerted, but not active } \\ \text { participant }\end{array} \\ \text { High Mean Value: } & 3.0 \mathrm{E}-1 & \mathrm{EF}=3 & \text { Use: } & \text { Written materials not used } \\ \text { Low Mean Value: } & 1.0 \mathrm{E}-2 & \mathrm{EF}=5 & \text { Use: } & \begin{array}{l}\text { Checking requires active } \\ \text { participation }\end{array}\end{array}$

The calculated results are summarized in Table 3. Table 4 should be consulted to obtain human error probabilities or rates. 


\subsubsection{Supervisor Verification Error}

The supervisor verification error includes a supervisor incorrectly verifying, or failing to verify, an action. These verification activities are assumed to occur during off-normal conditions ranging from minor incidents to major accidents. For credit to be taken for supervisor verification the presence of a supervisor should be required in a written administrative procedure or other document (e.g. Technical Safety Requirements, Conduct of Operations Manual, and/or emergency situation training materials, etc.). Credit for supervisor verification should not be given for tasks performed outside of the control room or for tasks where credit for checking has already been modeled (e.g., Sections 3.6.12, 3.6.13, 3.6.14, 3.6.35). Other influencing factors include ease of verification, time available, training, experience and level of dependence.

\subsubsection{Generic Model}

Dependence is the primary influence on this error probability. Dependence is a measure of the attentiveness or distraction of the verifying supervisor. The more distracted (less attentive) the supervisor is, the more he depends on the operators to perform their actions correctly and the more error prone is the supervisor's verification (higher HEP). Dependence is divided into five categories: zero, low, medium, high, and complete. Complete dependence with an operator implies that the supervisor is completely reliant on the operator to correctly perform a given task and no checking is taking place. This is an HEP of 1.0. No recovery factor would be modeled for this case. Zero dependence implies that the supervisor is independently (physically separate in time and space) and systematically (proceduralized) verifying the operator's actions. The zero level of dependence conflicts with a supervisor's function of maintaining an overview of the situation and is excluded from further consideration. Low, medium, and high dependence represents the spectrum of supervisor verification between complete and zero dependence.

Calculation of the supervisor verification conditional HEP (CHEP) requires the identification of the error probability for the action the supervisor is verifying. This action may be an alarm response from Table 20-23, or reading a gauge from Table 20-11, or operating a control from Table 20-12 in the Handbook. The HEPs for these actions are typically less than 0.05 . Using 0.05 as the basic HEP Table 20-21, column $b$ assigns a medium dependence CHEP of 3.1E-1 (median $=1.9 \mathrm{E}-1$ ) with an EF of five. This is used as the nominal value.

For the high value, the high dependence result of 5.8E-1 (median $=5.3 \mathrm{E}-1$ ) is applicable with an EF of two. (The Handbook EF of five was reduced to two to keep the 95th percentile at or below 1.0) The high value also applies if a high stress situation exists. 
Finally, the low value is $1.6 \mathrm{E}-1$ (median $=1.0 \mathrm{E}-1$ ), with an EF of five. This is the low dependence value from the Handbook.

\subsubsection{SRS-Specific Model}

No SRS-specific data were available for this human error.

\subsubsection{Recommended SRS-Specific Model}

Since no SRS-specific data were available for this human error, the generic model results, rounded as discussed in Section 3.3, are the recommended SRS results.

$\begin{array}{lcccl}\text { Nominal Mean Value: } & 3.0 \mathrm{E}-1 & \mathrm{EF}=3 & \text { Use: } & \begin{array}{l}\text { Check-off sheet, medium } \\ \text { dependence }\end{array} \\ \text { High Mean Value: } & 5.0 \mathrm{E}-1 & \mathrm{EF}=2 & \text { Use: } & \begin{array}{l}\text { No check-off sheet, high } \\ \text { dependence, high stress }\end{array} \\ \text { Low Mean Value: } & 1.0 \mathrm{E}-1 & \mathrm{EF}=3 & \text { Use: } \begin{array}{l}\text { Check-off sheet, low } \\ \text { dependence }\end{array}\end{array}$

The calculated results are summarized in Table 3 . Table 4 should be consulted to obtain human error probabilities or rates.

\subsubsection{Incorrect Labeling or Tagging}

Incorrect labeling or tagging of a container or object includes putting incorrect information on a tag or label or omitting the tag or label altogether. This error does not include failure to tag a component as part of a lockout procedure, which is covered under a separate human error in section 3.6.15. Influencing factors for this situation include organizational culture, quality of administrative controls, training, and experience.

\subsubsection{Generic Model}

Table 20-5, "Estimated HEP Per Item (or perceptual unit) in Preparation of Written Material," in the Handbook addresses tagging. In this section, the terms labeling and tagging can be used interchangeably. Items 1 and 3 in Table 20-5 both indicate a mean HEP of 4.8E-3 (median = 3.0E-3), with an $E F$ of five, which was used for the nominal case. 
Table 20-15, "The Four Levels of Tagging or Locking Systems," gives guidance that can be used for adjusting the nominal values based on administrative controls. Table 20-15, Item 1 suggests using the lower uncertainty bound when "very good" administrative controls exist, and Item 3 suggests the use of the upper uncertainty bound when "poor" administrative controls are in place. The quality of the administrative controls refers to the record keeping and personnel awareness associated with the use of a tag or label. From Table 20-5, Items 1 and 3 and Table 20-15, Item 3, for "poor" administrative controls, the mean HEP is $2.4 \mathrm{E}-2$ (median $=1.5 \mathrm{E}-2$ ), with an EF of five. For "very good" administrative controls, Table 20-15, Item 3, results in a mean HEP of 1.0E-3 (median = 6.0E-4), with an EF of five.

\subsubsection{SRS-Specinc Model}

No SRS-specific data were available for this human error.

\subsubsection{Recommended SRS-Specific Model}

Since no SRS-specific data were available for this human error, the generic model results, rounded as discussed in Section 3.3, are the recommended SRS results.

$\begin{array}{lllll}\text { Nominal Mean Value: } & 5.0 \mathrm{E}-3 & \mathrm{EF}=10 & \text { Use: } & \text { Normal administrative controls } \\ \text { High Mean Value: } & 3.0 \mathrm{E}-2 & \mathrm{EF}=5 & \text { Use: } & \text { Poor administrative controls } \\ \text { Low Mean Value: } & 1.0 \mathrm{E}-3 & \mathrm{EF}=10 & \text { Use: } & \text { Excellent administrative } \\ & & & & \text { controls }\end{array}$

The calculated results are summarized in Table 3. Table 4 should be consulted to obtain human error probabilities or rates.

\subsubsection{Incorrect Reading or Recording of Data}

Incorrect reading or recording of data includes situations where data are incorrectly read from an instrument, are incorrectly recorded, or are not recorded at all, when requested or indicated by procedure. Influencing factors for this human action include training, experience, display design, data collection forms, and time available.

\subsubsection{Generic Model}

This action is composed of an error of commission and omission. Table 20-10, "Estimated HEPs for Errors of Commission in Reading and Recording Quantitative Information from Unannunciated Displays," Item 5, was chosen as the nominal case model for the error of commission. 
The commission error HEP for reading and recording data under nominal conditions is a median value of 1.0E-2 with an EF of three. Table 20-7, "Estimated Probabilities of Errors of Omission per Item of Instruction when Use of Written Procedures is Specified," quantifies the error of omission. Table 20-7, Item 2, for correctly using a procedure with a long list and checkoff provisions, gives an error of omission median value of 3.0E-3 with an EF of three. The errors of omission and commission were combined by adding. The combined nominal mean HEP is $1.6 \mathrm{E}-2$ (median = 1.3E-2) with an EF of three. For the high value, Item 4, in Table 20-10, was used for the error of commission. Table 20-7, Item 2, was used for the error of omission. The errors of commission and omission are added together then multiplied by the high stress multiplier of five (Table 20-16, Item $6 \mathrm{a}$ ), resulting in a mean HEP of $4.3 \mathrm{E}-1$ (median $=2.7 \mathrm{E}-1$ ), with an EF of five. The high HEP is used for a poorly designed display, under very high stress conditions inside a control room, or for a poorly designed display, under nominal conditions outside the control room. The situation outside the control room was modeled by modifying the nominal value to the upper uncertainty bound. The low HEP was determined by assuming nominal conditions and using the lowest HEP in Table 20-10, Items 2 or 6 , combined with Table 20-7, Item 1, resulting in a mean value of $2.5 E-3$ (median = 2.0E-3), with an EF of three. The lowest HEP is used for well-designed user interfaces, such as digital readout displays. Recording of data did not influence these HEPs because in almost all situations, only three significant figures are recorded. Table 20-10, Item 8, is applicable and has a "negligible" HEP.

\subsubsection{SRS-Specific Model}

No SRS-specific data were available for this human error.

\subsubsection{Recommended SRS-Specific Model}

Since no SRS-specific data were available for this human error, the generic model results, rounded as discussed in Section 3.3, are the recommended SRS results.

$\begin{array}{lllll}\text { Nominal Mean Value: } & 1.0 \mathrm{E}-2 & \mathrm{EF}=5 & \text { Use: } & \text { Good display (graph) } \\ \text { High Mean Value: } & 5.0 \mathrm{E}-1 & \mathrm{EF}=2 & \text { Use: } & \text { Poor display } \\ \text { Low Mean Value: } & 3.0 \mathrm{E}-3 & \mathrm{EF}=10 & \text { Use: } & \text { Excellent display (digital } \\ & & & & \text { readout, indicator lamp) }\end{array}$

The calculated results are summarized in Table 3. Table 4 should be consulted to obtain human error probabilities or rates. 


\subsubsection{Miscalibration}

The miscalibration human error event involves gross miscalibration of an instrument such that safety or operational limits on equipment or processes no longer provide the intended protection. This type of error is influenced by such things as: quality of calibration procedure, whether the procedure is used, types of checks or recoveries, training, and experience.

\subsubsection{Generic Model}

Miscalibration was modeled using a THERP tree with basic human errors from the Handbook. The THERP tree is shown in Figure 1. Assumptions implicit in the nominal model are the following:

_ a calibration procedure exists and has been verified and validated

- for the error of omission/commission, only the final step of testing the component, by the calibration performer, is modeled; it is assumed that if the test is done correctly it will allow for complete recovery from any earlier errors in performing the calibration procedure

- only one person performs the actual calibration

_ before ("as found") and after ("as left") calibration instrument readings are entered on the checkoff sheet and a different operator (who signs-off on the work) verifies that the readings fall within a specified range after calibration is completed.

Applying appropriate basic human errors to the branches in the THERP tree in Figure 1, the resultant nominal case mean failure probability is $1.6 \mathrm{E}-2$ per calibration. The major contribution to this failure probability involves failure to use the calibration procedure, failure to use a checklist properly when using the procedure, an error of omission or commission during the calibration procedure, and failure of the operator to detect the error by comparing before and after instrument readings. Propagating the basic event uncertainties through the THERP tree in Figure 1 results in an EF of five.

The high failure probability estimate was obtained by eliminating the recovery (before and after reading verification) modeled in the nominal THERP tree. In addition, a higher mean probability (4E-1) of failing to use a calibration procedure was used (Table 20-6, Item 6, upper uncertainty bound, median $=2.5 \mathrm{E}-1$ ), rather than a mean of $8.1 \mathrm{E}-2$ (Table 20-6, Item 6, median $=$ 5.0E-2). The high failure probability estimate is 7.4E-2 per calibration, with an EF of seven. 
The low failure probability estimate was obtained by adding to the nominal case the recovery of the second person on the calibration team to correct errors (mean $=5.45 E-1$ ); one person performing the work, and the other observing and checking off steps (Table 20-22, Item 8, median = $5 E-1, E F=5$ reduced to 2$)$. In addition, a lower mean probability $(1.6 \mathrm{E}-2)$ of failing to use a calibration procedure was used (Table 20-6, Item 6, lower uncertainty bound, median =1E-2). Given these changes, the THERP tree in Figure 1 results in a low mean failure probability of 5.7E-3 per calibration, with an EF of four.

\subsubsection{SRS-Specific Model}

A search of the REAC data base for 1971 through 1988 uncovered miscalibration events for three systems. 12 The three systems are axial flux monitors, primary water system flow monitors, and secondary water system flow monitors. (1) For axial flux monitors, one miscalibration occurred in 454 calibrations. (2) For flow monitors in the primary water system, three miscalibrations occurred in 212 demands. (3) Finally, flow monitors in the secondary water system had two miscalibrations in 212 demands.

\subsubsection{Recommended SRS-Specific Model}

The three event sets discussed in section 3.6.12.2 were applied to the generic model nominal case in section 3.6.12.1, using the Bayesian update process. The percent change of the generic nominal case to the nominal recommended value was applied to adjust the high and low generic values to obtain high and low recommended values, respectively.

Using the Generic Model results as the prior and the SRS-Specific Model as the posterior in the Bayesian update process and rounding the results as discussed in Section 3.3, the following are the recommended SRS-Specific human error probabilities:

$\begin{array}{lllll}\text { Nominal Mean Value: } & 5.0 \mathrm{E}-3^{*} & \mathrm{EF}=10 & \text { Use: } & \text { Single-person, operator check } \\ \text { High Mean Value: } & 3.0 \mathrm{E}-2 & \mathrm{EF}=5 & \text { Use: } & \text { Single-person, no checks } \\ \text { Low Mean Value: } & 3.0 \mathrm{E}-3^{*} & \mathrm{EF}=10 & \text { Use: } & \text { Two-person team, operator } \\ & & & & \text { check }\end{array}$

* These values already include recoveries

The calculated results are summarized in Table 3. Table 4 should be consulted to obtain human error probabilities or rates. 


\subsubsection{Failure to Restore Following a Test}

A restoration error following testing involves failure to return equipment to their operational or safety status following a test. Similar to miscalibration, this error is influenced by such things as the quality of the procedure, whether the procedure is used, types of checks, training, and experience.

\subsubsection{Generic Model}

Failure to restore following testing was modeled using a THERP tree with basic human errors from the Handbook. The THERP tree is presented in Figure 2. Assumptions implicit in the nominal model are the following:

- a test procedure with restoration steps exists and has been verified and validated

- for the error of omission/commission, only the final step of (functional) testing the component, by the test performer, is modeled; it is assumed that if this test is done correctly it will allow for complete recovery from any earlier errors in performing the restoration procedure

- a single operations person performs the restoration

- an operator independently verifies the restoration following the test.

The resultant nominal case mean failure probability is $1.0 \mathrm{E}-2$ per test, as shown in Figure 2. Propagating the basic event uncertainties through the THERP tree in Figure 2 results in an EF of three .

The high and low values were estimated by applying different assumptions to the same THERP tree. For the high estimate, the recovery was eliminated, and a higher mean probability (3.75E-2) for failing to use the procedure was assumed (similar to miscalibration, Section 3.6.12). The resulting high failure probability estimate is $2.2 \mathrm{E}-2$ per test, with an EF of three. The low estimate was obtained by using the lower uncertainty bound probability value (4.2E-3) for failing to use the restoration procedure (Table 20-6, Item 5, lower uncertainty bound, median $=3 E-3$ ). Additionally, credit is given for a recovery (mean $=5.45 \mathrm{E}-1$ ) with a two-person team, with one person performing the work and the other observing and checking off steps (Table 20-22, Item 8, median $=5.0 \mathrm{E}-1$ ). Given these changes, the THERP tree in Figure 2 results in a low mean failure probability of 5.3E-3 per test, with an EF of four. 


\subsubsection{SRS-Specific Model}

No SRS-specific data were available for this human error.

\subsubsection{Recommended SRS-Specific Model}

Since no SRS-specific data were available for this human error, the generic model results, rounded as discussed in Section 3.3, are the recommended SRS results.

\begin{tabular}{|c|c|c|c|c|}
\hline Nominal Mean Value: & $1.0 \mathrm{E}-2 *$ & $E F=5$ & Use: & $\begin{array}{l}\text { Single-person, operator } \\
\text { check }\end{array}$ \\
\hline High Mean Value: & $3.0 \mathrm{E}-2$ & $E F=5$ & Use: & Single-person, no checks \\
\hline Low Mean Value: & $5.0 \mathrm{E}-3^{*}$ & $E F=10$ & Use: & $\begin{array}{l}\text { Two-person team, operator } \\
\text { check }\end{array}$ \\
\hline
\end{tabular}

* These values already include recoveries

The calculated results are summarized in Table 3. Table 4 should be consulted to obtain human error probabilities or rates.

\subsubsection{Failure to Restore Following Maintenance}

Failure to restore following maintenance involves failure to retum equipment to their operational or safety status following maintenance. Factors affecting such a failure include the following: quality of procedure, whether the procedure is used, types of checks, training, and experience.

\subsubsection{Generic Model}

The THERP tree used to model this human error is presented in Figure 3. Assumptions implicit in the nominal model are the following:

- the maintenance procedure with restoration steps has been verified and validated

- for the error of omission/commission, only the final step of (functional) testing the component, by the maintainer, is modeled; it is assumed that if the test is done correctly it will allow for complete recovery from any earlier errors in performing the restoration procedure

- a single person performs the maintenance activity

- since an operator independently verifies the equipment following the maintenance activities of maintenance personnel, the error likelihood for that operator is reduced by a factor of two. 
The resultant mean failure probability for the nominal case is $1.7 \mathrm{E}-2$ per maintenance. Propagating the basic event uncertainties through the THERP tree in Figure 3 results in an EF of five.

The high estimate was obtained by assuming a higher mean probability (6.5E-1) for failing to use the maintenance procedure was assumed (similar to testing, Section 3.6.13) and no recovery from the operator verification in the THERP tree in Figure 3. The resulting high failure probability estimate is $1.1 \mathrm{E}-1$ per maintenance, with an EF of six.

The low estimate was obtained by using the lower uncertainty bound probability value (9.6E-2) for failing to use the maintenance procedure (Table 20-6, Item 7, lower uncertainty bound, median $=6.0 \mathrm{E}-2, \mathrm{EF}=5$ ) and an additional recovery (mean $=5.45 \mathrm{E}-1$ ) was included for a twoperson team performing the maintenance activity, with one person performing the work and the other observirg and checking off steps (Table 20-22, Item 8, median $=5.0 \mathrm{E}-1$, EF reduced to two). Given these changes, the THERP tree in Figure 3 results in a low mean failure probability of $4.6 \mathrm{E}-3$ per maintenance, with an EF of six.

\subsubsection{SRS-Specific Model}

Two SRS-specific event data sets were identified for this situation. These data sets are failures to realign valves and failures to correctly restore batteries.

(1) The REAC data base contains seven reports from mid 1971 to mid 1988 involving nine failures to realign valves before reactor startup after flushing strainers. 12 These events were considered to be appropriate for failure to restore following maintenance. The demands for this event were estimated by assuming 5.6 reactor startups during each of the 18 years of operation for each or the three reactors. Also, for each startup, six valve alignments must be made. Therefore, the number of demands is

$(5.6$ startups $/ \mathrm{yr})(18 \mathrm{yr} /$ reactor $)(3$ reactor $)(6$ restorations/ startup $)=1814$ restorations.

(2) Another REAC data search dealt with restorations of batteries following tests, maintenance, or repair. Five human errors involving failures to correctly restore the batteries were identified during the period 1981 through 1985. 12 The demands during this period are

$(5 \mathrm{yr} /$ reactor $)(3$ reactor $)(5.6$ restorations/ yr-battery $)(12$ battery $)=1008$ restorations. 


\subsubsection{Recommended SRS-Specific Model}

The two event data sets discussed in section 3.6.14.2 were applied to the generic model nominal case in section 3.6.14.1, using the Bayesian update process. The percent change of the generic nominal case to the nominal recommended value was applied to adjust the high and low generic values to obtain high and low recommended values, respectively.

Using the Generic Model results as the prior and the SRS-Specific Model as the posterior in the Bayesian update process and rounding the results as discussed in Section 3.3, the following are the recommended SRS-Specific human error probabilities:

\begin{tabular}{|c|c|c|c|c|}
\hline Nominal Mean Value: & $5.0 \mathrm{E}-3^{*}$ & $E F=10$ & Use: & $\begin{array}{l}\text { Single person, operator } \\
\text { check }\end{array}$ \\
\hline High Mean Value: & $5.0 \mathrm{E}-2$ & $E F=5$ & Use: & Single-person, no checks \\
\hline Low Mean Value: & $3.0 \mathrm{E}-3^{*}$ & $E F=10$ & Use: & $\begin{array}{l}\text { Two-person team, operator } \\
\text { check }\end{array}$ \\
\hline
\end{tabular}

* These values already include recoveries

The calculated results are summarized in Table 3. Table 4 should be consulted to obtain human error probabilities or rates.

\subsubsection{Failure to Lock Out}

Lockout failures are any failure to properly conduct a lockout according to a written lockout plan (or procedure requiring lockout) and/or the administrative procedures that govern a lockout plan. The quality of the administrative controls (procedures and lockout plans), complexity of the lockout, training, and experience are predominant influencing factors in the HEP. Lockouts may be conducted under the control of a lockout plan or under an operating procedure.

\subsubsection{Generic Model}

From the Handbook, Tables 20-7 and 20-15 can be used for lockouts. Item 3 in Table 20-7 was chosen for the nominal case because it modeled common practice in many facilities. This value is considered appropriate for lockout plans with five to ten lockouts. The nominal mean HEP is 3.8E-3 (median $=3.0 \mathrm{E}-3$ ), with an EF of three. This is appropriate for a typical lockout process. For the high estimate, the highest value with procedures in use in Table 20-7, Item 4 was used in conjunction with the Table 20-15 recommendation that the upper uncertainty bound be used. Therefore, the mean is $3.8 \mathrm{E}-2$ (median $=3.0 \mathrm{E}-2$ ), with an EF of three. This value is considered 
appropriate for lockout plans with 11 to 100 lockouts. Finally, taking the lowest value with procedures in use in Table 20-7, Item 1 and the lower uncertainty bound as prescribed in Table $20-15$, the low mean estimate is $4.1 \mathrm{E}-4$ (median $=3.3 \mathrm{E}-4$ ), with an $\mathrm{EF}$ of three. This value applies to lockout plans with one to four lockouts.

\subsubsection{SRS-Specific Model}

A review of data related to lockouts in the Risk Assessment Fault Tree Data Banks System for the H-Canyon and F-Canyon areas indicated 53 incidents at these facilities involving lockout failures during 1980 through mid 1993. To estimate the number of lockouts during this period, lockout plan data were obtained for three SRS facilities: 221-H (H-Canyon), HB-Line, and 211-H (H-Area Outside Facilities). During the first half of 1993, these facilities had 1717 lockout plans in effect. Discussions with facility personnel indicated that the comparable F-Canyon areas would have a similar number of lockout plans. Extrapolating this information to 13.5 years, the total number of lockout plans is

$(13.5 \mathrm{yr} /$ area $)(1717$ lockout plans $/ 0.5 \mathrm{yr})(2$ area $)=92,718$ lockout plans.

\subsubsection{Recommended SRS-Specific Model}

The event data set discussed in section 3.6.15.2 were applied to the generic model nominal case in section 3.6.15.1, using the Bayesian update process. The percent change of the generic nominal case to the nominal recommended value was applied to adjust the high and low generic values to obtain high and low recommended values, respectively.

Using the Generic Model results as the prior and the SRS-Specific Model as the posterior in the Bayesian update process and rounding the results as discussed in Section 3.3, the following are the recommended SRS-Specific human error probabilities:

\begin{tabular}{|c|c|c|c|c|}
\hline Nominal Mean Value: & $5.0 \mathrm{E}-4$ & $E F=10$ & Use: & $\begin{array}{l}\text { Typical lockout plan (5 to } 10 \\
\text { lockouts) }\end{array}$ \\
\hline High Mean Value: & $5.0 \mathrm{E}-3$ & $E F=10$ & Use: & $\begin{array}{l}\text { Complex lockout plan (11 to } \\
100 \text { lockouts) }\end{array}$ \\
\hline Low Mean Value: & $1.0 \mathrm{E}-4$ & $E F=10$ & Use: & $\begin{array}{l}\text { Simple lockout plan (1 to } 4 \\
\text { lockouts) }\end{array}$ \\
\hline
\end{tabular}

The calculated results are summarized in Table 3. Table 4 should be consulted to obtain human error probabilities or rates. 


\subsubsection{Chemical Addition or Elution Error}

A chemical addition or elution error involves adding too little, too much, or the wrong chemical to a tank or process. Factors influencing the failure probability for this event include the quality of the procedure, the complexity of the action, training, and experience.

\subsubsection{Generic Model}

This error can be very complex to model; many different types of errors can contribute to this event depending on the facilities being analyzed. Also, varied numbers and types of recovery factors may be present. As a very simplistic model, the Handbook nominal mean HEP of 3.8E-3 (median $=3.0 \mathrm{E}-3$, Handbook page 20-13) for an error of omission or commission was used, with an EF of three. For the high and low mean estimates, a factor of ten difference from the nominal case was assumed, resulting in 3.8E-2 and 3.8E-4, respectively, with an EF of three for both. The high value applies to a complex process with multiple procedure steps, performed infrequently, or where temptation to work without a procedure is great. The low value applies to a very simple process with few procedure steps performed frequently or where recovery factors dominate in the process.

\subsubsection{SRS-Specific Model}

No SRS-specific data were available for this human error.

\subsubsection{Recommended SRS-Specific Model}

Since no SRS-specific data were available for this human error, the generic model results, rounded as discussed in Section 3.3, are the recommended SRS results.

$\begin{array}{lllll}\text { Nominal Mean Value: } & 3.0 \mathrm{E}-3 & \mathrm{EF}=10 & \text { Use: } & \text { Typical process } \\ \text { High Mean Value: } & 3.0 \mathrm{E}-2 & \mathrm{EF}=5 & \text { Use: } & \text { Complex process } \\ \text { Low Mean Value: } & 3.0 \mathrm{E}-4 & \mathrm{EF}=10 & \text { Use: } & \text { Simple process }\end{array}$

The calculated results are summarized in Table 3. Table 4 should be consulted to obtain human error probabilities or rates. 


\subsubsection{Transfer Error}

A transfer error involves inadvertently transferring a liquid to an area (a tank, sump, room, or vessel). This error was quantified on a per area per hour basis, unlike most of the other events, which are failure probabilities per action. The reason for quantifying this event on a per hour basis is that the result is easy for analysts to use in risk models. The analyst does not have to trace all piping paths to the area of concem, identify all operations that could result in an inadvertent transfer through the piping path, determine how many operations occur per year, and then apply some failure probability per operation. If an analysis is being performed with multiple tanks in a single space (e.g., cell), then the transfer error failure rate may be applied to each vessel, as defined by the logic structure of the risk analysis fault tree.

\subsubsection{Generic Model}

Error probabilities for this action are highly dependent on the design of the facility. For this reason, no generic model was formulated for this action.

\subsubsection{SRS-Specific Model}

Reference 13 documents a search of the Risk Assessment Fault Tree Data Banks System to identify transfer errors at the F-Canyon and H-Canyon facilities at the SRS. The search identified 137 transfer errors in 4,380 tank-years, or 38,370,000 tank-hours. This search covered 1961 through 1990. This gives an error rate of 3.5E-6 per tank-hour. This rate is used as the nominal mean value and the error factor is obtained from Table $2(E F=10)$. Adjusting the nominal value by the EF, the high value is $3.5 \mathrm{E}-5$ with an EF of ten. The low value is $3.5 \mathrm{E}-7$ with an EF of ten. These failure rate estimates include mechanical failure rates.

\subsubsection{Recommended SRS-Specific Model}

Since no generic data were available for this human error, the SRS-Specific model results, rounded as discussed in Section 3.3, are the recommended SRS results.

$\begin{array}{lllll}\text { Nominal Mean Value: } & \begin{array}{l}3.0 \mathrm{E}-6 / \\ \text { tank-h* }\end{array} & \mathrm{EF}=10 & \text { Use: } & \begin{array}{l}\text { Moderate activity(10 potential } \\ \text { transfers/year) }\end{array} \\ \text { High Mean Value: } & \begin{array}{l}3.0 \mathrm{E}-5 / \\ \text { tank-h* }\end{array} & \mathrm{EF}:=10 & \text { Use: } & \begin{array}{l}\text { High activity (100 potential } \\ \text { transfers/year) }\end{array} \\ \text { Low Mean Value: } & \begin{array}{l}3.0 \mathrm{E}-7 / \\ \text { tank-h* }\end{array} & \mathrm{EF}=10 \quad \text { Use: } & \text { Low activity (1 potential transfer/year) } \\ \text { * Values presented include contributions from mechanical failures. } & \end{array}$

The calculated results are summarized in Table 3. Table 4 should be consulted to obtain human error probabilities or rates. 


\subsubsection{Overfilling of a Tank}

An overfilling error results in a tank or vessel exceeding its physical or administratively rated capacity.

\subsubsection{Generic Model}

Overfilling of a tank was treated similarly to a transfer error (Section 3.6.17). For this reason, no generic model was formulated.

\subsubsection{SRS-Specific Model}

Reference 13 also contains information on overfilling errors at the F-Canyon and H-Canyon facilities at the SRS. For the cold feed preparation processes in the F-Canyon and H-Canyon, 125 events occurred in $38,370,000$ tank-hours. For the waste and evaporation processes, 85 events occurred in 1,020 tank-years, or 8,935,000 tank-hours. This gives a human error rate of 4.4E-6 per tank-hour. This rate is used as the nominal mean value and the error factor is obtained from Table 2 $(E F=10)$. Adjusting the nominal value by the EF, the high mean value is $4.4 E-5$ with an $E F$ of ten. The low mean value is 4.4E-7 with an EF of ten. These failure rate estimates include mechanical failure rates.

\subsubsection{Recommended SRS-Specific Model}

Since no generic data were available for this human error, the SRS-Specific model results, rounded as discussed in Section 3.3, are the recommended SRS results.

$\begin{array}{lllll}\text { Nominal Mean Value: } & \begin{array}{l}5.0 \mathrm{E}-6 / \\ \tan \mathrm{k}-\mathrm{h}^{*}\end{array} & \mathrm{EF}=10 & \text { Use: } & \begin{array}{l}\text { Moderate activity (10 potential } \\ \text { transfers/year) }\end{array} \\ \text { High Mean Value: } & \begin{array}{l}5.0 \mathrm{E}-5 / \\ \tan \mathrm{k}-\mathrm{h}^{*}\end{array} & \mathrm{EF}=10 & \text { Use: } & \text { High activity (100 potential } \\ & 5.0 \mathrm{E}-7 / & \mathrm{EF}=10 & \text { Use: } & \text { Low activity (1 potential } \\ \text { tank-h*ansfers/year) } & & & & \text { transfer/year) }\end{array}$

* Values presented include contributions from mechanical failures.

The calculated results are summarized in Table 3. Table 4 should be consulted to obtain human error probabilities or rates. 


\subsubsection{Laboratory Analysis Error}

This human error involves errors in conducting laboratory analyses for process control and safety and environmental monitoring. Factors that influence laboratory errors are training, experience, ease of analysis procedure, normal variability of results, and workload.

\subsubsection{Generic Model}

A laboratory analysis error was modeled simplistically using the Handbook mean HEP of 3.8E-3 (median $=3.0 \mathrm{E}-3$ ) for an error of omission or commission, with an EF of three. However, credit was taken for a check by laboratory personnel (not Operations) of the analysis for the nominal and low cases. For the nominal case, Item 1 in Table 20-22 was used for the failure probability of the check (mean of $1.6 \mathrm{E}-1$ with an EF of five), resulting in a nominal case result of $6.1 \mathrm{E}-4$. The EF is seven. For the high estimate, the error of omission or commission was used directly, which implies no check of the analysis. The result is 3.8E-3, with an EF of three. Finally, for the low estimate, Item 4 in Table 20-22 was used for the failure probability of the check (mean of $1.6 \mathrm{E}-2$ with an EF of five), resulting in a low estimate of 6.1E-5, with an EF of seven.

\subsubsection{SRS-Specific Model}

Reference 14 documents a search of the SRS Risk Assessment Fault Tree Data Banks System for laboratory errors from 1976 through 1983. The search uncovered 20 events, of which 18 were human related. The 18 human error events involved cases where both an incorrect laboratory analysis was performed and operations personnel did not recognize the analysis as incorrect. It is not known how many laboratory analysis errors were made that were detected by Operations personnel before use. Reference 14 indicated that the probability for operations personnel using an incorrect laboratory result might range from $1.0 \mathrm{E}-1$ to $5.0 \mathrm{E}-1$, based on information from the Handbook. In order to be consistent with the human error probabilities presented in this document, a value of 1.0E-1 was assumed. This is the nominal value for Checker Verification Error (Table 3, Item 8). Therefore, using this value to adjust the number of events to remove the influence of Operations (not Laboratory) verifications results in an estimate of 180 laboratory analysis errors during 1976 through 1983. Reference 14 also indicates that approximately 96,500 laboratory analyses were performed each year, based on activity during 1976 and 1977 . Therefore, the total number of analyses is 772,000 . 


\subsubsection{Recommended SRS-Specific Model}

The event data set discussed in section 3.6.19.2 were applied to the generic model nominal case in section 3.6.19.1, using the Bayesian update process. The percent change of the generic nominal case to the nominal recommended value was applied to adjust the high and low generic values to obtain high and low recommended values, respectively.

Using the Generic Model results as the prior and the SRS-Specific Model as the posterior in the Bayesian update process and rounding the results as discussed in Section 3.3, the following are the recommended SRS-Specific human error probabilities:

$\begin{array}{lllll}\text { Nominal Mean Value: } & 3.0 \mathrm{E}-4^{*} & \mathrm{EF}=10 & \text { Use: } & \text { Low dependence check } \\ \text { High Mean Value: } & 1.0 \mathrm{E}-3 & \mathrm{EF}=10 & \text { Use: } & \text { No check } \\ \text { Low Mean Value: } & 3.0 \mathrm{E}-5^{*} & \mathrm{EF}=10 & \text { Use: } & \text { Zero dependence check }\end{array}$

* These values already include recoveries

The calculated results are summarized in Table 3. Table 4 should be consulted to obtain human error probabilities or rates.

\subsubsection{Failure to Verify Parameter with Calculation}

This human error probability involves calculation errors performed under the guidance of a procedure. Influencing factors for this task include difficulty of calculation, procedure usage, time available, training, and experience. Calculations performed by operating personnel are usually done on worksheet forms. These sheets usually provide the expected range or limit of the answer, if it can be projected in advance. Calculations may be conducted as part of standard operating procedures or abnormal operating procedures. The calculations may be done by hand or with a calculator.

\subsubsection{Generic Model}

Modeling for this task was done using a THERP tree. Three types of calculational situations were modeled. The nominal case model (Figure 4) involves a one-step calculation and has two branches. These basic events involve proredure usage, calculation, and a verification for out-of-range results. The basic error probabilities used in the THERP tree are indicated in Figure 4. The nominal case mean error probability is $2.0 \mathrm{E}-2$. Propagating the basic event uncertainties through the THERP tree in Figure 4, the EF is two. 
For the high estimate, no credit was taken for the range verification step in Figure 4. Also, a higher probability was used for failure to use the procedure, 8.1E-2 with an EF of five (Table 20-6. Item 6). The resulting high mean failure probability is $9.4 \mathrm{E}-2$, with an EF of four. For the low estimate, it was assumed that a procedure would be used in Figure 4, resulting in a mean value of 7.1E-3, with an EF of four.

\subsubsection{SRS-Specific Model}

No SRS-specific data were available for this human error.

\subsubsection{Recommended SRS-Specific Model}

Since no SRS-specific data were available for this human error, the generic model results, rounded as discussed in Section 3.3, are the recommended SRS results.

$\begin{array}{lllll}\text { Nominal Mean Value: } & 3.0 \mathrm{E}-2^{*} & \mathrm{EF}=5 & \text { Use: } & \begin{array}{l}\text { Procedure usually used, } \\ \text { verification }\end{array} \\ \text { High Mean Value: } & 1.0 \mathrm{E}-1 & \mathrm{EF}=3 & \text { Use: } & \begin{array}{l}\text { No verification } \\ \text { Low Mean Value: }\end{array} \\ 5.0 \mathrm{E}-3^{*} & \mathrm{EF}=10 & \text { Use: } & \begin{array}{l}\text { Procedure almost always used, } \\ \text { verification }\end{array}\end{array}$

* These values already include recoveries

The calculated results are summarized in Table 3. Table 4 should be consulted to obtain human error probabilities or rates.

\subsubsection{Random Actuation/Shutdown of System}

Random actuation or shutdown of a system involves inappropriate shutdown or actuation of a system by accident. An example of this type of action is an accidental bumping of a system shut-off switch, resulting in the loss of the system. An intentional, inappropriate shutdown or actuation of a system, whether it is due to an incomplete knowledge of the implications of such an action or by accident, should be modeled as a failure of administrative control, Section 3.6.1. An example of this type of action is the intentional shutting down of a heating, ventilating, or air conditioning (HVAC) system based on the belief that the system is no longer needed for the plant configuration at that time, while in actuality the HVAC system is needed for some system of concern. 


\subsubsection{Generic Model}

Quantification of this event is very difficult because of the lack of a clear demand or reason for such an action to occur. A simplistic model was constructed based on the experience that such errors are rare and contribute less than $10 \%$ to a system's overall unreliability. To estimate system unreliability, ten critical components were assumed, any of which could fail the entire system. Typical component failure rates, per hour $(\mathrm{h})$, range from $1.0 \mathrm{E}-4 \mathrm{~h}$ to $1.0 \mathrm{E}-6 / \mathrm{h} .10$ Assuming an average component failure rate of $1.0 \mathrm{E}-5 / \mathrm{h}$ and ten compunents, the system failure rate is $1.0 \mathrm{E}-4 / \mathrm{h}$. Therefore, $10 \%$ of this value is $1.0 \mathrm{E}-5 / \mathrm{h}$, which was used for the nominal case. An EF of ten was assumed, based on typical EFs in Reference 10. For the high and low estimates, a factor of ten difference from the nominal case was assumed. The results are $1.0 \mathrm{E}-4 / \mathrm{h}$ and $1.0 \mathrm{E}-6 / \mathrm{h}$, respectively, with EFs of ten. The high value should be used for high traffic areas, congested areas, or areas with increased personnel activity that may result in random actuation or shutdown. The low value applies to remote areas with little personnel activity.

\subsubsection{SRS-Specific Model}

Two sets of event data were collected. 12 These two event data sets are spurious actuation of the reactor Supplementary Safety System (SSS) and closure of reactor rotovalves.

(1) The first involves spurious operation of the reactor SSS. During the period 1977 through 1988, the REAC data base indicated one human caused spurious actuation of the SSS. The number of operational hours during which such an event could occur is

$(12 \mathrm{yr} /$ reactor $)(3$ reactor $)(8760 \mathrm{~h} / \mathrm{yr})(0.7)=220,752 \mathrm{~h}$.

The 0.7 multiplier represents the fraction of time each year that each reactor was operating.

(2) The other data set involves closure of the reactor rotovalves. The REAC data base indicated one human-caused incident in 15.2 years. The number of hours for this event is

$(15.2 \mathrm{yr} /$ reactor $)(3 \mathrm{reactor})(8760 \mathrm{~h} / \mathrm{yr})(0.3)=119,637 \mathrm{~h}$.

The 0.3 multiplier represents the fraction of time each year that each reactor was shut down. 


\subsubsection{Recommended SRS-Specific Model}

The two event data sets discussed in section 3.6.21.2 were applied to the generic model nominal case in section 3.6.21.1, using the Bayesian update process. The percent change of the generic nominal case to the nominal recommended value was applied to adjust the high and low generic values to obtain high and low recommended values, respectively.

Using the Generic Model results as the prior and the SRS-Specific Model as the posterior in the Bayesian update process and rounding the results as discussed in Section 3.3, the following are the recommended SRS-Specific human error probabilities:

\begin{tabular}{|c|c|c|c|c|}
\hline Nominal Mean Value: & $5.0 \mathrm{E}-6 / \mathrm{h}$ & $E F=10$ & Use: & $\begin{array}{l}\text { Some activities could affect } \\
\text { system }\end{array}$ \\
\hline High Mean Value: & $5.0 \mathrm{E}-5 / \mathrm{h}$ & $E F=10$ & Use: & $\begin{array}{l}\text { Many activities could affect } \\
\text { system }\end{array}$ \\
\hline Low Mean Value: & $5.0 \mathrm{E}-7 / \mathrm{h}$ & $E F=10$ & Use: & $\begin{array}{l}\text { Almost no activities could } \\
\text { affect system }\end{array}$ \\
\hline
\end{tabular}

The calculated results are surnmarized in Table 3. Table 4 should be consulted to obtain human error probabilities or rates.

\subsubsection{Vehicle Collision with Stationary Object}

This event involves a moving vehicle colliding with a stationary object such as a building, tank, tree, or parked vehicle.

\subsubsection{Generic Model}

National data were used to quantify this event. Sample vehicle accident rates are the following:

- 2.5E-6/mile (Bureau of Motor Carrier Safety, all Califomia roadways, 1960 - 1972) 15

- 6.4E-6/mile (American Petroleum Institute, all roadways, 1968 - 1981) 15

- 2.0E-6/mile (Handbook of Chemical Hazard Analysis Procedures) 16

- $\quad$ 7.0E-6/mile (National Safety Council, govemment division) 17 . 
A geometric average of these estimates was determined, using the following equation:

$$
A V E_{\text {geometric }}=\left[\pi\left(I_{i}\right)\right]^{1 / n}
$$

where $\pi()=$ product of the estimates in parentheses

$I_{i}=$ estimate from source $i$

$\mathrm{n}$ = number of sources.

The resulting geometric average is $3.9 \mathrm{E}-6 /$ mile. (The geometric average is often used when the various estimates being averaged may differ significantly. The arithmetic average is $4.5 \mathrm{E}-6 / \mathrm{mile}$, which is not significantly different.)

Reference 15 indicates that $9 \%$ of vehicle accidents involve collision with a fixed object. Therefore, the accident rate for this event is

$$
(3.9 \mathrm{E}-6 / \mathrm{mile})(0.09)=3.5 \mathrm{E}-7 / \mathrm{mile} \text {. }
$$

This accident rate was used for the nominal case mean value. For the high and low estimates, a factor of ten difference from the nominal case was assumed, resulting in $3.5 \mathrm{E}-6 / \mathrm{mile}$ and $3.5 \mathrm{E}-8 / \mathrm{mile}$, respectively. No EF information is given in the sources reviewed. The high value should be used given bad weather or a congested road with many objects near the road. The low value should be used for a freeway environment.

It should be noted that the accident rate for this event includes both mechanical failures resulting in accidents and driver errors. The human error contribution to these accident rates is greater than $50 \% .15$

\subsubsection{SRS-Specific Model}

Reference 18 includes a review of truck accidents at the SRS from 1963 through 1982 . Of the truck accidents listed in the reference, 30 involve collisions with stationary objects, such as parked vehicles, overpasses, gate houses, and others. During this period, hazardous material truck transportation at the SRS involved approximately 100,000 miles per year. Given the assumption in Reference 18 that such transportation is $10 \%$ of all truck transportation at SRS, approximately $1,000,000$ miles per year of truck traffic occurs. This results in $20,000,000$ miles over the 20-year period reviewed. 


\subsubsection{Recommended SRS-Specific Model}

The SRS-specific event data discussed in section 3.6.22.2 were applied to the generic model nominal case in section 3.6.22.1, using the Bayesian update process. The percent change of the generic nominal case to the nominal recommended value was applied to adjust the high and low generic values to obtain high and low recommended values, respectively.

Using the Generic Model results as the prior and the SRS-Specific Model as the posterior in the Bayesian update process and rounding the results as discussed in Section 3.3, the following are the recommended SRS-Specific human error probabilities:

\begin{tabular}{|c|c|c|c|c|}
\hline Nominal Mean Value: & $1.0 \mathrm{E}-6 / \mathrm{mile}^{*}$ & $E F=10$ & Use: & Typical highway environment \\
\hline High Mean Value: & $1.0 \mathrm{E}-5 / \mathrm{mile}^{*}$ & $E F=10$ & Use: & $\begin{array}{l}\text { Congested road, many objects } \\
\text { close to road, bad weather }\end{array}$ \\
\hline Low Mean Value: & $1.0 \mathrm{E}-7 / \mathrm{mile}^{*}$ & $E F=10$ & Use: & Freeway environment \\
\hline
\end{tabular}

* Values presented include contributions from mechanical failures.

The calculated results are summarized in Table 3. Table 4 should be consulted to obtain human error probabilities or rates.

\subsubsection{Single Vehicle Accident}

Single vehicle accidents involve vehicl overtums (no impact with a stationary object or another vehicle).

\subsubsection{Generic Model}

The single vehicle accident was quantified similarly to the previous event, but assuming $26 \%$ of all accidents are of this type. 15 The resulting nominal, high and low error rates are $1.0 \mathrm{E}-6 / \mathrm{mile}$, $1.0 \mathrm{E}-5 / \mathrm{mile}$, and $1.0 \mathrm{E}-7 / \mathrm{mile}$. Also, these accident rates include both mechanical problems and driver errors. Again, driver errors contribute over $50 \%$ to these results. The high value should be used for bad weather or a congested road. The low value should be used given a freeway environment.

\subsubsection{SRS-Specific Model}

Reference 18 also identified truck accidents that are appropriate for the category of single vehicle accidents. Of the events listed, 15 involved such events as truck jack-knifing, running off roads, overtums, and others. Again, the 20-year period involves approximately $20,000,000$ miles of truck operation. 


\subsubsection{Recommended SRS-Specific Model}

The SRS-specific event data discussed in section 3.6.23.2 were applied to the generic model nominal case in section 3.6.23.1, using the Bayesian update process. The resultant recommended value was unchanged from the generic nominal case. Hence, the high and low recommended values are not changed from their generic values.

Using the Generic Model results as the prior and the SRS-Specific Model as the posterior in the Bayesian update process and rounding the results as discussed in Section 3.3, the following are the recommended SRS-Specific human error probabilities:

Nominal Mean Value: $\quad 1.0 \mathrm{E}-6 / \mathrm{mile}^{*} \quad \mathrm{EF}=10 \quad$ Use: Typical highway environment High Mean Value: $\quad 1.0 \mathrm{E}-5 / \mathrm{mile}^{*} \quad \mathrm{EF}=10 \quad$ Use: Congested road, bad weather Low Mean Value: $\quad 1.0 \mathrm{E}-7 / \mathrm{mile}^{*} \quad \mathrm{EF}=10 \quad$ Use: Freeway environment

* Values presented include contributions from mechanical failures.

The calculated results are summarized in Table 3. Table 4 should be consulted to obtain human error probabilities or rates.

\subsubsection{Vehicle Collision with Another Moving Vehicle}

This event involves a moving vehicle colliding with another moving vehicle.

\subsubsection{Generic Model}

Vehicle collisions with other moving vehicles were quantified similarly to the previous two events, but assuming $62 \%$ of accidents are of this type. 15 The results for the nominal, high, and low cases are $2.5 \mathrm{E}-6 / \mathrm{mile}, 2.5 \mathrm{E}-5 / \mathrm{mile}$, and $2.5 \mathrm{E}-7 / \mathrm{mile}$, respectively. Driver errors contribute over $50 \%$ to these results. The guidelines for use of the high and low values are similar to those for single vehicle accidents.

\subsubsection{SRS-Specific Model}

Reference 18 identified 19 truck collision events involving other moving vehicles. The 20year period involves $20,000,000$ miles of truck operation. 


\subsubsection{Recommended SRS-Specific Model}

The SRS-specific event data discussed in section 3.6.24.2 were applied to the generic model nominal case in section 3.6.24.1, using the Bayesian update process. The percent change of the generic nominal case to the nominal recommended value was applied to adjust the high and low generic values to obtain high and low recommended values, respectively.

Using the Generic Model results as the prior and the SRS-Specific Model as the posterior in the Bayesian update process and rounding the results as discussed in Section 3.3, the following are the recommended SRS-Specific human error probabilities:

$\begin{array}{lllll}\text { Nominal Mean Value: } & 1.0 \mathrm{E}-6 / \mathrm{mile}^{*} & \mathrm{EF}=10 & \text { Use: } & \text { Typical highway environment } \\ \text { High Mean Value: } & 1.0 \mathrm{E}-5 / \mathrm{mile}^{*} & \mathrm{EF}=10 & \text { Use: } & \text { Congested road, bad weather } \\ \text { Low Mean Value: } & 1.0 \mathrm{E}-7 / \mathrm{mile}^{*} & \mathrm{EF}=10 & \text { Use: } & \text { Freeway environment }\end{array}$

* Values presented include contributions from mechanical failures.

The calculated results are summarized in Table 3. Table 4 should be consulted to obtain human error probabilities or rates.

\subsubsection{Dropping of Load When Using Forklift}

This event involves dropping a load when using a forklift to lift or move the load.

\subsubsection{Generic Model}

No generic estimates were identified for dropping of a load when using a forklift. A polling of several PRA practitioners 12 resulted in the following estimates for such errors: $1.0 \mathrm{E}-3 /$ operation for the nominal case, 1.0E-2/operation for the high case, and 1.0E-4/operation for the low case. These failure probability estimates do not include mechanical failure rates. An operation was defined to be a lift, move, and setting down of a load.

\subsubsection{SRS-Specific Model}

Five sets of SRS data were collected for this event. These events are pallet shipping from the central warehouse, material handling in the central warehouse, Tire and Lube Shop drum handling, transuranic drum handling, and waste box container handling. 
(1) For the shipping area at the central warehouse, four load drop events (pallets damaged) were identified over the period 1992 through 1993. These events were identified from a review of the Transportation Department records. During this period, the shipping organization handled 23,104 pallets. Assuming two forklift operations (each operation involves a lift, move, and set down) per pallet, the number of operations is

$(23,104$ pallet $)(2$ operations/pallet $)=46,208$ operations

(2) For the central warehouse, there were four incidents in 1992 and three in the first half of 1993 involving forklifts damaging loads, from a review of the Materials and Inventory Department safety records. During a typical year, the warehouse handles approximately 6000 receipts per month. Approximately four forklift operations are needed per receipt to place the item in storage. Also, the warehouse handles approximately 25,000 orders per month, with one forklift operation per order to place the item from storage on a pallet. Finally, the warehouse also delivers to shipping the same number of pallets that shipping handles, or 23,104 per year. Each pallet requires one forklift operation. Converting this information to the total number of forklift operations during the one and one-half year period yields

$(6000 \mathrm{receipt} / \mathrm{smo})(12 \mathrm{mo} / \mathrm{yr})(1.5 \mathrm{yr})(4$ operations/receipt $)+$ $(25,000$ orders/mo $)(12 \mathrm{mo} / \mathrm{yr})(1.5 \mathrm{yr})(1$ operation/order $)+$ $(23,104 \mathrm{pallet} / \mathrm{syr})(1.5 \mathrm{yr})(1$ operation/pallet $)=916,656$ operations

(3) For the Tire and Lube Shop, no events were identified in four years of operation. In this operation, an average of ten drums of hazardous waste (mostly waste oil and antifreeze) are handled per week. Each drum handling requires four forklift operations. Therefore, the total number of forklift operations over the four-year period is

$(10$ drums/week $)(52$ weeks/yr)(4 yr)(4 operations/drum $)=8,320$ operations.

(4) For transuranic (TRU) drum handling, the Risk Assessment Fault Tree Data Banks System indicated one event where a drum was dropped (actually knocked down) by a forklift for all SRS Waste Management facilities during 1989 through 1992. The number of TRU drum forklift operations during this time was estimated from the number of drum placements on storage pads and the number of drums X-rayed. From 1989 through 1992, 6704 drums were placed on the storage pads. One forklift operation was assumed for each drum placement. Also, in 1991 and 1992, 10,300 drums were $\mathrm{X}$-rayed. Each $\mathrm{X}$-ray operation was assumed to require two forklift operations. Therefore, the TRU forklift operations during 1989 through 1992 is

$(6704$ drums $)(1$ operation/drum $)+(10,300 \mathrm{X}$-rays $)(2$ operations/X-ray $)=27,304$ operations. 
(5) Finally, from 1988 through 1992, two waste box containers (one each of B-25 and B-12) were dropped by forklifts while placing such containers in the low level waste trenches. During this period, 31,670 B-25 boxes and 2,261 B-12 boxes were placed in the trenches. Each box placement requires one operation. Therefore, the total number of forklift operations during 1988 through 1992 is

$$
(31,670 \text { box }+2,261 \text { box })(1 \text { operation/box })=33,931 \text { operations. }
$$

\subsubsection{Recommended SRS-Specific Model}

Events (1), (3), (4), and (5), discussed in section 3.6.25.2, were applied to the generic model nominal case in section 3.6.25.1 using the Bayesian update process. The performance shaping factors associated with these events were assumed to be representative of a nominal situation. The percent change of the generic nominal case to the nominal recommended value was applied to adjust the high generic value to obtain the high recommended value. The low recommended value was obtained by applying event (2) from section 3.6.25.2 to the generic model low case. Event (2) performance shaping factors were assumed to be representative of the low probability situation.

Using the Generic Model results as the prior and the SRS-Specific Model as the posterior in the Bayesian update process and rounding the results as discussed in Section 3.3, the following are the recommended SRS-Specific human error probabilities:

\begin{tabular}{|c|c|c|c|c|}
\hline Nominal Mean Value: & 5.0E-5/operation* & $E F=10$ & Use: & Typical load \\
\hline High Mean Value: & 5.0E-4/operation ${ }^{*}$ & $E F=10$ & Use: & $\begin{array}{l}\text { Unusual, unevenly } \\
\text { balanced load }\end{array}$ \\
\hline Low Mean Value: & 1.0E-5/operation ${ }^{*}$ & $E F=10$ & Use: & $\begin{array}{l}\text { Standardized load, } \\
\text { spotter present }\end{array}$ \\
\hline
\end{tabular}

* An operation was defined as a lift, move, and setting down of a load.

The calculated results are summarized in Table 3. Table 4 should be consulted to obtain human error probabilities or rates. 


\subsubsection{Puncturing of Load When Using Forklin}

This is a special case of forklift damage to a load that involves puncturing the load with the forklift forks.

\subsubsection{Generic Model}

No generic data were identified for puncturing of a load when using a forklift. As a rough estimate, it was assumed that puncture events are as likely as dropping events. Therefore, the results in the previous section (3.6.25.3) were used as the generic model for puncturing of a load when using a forklift: 5.0E-5/operation for the nominal case, 5.0E-4/ operation for the high case, and 1.0E-5/operation for the low case. These failure probability estimates do not include mechanical failure rates.

\subsubsection{SRS-Specific Model}

A review of forklift puncturing and dropping/ hitting events from the SRS Risk Assessment Fault Tree Data Banks System during 1988 through 1992 indicated that there were three puncture events and six dropping/hitting events.

\subsubsection{Recommended SRS-Specific Model}

In section 3.6.26.2 the number of operations associated with load puncturing events could not be determined. An aiternate approach was to determine the relative occurrence of load puncturing events to load dropping events. This was done previously in section 3.6.26.2 (the result being 3/6). The recommended probabilities for the load dropping event in section 3.6.25.3 were adjusted by this ratio to give the nominal, high, and low recommended load puncturing error probabilities. The following are the recommended SRS-Specific human error probabilities:

\begin{tabular}{|c|c|c|c|c|}
\hline Nominal Mean Value: & 3.0E-5/operation* & $E F=10$ & Use: & Typical load \\
\hline High Mean Value: & 3.0E-4/operation ${ }^{*}$ & $E F=10$ & Use: & $\begin{array}{l}\text { Unusual, unevenly } \\
\text { balanced load }\end{array}$ \\
\hline Low Mean Value: & 5.0E-6/operation ${ }^{*}$ & $E F=10$ & Use: & $\begin{array}{l}\text { Standardized load, } \\
\text { spotter present }\end{array}$ \\
\hline
\end{tabular}

* An operation was defined as a lift, move, and setting down of a load.

The calculated resuits are summarized in Table 3. Table 4 should be consulted to obtain human error probabilities or rates 


\subsubsection{Dropping of Load When Using Crane/Hoist}

This event involves dropping a load when using a crane or hoist.

\subsubsection{Generic Model}

Dropping of loads when using cranes or hoists was quantified using generic data. Reference 19 indicates a rate of $1.5 \mathrm{E}-4$ /operating-hour for such events. No EF information is given in this source. This estimate was based on 200 load drops in 2000 crane-years of operation and additional crane data from nuclear power plants. If it is assumed that an average operation (lift, move, and setting down) takes one operating hour, then the failure rate is also $1.5 \mathrm{E}-4$ /operation. This was used for the nominal case. The high and low estimates were obtained by assuming a factor of ten difference from the nominal case, resulting in 1.5E-3/operation and 1.5E-5/operation, respectively. The high value should be used for unusual, unevenly balanced loads with standard construction or industrial equipment. The high value should also be used for special nuclear application equipment operated remotely by viewing through television cameras, periscopes, shield windows or water. The low value applies to standardized loads with a spotter present. These failure probability estimates do not include mechanical failure rates.

\subsubsection{SRS-Specific Mode?}

Five different sets of SRS data were collected for this event. These events are Central Services Works Engineering (CSWE) rigging activities, three types of activities involved with low level radioactive waste vault construction, and TRU drum movements.

(1) For the CSWE rigging activities, two crane drops were identified from the SRS Risk Assessment Fault Tree Data Banks System during the period 1988 through 1992. During this period the rigging activities included approximately 130 lifting jobs per month, with an average of five operations (lift, move, and set down) per job. Therefore, the number of operations during this period is

$(130 \mathrm{job} / \mathrm{mo})(12 \mathrm{mo} / \mathrm{yr})(5 \mathrm{yr})(5$ operations/job $)=39,000$ operations.

(2) During the construction of the SRS low level radioactive waste vaults, one drop occurred involving a large object such as roof beams, concrete form works, and others. During the four-year construction period, 852 such operations (lifts) occurred.

(3) Also during the SRS low level radioactive waste vaults construction, 3,000 operations involving standard concrete slabs occurred without incident. 
(4) Finally, during the SRS low level radioactive waste vaults construction, other types of operations involving small objects resulted in no drops in one and one-half years. The number of operations for this type of activity is

$(50$ operation/day $)(250$ day/yr $)(1.5 \mathrm{yr})=18,750$ operations.

(5) Finally, for TRU drums placed in culverts, one incident was identified in five years. The number of operations during this period was 6,884 .

\subsubsection{Recommended SRS-Specific Model}

Event data sets (3) and (5), discussed in section 3.6.27.2, were applied to the generic model nominal case in section 3.6.27.1. Event set (2) was applied to the high case. Event data sets (1) and (4) were applied to the low case. The performance shaping factors associated with these event data sets were assumed to be representative of their respective nominal, high, or low case.

Using the Generic Model results as the prior and the SRS-Specific Model as the posterior in the Bayesian update process and rounding the results as discussed in Section 3.3, the following are the recommended SRS-Specific human error probabilities:

\begin{tabular}{|c|c|c|c|c|}
\hline Nominal Mean Value: & 1.0E-4/operation * & $E F=10$ & Use: & Typical load \\
\hline High Mean Value: & 1.0E-3/operation $*$ & $E F=10$ & Use: & $\begin{array}{l}\text { Unusual, unevenly } \\
\text { balanced load }\end{array}$ \\
\hline Low Mean Value: & 3.0E-5/operation* & $E F=10$ & Use: & $\begin{array}{l}\text { Standardized load, } \\
\text { spotter present }\end{array}$ \\
\hline
\end{tabular}

* An operation was defined as a lift, move, and setting down of a load.

The calculated results are summarized in Table 3. Table 4 should be consulted to obtain human error probabilities or rates.

\subsubsection{Crane/Hoist Strikes Stationary Object}

This error is a crane or hoist striking a stationary object while moving during operations.

\subsubsection{Generic Model}

No generic data were identified for such events. It was assumed that the error rates for such events are similar to the dropping of a load, Section 3.6.26. Results are then 1.5E-4/operation for the 
nominal case, 1.5E-3/ operation for the high case, and 1.5E-5/operation for the low case. The high value applies in cases of poor visibility with no spotter. The high value should be used for unusual, unevenly balanced loads with standard construction or industrial equipment. The high value should also be used for special nuclear application equipment operated remotely by viewing through television cameras, periscopes, shield windows or water. The low values applies if a spotter is present and visibility is good. These failure probability estimates do not include mechanical failure rates.

\subsubsection{SRS-Specific Model}

A review of rigging of miscellaneous equipment for disposal in the burial grounds indicated two incidents in which the crane or load hit an object. These events were identified from the Risk Assessment Fault Tree Data Banks System during 1988 through 1992. Review of the burial ground rigging forman's log for a two-month period indicated approximately 315 operations. Extrapolating this to five years, the number of operations is

(315 operations $/ 2 \mathrm{mo})(12 \mathrm{mo} / \mathrm{yr})(5 \mathrm{yr})=9,450$ operations

\subsubsection{Recommended SRS-Specific Model}

The event data set discussed in section 3.6.28.2 was applied to the generic model nominal case in section 3.6.28.1, using the Bayesian update process. The percent change of the generic nominal case to the nominal recommended value was applied to adjust the high and low generic values to obtain high and low recommended values, respectively.

Using the Generic Model results as the prior and the SRS-Specific Model as the posterior in the Bayesian update process and rounding the results as discussed in Section 3.3, the following are the recommended SRS-Specific human error probabilities:

$\begin{array}{lllll}\text { Nominal Mean Value: } & 3.0 \mathrm{E}-4 \text { operation }^{*} & \mathrm{EF}=10 & \text { Use: } & \text { Typical visibility } \\ \text { High Mean Value: } & 3.0 \mathrm{E}-3 / \text { operation }^{*} & \mathrm{EF}=10 & \text { Use: } & \text { No spotter, low visibility } \\ \text { Low Mean Value: } & 3.0 \mathrm{E}-5 / \text { operation }^{*} & \mathrm{EF}=10 & \text { Use: } & \text { Spotter present }\end{array}$

* An operation was defined as a lift, move, and setting down of a load.

The calculated results are summarized in Table 3. Table 4 should be consulted to obtain human error probabilities or rates. 


\subsubsection{Excavation Error}

Excavation errors involve operator errors using heavy equipment, including digging too deeply, digging in the wrong location, digging without proper authorization, or striking an unanticipated object during digging. Influencing factors are training, experience, procedures, quality of directions/instructions, and facility configuration control.

\subsubsection{Generic Model}

No generic data were identified for excavation errors. Based on discussions with SRS personnel associated with the burial grounds, low level vaults, and H-Tank Farm, a nominal error probability of 1.0E-2/excavation was recommended. ${ }^{12}$ The high and low estimates are $1.0 \mathrm{E}-1 /$ excavation and 1.0E-3/excavation, respectively. The high value should be used given a poor review of the area to be excavated. The low value applies given an excellent review, including a survey for underground objects. Many of the influencing factors listed above represent administrative controls. Handbook Table 20-6, Item 1, gives an HEP for failure to use administrative controls a mean probability of $1.6 \mathrm{E}-2$ (median $=1.0 \mathrm{E}-2$ ) and an $\mathrm{EF}=5$. This corresponds well with the nominal value obtained from the subject matter experts. These failure probability estimates do not include mechanical failure rates.

\subsubsection{SRS-Specific Model}

Two sets of excavation error data were collected. 12 These event data sets included activities associated with excavations at the H-Tank Farm and H-Area geotechnical ground drilling. (1) The first involved excavations at the H-Tank Farm. During 1989 through 1992, the SRS Risk Assessment Fault Tree Data Banks System indicated four incidents involving unearthing unexpected objects or hitting objects known to be present. The number of excavations during this period is

$(12$ excavation $/ \mathrm{mo})(12 \mathrm{mo} / \mathrm{yr})(4 \mathrm{yr})=576$ excavations.

(2) For H-Area geotechnical ground drilling, one excavation error was identified from the SRS Risk Assessment Fault Tree Data Banks System, for the period from March through August 1993. This operation has involved 62 drillings.

\subsubsection{Recommended SRS-Specific Model}

The two event data sets discussed in section 3.6.29.2 were applied to the generic model nominal case in section 3.6.29.1, using the Bayesian update process. The resultant recommended 
value was unchanged from the generic nominal case. Hence, the high and low recommended values are not changed from their generic values.

Using the Generic Model results as the prior and the SRS-Specific Model as the posterior in the Bayesian update process and rounding the results as discussed in Section 3.3, the following are the recommended SRS-Specific human error probabilities:

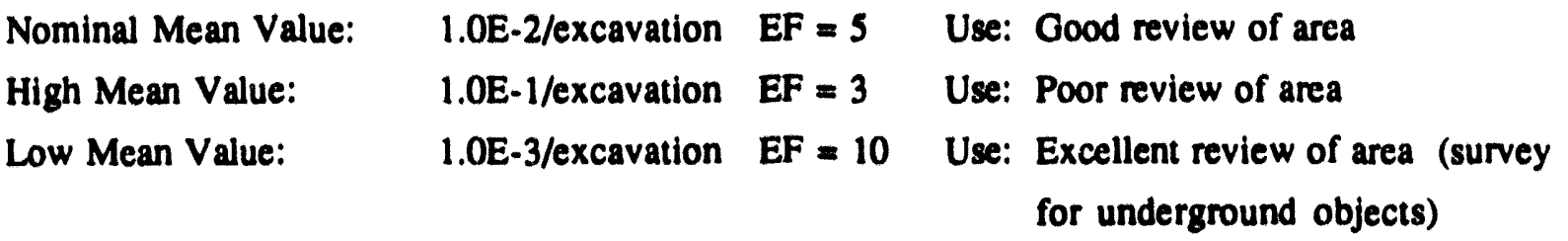

The calculated results are summarized in Table 3. Table 4 should be consulted to obtain human error probabilities or rates.

\subsubsection{Diagnosis Error}

Diagnosis errors occur when a situation requiring action to prevent or mitigate an incident is incorrectly identified or not identified at all. Influencing factors in this situation are time available, training, experience, difficulty of problem, quality of indicators, and use of procedures. Time available for diagnosis is the primary parameter affecting this probability, assuming adequate levels of staffing, training, procedures, and experience.

\subsubsection{Generic Model}

Several documents discussing diagnosis errors were reviewed to identify the most appropriate model for this application. These documents were Human Cognitive Reliability (HCR) 6 , the Handbook ${ }^{3}$, and INTENT. ${ }^{7}$ HCR and the Handbook provide models that are not facility specific. INTENT is facility specific, requiring a detailed knowledge of the facility before meaningful error probabilities can be generated. The probabilities for this generic application must be facility independent, so the HCR and Handbook methods were chosen.

HCR divides diagnosis errors into skill-based, rule-based, and knowledge-based actions. Skillbased actions are those that are leamed through repetition of the given action or of similar actions. Skill-based actions are mechanical in nature and do not involve significant conscious thought. Rulebased decisions are made by following a written procedure or other administrative control in a stepby-step fashion, usually with yes or no decision points in answer to clearly quantifiable questions. 
Knowledge-based decisions require information about the system that has been leamed over a long period of time. The information must be recalled from long-term memory and combined with other information such as system parameters or the occurrence of apparently unrelated events to reach a diagnosis.

The human errors addressed here are primarily concemed with knowledge-based actions. Formulas presented in HCR and the Handbook (Table 20-3) give HEPs based on the elapsed time from when the operator has sufficient information to reach a correct diagnosis. HCR and the Handbook provide the same HEPs when diagnosing a single event with only one independent failure. However, HCR has longer time frames than the Handbook. The HCR equation for knowledge-based diagnoses is a function of a normalized time, involving the actual time divided by the time needed to perform whatever action is required. This normalized time ranges from 1.0 to 10.0, with diagnosis error probabilities ranging from 5.0E-1 to 1.0E-3, respectively. The error probabilities from HCR were assumed to be medians. The Handbook provides the following median estimates, based on actual time: 1.0 for 0 to ten minutes, 1.0E-1 for ten to 20 minutes, $1.0 \mathrm{E}-2$ for 20 to 30 minutes, and $1.0 \mathrm{E}-3$ for greater than 30 minutes. All of the results except 1.0 have EFs of ten.

If one assumes an average time of five minutes is required for action, then the HCR normalized times can be converted to actual times, similar to the Handbook. Then the HCR and Handbook results can be approximately and somewhat conservatively collapsed into the following mean failure probabilities: $1.0 \mathrm{E}-1$ for 10 to 30 minutes, $1.0 \mathrm{E}-2$ for greater than 30 minutes to 120 minutes, and 1.0E-3 for greater than 120 minutes, on the same shift. The nominal case is $1.0 \mathrm{E}-2$, the high case is $1.0 \mathrm{E}-1$, and the low case is $1.0 \mathrm{E}-3$. EFs of ten were assumed.

\subsubsection{SRS-Specific Model}

No SRS-specific data were available for this human error.

\subsubsection{Recommended SRS-Specific Model}

Since no SRS-specific data were available for this human error, the generic model results, rounded as discussed in Section 3.3, are the recommended SRS results.

Nominal Mean Value: $\quad 1.0 \mathrm{E}-2 \quad \mathrm{EF}=5 \quad$ Use: Knowledge-based, 30 to 120 minutes

High Mean Value: $\quad 1.0 \mathrm{E}-1 \quad \mathrm{EF}=3 \quad$ Use: Knowledge-based, 10 to 30 minutes

Low Mean Value: $\quad 1.0 \mathrm{E}-3 \quad \mathrm{EF}=10 \quad$ Use: Knowledge-based, greater than 120 minutes

The calculated results are summarized in Table 3. Table 4 should be consulted to obtain human error probabilities or rates. 


\subsubsection{Fallure of Visual Inspection}

Failure of visual inspection includes failure to observe ahnormal characteristics such as leaks, damage to structures, build-up of material, etc., during routine or abnormal inspections (does not include manual detection of fire which is covered in Section 3.6.32). This task may include the use of TV cameras, periscopes, or other means of visual observation.

\subsubsection{Generic Model}

The nominal case is applicable to normal operating inspections conducted using written procedures. The mean nominal HEP is $1.6 \mathrm{E}-1$ (median $=1.0 \mathrm{E}-1$ ) with an EF of five (Table 20-22, Item 1 , in the Handbook). The high case is applicable to normal operating inspections conducted without the use of written procedures or special oral instructions. The mean high HEP is 5.7E-1 (Table 20-27. Item 1) with an EF of two. (The Handbook EF of ten was reduced to two to keep the 95th percentile at or below 1.0.) The high HEP estimate would be used in cases where a periodic inspection for the bulld-up of material is conducted, but the locations inspected are not readily accessible, well lighted, or easily visible. The high estimate should also be used for more difficult inspection tasks such as spotting a valve that is mispositioned. Finally, the low case is applicable to abnormal operating inspections conducted using written procedures or special oral instructions and/or any deviations are large and considered to always be detected (e.g., a large pool of water on the floor, etc.). The THERP tree in Figure 5 represents the low case failure probability. The mean low HEP is 9.8E-3 with an EF of two .

\subsubsection{SRS-Specific Model}

No SRS-specific data were available for this human error.

\subsubsection{Recommended SRS-Specific Model}

Since no SRS-specific data were available for this human error, the generic model results, rounded as discussed in Section 3.3, are the recommended SRS results.

Nominal Mean Value: $\quad 1.0 \mathrm{E}-1 \quad \mathrm{EF}=3 \quad$ Use: Procedure usually followed, event easy to observe

High Mean Value: $\quad 5.0 \mathrm{E}-1 \quad \mathrm{EF}=2$ Use: Event difficult to observe

Low Mean Value: $\quad 1.0 \mathrm{E}-2 \quad \mathrm{EF}=5 \quad$ Use: Procedure followed, event easy to observe (damage very prominent)

The calculated results are summarized in Table 3. Table 4 should be consulted to obtain human error probabilities or rates. 


\subsubsection{Fallure of Manual Fire Detection}

Failure of manual fire detection is the failure of personnel to detect a fire without the aid of automatic fire detection means. The primary influencing factor is the time personnel spend in the general vicinity of the fire area.

\subsubsection{Generic Model}

The report Nuclear Power Plant Fire Protection - Fire-Hazards Analysis (Subsystems Study Task 4) provides information for this human error. 20 Table 4, Items $C_{1}$ and $E_{1}$ in that reference, lists success probabilities for manual detection of fires in their early stages, including proper notification. The fallure probabilities were obtained by subtracting the success values from 1.0. The results are failure probabilities of $1.0 \mathrm{E}-1$ to $1.0 \mathrm{E}-2$ if the area is occupied $100 \%$ of the time, and 1.0 if unoccupied. For this study 5.0E-2 was used as the detection failure probability when an area is occupied, and 5.0E-1 was used when an area is unoccupied. The smell or sight of smoke or the sight of flames or glow from a fire may extend beyond the "unoccupied" area to alert personnel. For this reason, the value 1.0 for an unoccupied area was considered to be too high. A simple generic model for non-detection is the following:

$P_{\text {nd }}=(X)\left(P_{\text {occ }}\right)+(1-X)\left(P_{\text {noc }}\right)$

where $P_{n d}=$ probability of non-detection

$$
\begin{aligned}
& X=\text { fraction of time the area is occupied } \\
& P_{\text {occ }}=\text { non-detection probability when area is occupied }(5.0 \mathrm{E}-2) \\
& P_{\text {noc }}=\text { non-detection probability when area is not occupied }(5.0 \mathrm{E}-1) \text {. }
\end{aligned}
$$

For the nominal case, it was assumed that the area is occupied $80 \%$ of the time. The non-detection probability is then $1.4 \mathrm{E}-1$. For the high value, it was assumed that the area is not occupied, resulting in a non-detection mean probability of 5.0E-1. Finally, for the low value, it was assumed the area is always occupied, resulting in 5.0E-2.

\subsubsection{SRS-Specific Model}

A search of the SRS Risk Assessment Fault Tree Data Banks System indicated 225 fire incidents from 1983 through June 30,1993. All but two of these fires were detected while in progress. Both of these fires occurred in unoccupied areas. Information was not available concerning the percentage of time the other fire areas were occupied. Therefore, for conservatism, all events were assumed to occur in areas that are occupied $100 \%$ of the time. All types of fire incidents occurring in the data bank (e.g., facility, vehicle, grass, etc.) were included in the total. 


\subsubsection{Recommended SRS-Specific Model}

The Bayesian update was applied to the probability of manual detection given an occupant in the area (mean $=5.0 \mathrm{E}-2$ with an assumed EF of five). The Bayesian update posterior is $1.1 \mathrm{E}-2$ with an EF of 2.6. This was rounded to 1.0E-2 with an EF of five. This value was then inserted into the model in place of 5.0E-2, and the new results were obtained. The nominal, high, and low values did not change from their generic values.

Using the Generic Model results as the prior and the SRS-Specific Model as the posterior in the Bayesian update process and rounding the results as discussed in Section 3.3, the following are the recommended SRS-Specific human error probabilities:

$\begin{array}{llll}\text { Nominal Mean Value: } & 1.0 \mathrm{E}-1 & \mathrm{EF}=3 & \text { Use: Area occupied } 80 \% \text { of time } \\ \text { High Mean Value: } & 5.0 \mathrm{E}-1 & \mathrm{EF}=2 & \text { Use: Area unoccupied } \\ \text { Low Mean Value: } & 1.0 \mathrm{E}-2 & \mathrm{EF}=5 & \text { Use: Area occupied } 100 \% \text { of time }\end{array}$

The calculated results are summarized in Table 3. Table 4 should be consulted to obtain human error probabilities or rates.

\subsubsection{Failure of Manual Fire Suppression By Occupant}

This human error involves failure to suppress a fire using manual fire suppression means such as fire extinguishers, hose stands, or other means. Also this fire suppression covers actions taken only by personnel assigned to the facility or general area of the fire.

\subsubsection{Generic Model}

In Reference 20, Table 4, Items $E_{3}$ and $I_{3}$, list success probabilities for fire suppression of fires in early stages using hand-held fire extinguishers. Such fire suppression is possible only if the fire is identified in its early stages. Three sets of influencing factors were chosen from Reference 20 :

- $\quad$ standard installation and maintenance of fire extinguishers (per appropriate facility fire protection code) and personnel are properly trained in their usage

- $\quad$ substandard installation and maintenance of fire extinguishers but personnel are properly trained in their usage

- personnel receive poor or no fire extinguisher training.

The second set was chosen for the nominal case. The failure probability is $1.5 \mathrm{E}-1$. No EF information is given in Reference 20. 
For the high value, the third set of influencing factors was chosen, resulting in a failure probability of 5.0E-1. For the low value, the first set was chosen. The failure probability is 5.0E-2.

\subsubsection{SRS-Specific Model}

A search of the SRS Risk Assessment Fault Tree Data Banks System for 1983 through June 30, 1993 indicated 186 fires extinguished by either occupants or the fire department or brigade. Fire suppression by the fire department or fire brigade is assumed to be the failure of suppression by the occupant. Four types of situations were identified in these 186 events. The fire events occurred in facilities, vehicles, waste containers, and grass or brush areas. (1) Of the 109 fire events that occurred in facilities, 88 were extinguished by occupants and 21 were put out by the fire department. (2) Of the 57 vehicle fires, 29 were extinguished by occupants and 28 by the fire department. For waste containers, nine fires occurred. Two of these were extinguished by personnel nearby ("occupants"), and seven were handled by the fire department. (4) Finally, of the 11 grass or brush fires, three were put out by nearby personnel and eight by the fire department.

\subsubsection{Recommended SRS-Specific Model}

Event data sets one and two, discussed in section 3.6.33.2, were applied to the generic model nominal case in section 3.6.33.1. Event sets three and four were applied to the high case. The low case used the same percent change as the generic nominal case ratio to the nominal recommended case, to obtain the low recommended value. Event data set performance shaping factors were assumed to be representative of the case (nominal, high, or low) they modified.

Using the Generic Model results as the prior and the SRS-Specific Model as the posterior in the Bayesian update process and rounding the results as discussed in Section 3.3, the following are the recommended SRS-Specific human ermr probabilities:

\begin{tabular}{|c|c|c|c|c|}
\hline Nominal Mean Value: & $3.0 \mathrm{E}-1$ & $E F=3$ & Use: & $\begin{array}{l}\text { Typical fire extinguisher } \\
\text { installation/maintenance }\end{array}$ \\
\hline High Mean Value: & $5.0 \mathrm{E}-1$ & $E F=2$ & Use: & $\begin{array}{l}\text { Poor fire extinguisher } \\
\text { installation/maintenance }\end{array}$ \\
\hline Low Mean Value: & $1.0 \mathrm{E}-1$ & $E F=3$ & Use: & $\begin{array}{l}\text { Excellent fire extinguisher } \\
\text { installation/maintenance }\end{array}$ \\
\hline
\end{tabular}

The calculated results are summarized in Table 3. Table 4 should be consulted to obtain human error probabilities or rates. 


\subsubsection{Failure of Manual Fire Suppression By Non-Occupant}

This event involves failure of a fire brigade or fire department to suppress a fire using manual fire suppression means. Factors affecting this failure probability include the size and type of fire, training and experience, and time to respond.

\subsubsection{Generic Model}

Reference 20 provides some information on this type of failure probability. Table 4 , Item $R_{3}$ in that reference lists a failure probability of $6.0 \mathrm{E}-1$ if the response occurs within ten minutes. This was assumed to be the nominal value. An EF of two was assumed. For the high value, 1.0 was assumed. For the low value, a failure probability of $1.0 \mathrm{E}-1$ was assumed. This value does not come from Reference 23, but is meant to cover cases where the fire response team is well-trained and the fire is not difficult to suppress (i.e., the fire is detected locally). This value is not recommended for fires in unoccupied buildings.

\subsubsection{SRS-Specific Model}

A search of the SRS Risk Assessment Fault Tree Data Banks System for 1983 through June 30, 1993 indicated 67 fires that were suppressed by the fire department. Of these, nine were juoged to have resulted in heavy damage. These nine events were interpreted as failures of the fire department to suppress the fires, even though the fires were eventually suppressed.

\subsubsection{Recommended SRS-Specific Model}

Event data set discussed in section 3.6.34.2 was applied to the generic model nominal case in section 3.6.34.1, using the Bayesian update process. The percent change of the generic nominal case ratio to the nominal recommended value was applied to adjust the high and low generic values to obtain high and low recommended values.

Using the Generic Model results as the prior and the SRS-Specific Model as the posterior in the Bayesian update process and rounding the results as discussed in Section 3.3, the following are the recommended SRS-Specific human error probabilities: 


\begin{tabular}{|c|c|c|c|c|}
\hline Nominal Mean Value: & $1.0 \mathrm{E}-1$ & $E F=3$ & Use: & $\begin{array}{l}\text { Response by } 10 \text { minutes, } \\
\text { typical fire }\end{array}$ \\
\hline High Mean Value: & $3.0 \mathrm{E}-1$ & $E F=3$ & Use: & $\begin{array}{l}\text { Response much longer than } 10 \\
\text { minutes, difficult fire }\end{array}$ \\
\hline Low Mean Value: & $3.0 \mathrm{E}-2^{*}$ & $E F=5$ & Use: & $\begin{array}{l}\text { Response less than } 10 \text { minutes, } \\
\text { simple fire }\end{array}$ \\
\hline
\end{tabular}

The calculated results are summarized in Table 3. Table 4 should be consulted to obtain human error probabilities or rates.

\subsubsection{Failure of Long-Term Accident Recovery}

Failure of long-term accident recovery involves the failure to diagnose a situation and to correctly identify a recovery action when hours to days are available for the recovery. This type of error is influenced by such things as: quality of written emergency pmcedures, use of independent verification for critical action steps, availability of electrical power, quality of training and simulated practice drills, and the complexity of the recove:y action. This event is assumed to be a design basis event and the equipment necessary for the recovery is assumed to be available.

\subsubsection{Generic Model}

Failure of long-term accident recovery was modeled using a THERP tree with basic human errors from the Handbook. The THERP tree is shown in Figure 6. Assumptions implicit in the nominal model are the following:

- verified and validated written step-by-step Emergency procedures with checkoff provisions are in use at the facility being analyzed

- no electrical power is available following the catastrophic event

- skilled personnel (completed training qualification and have six months or more on the job experience) are available to perform all tasks

- equipment required for recovery following the catastrophic event is available (has been stored and maintained properly to survive a catastrophic event)

- the recovery action is assumed to be either a single simple task or a completely dependent set of simple tasks

- the time available to recover from the catastrophic event is 24 to 48 hours and a second shift of skilled personnel is available 
- a recovery factor of one coworker checking the work performed by the primary operator is assessed

- operators must perform field walkdowns of equipment to verify status

The nominal case for long-term accident recovery assumes stress has subsided to moderately high levels for the operators on shift during the initiating event. Stress is assumed to have decreased to optimal levels for subsequent shifts but low dependence on the previous shift is conservatively assessed. Recovery actions are to be completed within 24 to $\mathbf{4 8}$ hours following the initiating event. Applying appropriate basic human error probabilities to the branches in the THERP tree in Figure 6, the resultant nominal case mean failure probability is 2.3E-3. The basic HEPs for the operators on shift during the initiating event were modified for the effects of moderately high stress by using a multiplier of two (Table 20-16, Item 4a). The major contribution to this failure probability involves the failure to use a procedure checklist properly, omitting a step in the procedure, and the failure of the recovery by second shift personnel to correct any errors made by the previous shift. Propagating the basic event uncertainties through the THERP tree in Figure 6 results in an EF of eight.

The high failure probability for long-term accident recovery assumes an extremely high stress level with recovery actions to be completed within a short time frame of approximately two to twenty-four hours following a catastrophic event initiator. The high failure probability estimate was obtained by eliminating the two recoveries modeled in the nominal THERP tree and adjusting the diagnosis HEP to allow sixty minutes to be available for diagnosis of the event resulting in a mean diagnosis HEP of 3.4E-2 (median = 4.0E-3) with an EF of 30 (Figure 12-4 in the Handbook, upper bound curve). The other basic human error probabilities were increased for the effects of extremely high stress by using a multiplier of five (Table 20-16, Item 6a). The high mean failure probability for long-term accident recovery wih no recoveries is $1.2 \mathrm{E}-1$ with an $\mathrm{EF}$ of ten.

The low failure probability assumes that stress has subsided to optimal levels with recovery actions to be completed within a three to seven day time frame following the catastrophic event initiator. No modifications for the effects of stress are assigned due to the length of time available for recovery from this event. The stress tables in the Handbook are typically modeling reactor control room operator mitigating actions that must be performed in a relatively short period of time (less than two hours after the initiating event) (Handbook, Figure 17-2, page 17-15). The low failure probability estimate was obtained by adjusting the diagnosis HEP on the nominal THERP tree to allow twelve hours for diagnosis of the event resulting in a mean of 5.1E-3 (median $=6.0 \mathrm{E}-4$ ), with an EF of 30 (Figure 12-4 in the Handbook, upper bound curve). The recovery factor of second shift personnel was lowered to a mean of 1.2E-3 (median $=1.0 \mathrm{E}-3$ ) with an EF of three (Table 20-6, Item 2). The resultant lo'v mean failure probability for long-term accident recovery is $2.3 \mathrm{E}-5$ with an $\mathrm{EF}$ of 12 . 


\subsubsection{SRS-Specific Model}

No SRS-specific data were available for this human error.

\subsubsection{Recommended SRS-Specific Model}

Since no SRS-specific data were available for this human error, the generic model results, rounded as discussed in Section 3.3, are the recommended SRS results.

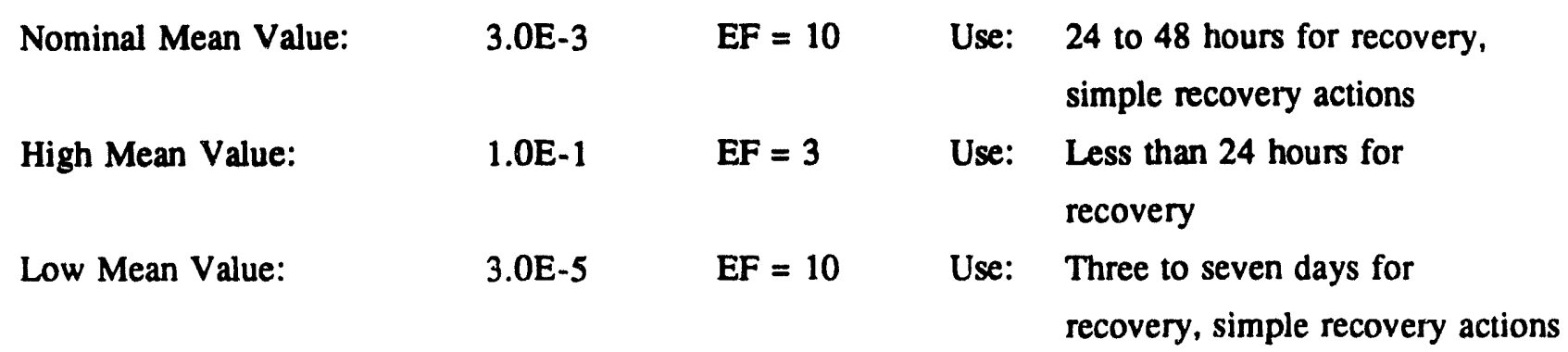

The calculated results are summarized in Table 3. Table 4 should be consulted to obtain human error probabilities or rates. 


\section{PEER REVIEW}

The external peer review performed by JBF Associates, Inc. focused on the contents of the draft document - the reasonableness of its assumptions, the consistency of its models, and the accuracy of its calculations. The extemal peer reviewers did not independently check the SRSspecific data sources.

The external peer reviewers first reviewed the human error models and assumptions in the report and provided comments to the authors. After the comments were addressed, the calculations in the report were reviewed for both the nominal models and the Bayesian modifications. Finally, the extemal reviewers suggested some wording changes in the text to improve its technical accuracy and readability.

The intemal peer review performed for this project was three-fold. First, several parties were active in the the selection of the representative human errors to be modeled and quantified. They included risk analysts and human factors specialists from both the Process Safety Technology (PST) and Waste and Environmental Technology (WEST) Sections of the Safety Technology Department. An additional selection criterion is that each representative human error must have shown up in one or more recent SARs or risk analysis calculations. A group concensus was reached for the inclusion or exclusion of human errors from the representative list.

Second, the internal peer review concentrated on the selection of appropriate search criteria for SRS Risk Assessment Fault Tree Data Banks System. Selection of years of operation (date), facility, operation and equipment codes was reviewed by the Data and Consequences Analysis Group within the PST Section. To ensure that no human error events were missed during the searches, all equipment codes that had any human error component were chosen (35 in all).

Third, each model was reviewed, discussed, and reiterated many times before it appeared in its final form. Each calculation was checked against its the original data source and for its agreement with the selected methodology. 


\section{SUMMARY AND CONCLUSIONS}

As part of an overall effort to upgrade and streamline methodologies for safety analyses of nonreactor nuclear facilities at the SRS, a human error data base has been developed. The data base includes models and quantification results for 35 representative human errors. Periodic updates to this report are planned as additional data or methodologies become available. For 16 of the human errors, the recommended SRS-specific human error probabilities or rates are based solely on the generic models (i.e., no actual SRS data available). SRS-specific human error data were collected for 19 of the 35 human errors. Of these 19 human errors, the final recommended values for two human errors were based solely on the actual SRS-specific human error data. Recommended SRS-specific human error probabilities or rates were obtained by combining the generic models with the SRSspecific data for the remaining 17 human errors. The generic and SRS-specific human error models with the Bayesian update results are documented in Table 3 in this report.

The collection of SRS-specific human error data to support and update the generic human error model results is a major strength of this project. Few human error analyses include comparisons with site-specific data. Approximately 50\% of the human errors are supported by SRSspecific data. The SRS-specific data resulted in the generic model human error probabilities increasing for four of the events, decreasing for 11 of the events, and remaining the same for the other two events. However, only in one case did the updated result vary by a factor of ten or more (dropping of load when using forklift); the SRS-specific data indicated a lower probability of error than the generic model indicated. 


\section{REFERENCES}

1. PRA Procedures Guide, U.S. Nuclear Regulatory Commission, NUREG/CR-2300, January 1983, pp. 5-46 through 5-52.

2. W. S. Durant, D. F. Baughman and C. S. Townsend, Separations Facilities Fault Tree Data Bank (SEPR) 1992 Status Report (U), Savannah River Site, WSRC-TR-93-309, May 1993.

3. A. D. Swain and H. E. Guttmann, Handbook of Human Reliability Analysis with Emphasis on Nuclear Power Plant Applications, U.S. Nuclear Regulatory Commission, NUREG/CR-1278, August 1983.

4. A. D. Swain, Accident Sequence Evaluation Program Human Reliability Analysis Procedure, U.S. Nuclear Regulatory Commission, NUREG/CR-4772, February 1987.

5. Central Safety Evaluation Team, Human Reliability Analysis Application Guide, Martin Marietta Energy Systems, Inc., ES/CSET-16, May 1993.

6. G. W. Hannaman et al., Human Cognitive Reliability Model for PRA Analysis (draft), NUS Corporation, NUS-4531, December 1984.

7. D. I. Gertman et al., "INTENT: a method for estimating human error probabilities for decisionbased errors," Reliability Engineering and System Safety, 35, 1992, pp. 127-136.

8. T. A. Wheeler et al., Analysis of Core Damage Frequency from Internal Events: Expert Judgment Elicitation, U.S. Nuclear Regulatory Commission, NUREG/CR-4550, Vol. 2, 1989.

9. Reactor Safety Study: An Assessment of Accident Risks in U.S. Commercial Nuclear Power Plants, U.S. Nuclear Regulatory Commission, WASH-1400 (NUREG 75/074), October 1975.

10. C. H. Blanton and S. A. Eide, SRS Generic Data Base Development (U), Savannah River Site, WSRC-TR-93-262, June 1993.

11. T. A. Dillehay et al., "REAC Database Supplement", BASIS User's Guide (U), WSRC-IM-90-34, Savannah River Site, April 1990.

12. R. E. Vail and H. C. Benhardt, "SRS-Specific Data Compilation in Support of Human Error Data Base Development (U)", WSRC-TR-94-0109, Savannah River Site, February 1994.

13. J. H. Weber, Statistical Analysis of Frequency of DWPF Accident Scenarios (U), Savannah River Site, WSRC-TR-93-335, June 1993.

14. W. C. Perkins, "The Probability of Process Laboratory Errors Affecting Reprocessing Operations," In: Proceedings of the International Topical Meeting on Advances in Human Factors in Nuclear Power Systems, (pp. 180-183), American Nuclear Society, Knoxville, TN, April 21-24, 1986, (CONF-860415).

15. L. E. Fischer et al., Shipping Container Response to Severe Highway and Railway Accident Conditions Main Report, U.S. Nuclear Regulatory Commission, NUREG/CR-4892-VI, February 1987.

16. Handbook of Chemical Hazard Analysis Procedure, U.S. Federal Emergency Management Agency, 1989.

17. Accident Facts, 1991 Edition, U.S. National Safety Council.

18. Evaluation of Accident Risks in the Transportation of Hazardous Materials By Truck and Rail at the Savannah River Site (U), Savannah River Site, WSRC-RP-89-715, Revision 1,

September 1992. 
19. WRAP Module I Preliminary Safety Evaluation, Westinghouse Hanford Company, WHC-SD-W026-PSE-001, Revision OA, 1991.

20. D. L. Berry and E. E. Minor, Nuclear Power Plant Fire Protection - Fire-Hazards Analysis (Subsystems Study Task 4), U.S. Nuclear Regulatory Commission, NUREG/CR-0654, September 1979. 


\begin{tabular}{|c|c|c|}
\hline ype & Human Enor Event & B.c.intion: \\
\hline Basic & 1. Failure of administrative control & Failure to follow a policy or procedure \\
\hline Basic & 2. Failure to respond to compelling signal & Failure to notice/respond to an alarm/annunciator/other compelling signal \\
\hline Basic & 3. Failure to verify within control room & $\begin{array}{l}\text { Failure to select correct instrument for verification, or given the correct } \\
\text { selection, failure to verify within the control room the status of an } \\
\text { instrument when requested or indicated by procedure }\end{array}$ \\
\hline Basic & 4. Failure to verify outside control room & Similar to \#3, but outside the control room \\
\hline Basic & 5. Error in selecting control within control room & $\begin{array}{l}\text { Selecting the wrong control or improperly operating a control in the control } \\
\text { room }\end{array}$ \\
\hline Basic & 6. Error in selecting control outside control room & Similar to $\# 5$, but outside the control room \\
\hline Basic & 7. Communication error & $\begin{array}{l}\text { Error in communicating instructions/responses/results face-to-face, over a } \\
\text { phone, by walkie-talkie, or by PA system }\end{array}$ \\
\hline Basic & 8. Checker verification error & Checker fails to verify action \\
\hline Basic & 9. Supervisor verification error & Supervisor incorrectly verifies or fails to verify an action \\
\hline Basic & 10. Incorrect labeling or tagging & $\begin{array}{l}\text { Container/component/indicator is labeled or tagged incorrectly, or the label } \\
\text { or tag is missing (does not include failure to tag a component as part of a } \\
\text { lockout procedure, which is covered under a separate human error) }\end{array}$ \\
\hline Basic & 11. Incorrect reading or recording of data & $\begin{array}{l}\text { Data are incorrectly read from an indicator, are incorrectly recorded, or are not } \\
\text { recouded }\end{array}$ \\
\hline
\end{tabular}




\begin{tabular}{|c|c|c|}
\hline Type & Human Error Event & Description \\
\hline $\begin{array}{l}\text { Complex/Maintenance } \\
\text { and Testing }\end{array}$ & 12. Miscalibration & $\begin{array}{l}\text { Gross miscalibration of an instrument such that safety or operational limits } \\
\text { may be exceeded }\end{array}$ \\
\hline $\begin{array}{l}\text { Complex/Maintenance } \\
\text { and Testing }\end{array}$ & 13. Failure to restore following a test & $\begin{array}{l}\text { Faihure to return equipment to their operational or safety status following a } \\
\text { lest }\end{array}$ \\
\hline $\begin{array}{l}\text { Complex/Maintenance } \\
\text { and Testing }\end{array}$ & 14. Failure to restore following maintenance & $\begin{array}{l}\text { Failure to return equipment to their operational or safety status following } \\
\text { maintenance }\end{array}$ \\
\hline $\begin{array}{l}\text { Complex/Maintenance } \\
\text { and Testing }\end{array}$ & 15. Failure to lock out & $\begin{array}{l}\text { Failure to properly conduct a lockout including associated administrative } \\
\text { controls }\end{array}$ \\
\hline $\begin{array}{l}\text { Complex/Facility } \\
\text { Operations }\end{array}$ & 16. Chemical addition/elution error & Adding too much, too little, or the wrong chemical \\
\hline $\begin{array}{l}\text { Complex/Facility } \\
\text { Operations }\end{array}$ & 17. Transfer error & Inadvertent transfer of a liquid to an area (tank, sump, rocm, etc.) \\
\hline $\begin{array}{l}\text { Complex/Facility } \\
\text { Operations }\end{array}$ & 18. Overfilling of a tank & Tank overfilling results in exceeding tank capacity \\
\hline $\begin{array}{l}\text { Complex/Facility } \\
\text { Operations }\end{array}$ & 19. Laboratory analysis error & Error in laboratory analysis \\
\hline $\begin{array}{l}\text { Complex/Facility } \\
\text { Operations }\end{array}$ & 20. Failure to verify parameter with calculation & Calculation error while following procedures \\
\hline $\begin{array}{l}\text { Complex/Facility } \\
\text { Operations }\end{array}$ & 21. Random actuation/shutdown of system & $\begin{array}{l}\text { Inappropriate actuation or shutdown of a system, either intentionally } \\
\text { (unaware of implications of the action) of by accident }\end{array}$ \\
\hline $\begin{array}{l}\text { Complex/Mobile } \\
\text { Equipment Operation }\end{array}$ & 22. Vehicle collision with stationary object & $\begin{array}{l}\text { Vehicle collision with stationary object (building, tank, tree, perked vehicle, } \\
\text { etc.) }\end{array}$ \\
\hline
\end{tabular}




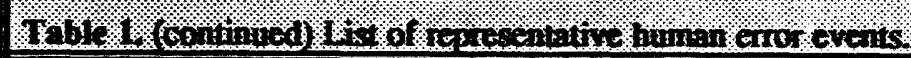

\begin{tabular}{|c|c|c|}
\hline Type & Human Error Event & Description \\
\hline $\begin{array}{l}\text { Complex/Mobile } \\
\text { Equipment Operation }\end{array}$ & 23. Single vehicle accident & Vehicle overturns (no impact with stationary object or another vehicle) \\
\hline $\begin{array}{l}\text { Complex/Mobile } \\
\text { Equipment Operation }\end{array}$ & 24. Vehicle collision with another moving vehicle & Vehicle collides with another moving vehicle \\
\hline $\begin{array}{l}\text { Complex/Mobile } \\
\text { Equipment Operation }\end{array}$ & 25. Dropping of load when using forklift & Dropping of load when using forklift to move or lift loed \\
\hline $\begin{array}{l}\text { Complex/Mobile } \\
\text { Equipment Operation }\end{array}$ & 26. Puncturing of load when using forklift & Puncturing of load with fortlift forks \\
\hline $\begin{array}{l}\text { Complex/Mobile } \\
\text { Equipment Operation }\end{array}$ & 27. Dropping of load when using crane/hoist & Load is dropped when using a crane or hoist \\
\hline $\begin{array}{l}\text { Complex/Mobile } \\
\text { Equipment Operation }\end{array}$ & 28. Crane/hoist strikes stationary objoct & $\begin{array}{l}\text { During crane or hoist operations, the crane or hoist impacts against a } \\
\text { stationary object }\end{array}$ \\
\hline $\begin{array}{l}\text { Complex/Mobile } \\
\text { Equipment Operation }\end{array}$ & 29. Excavation error & $\begin{array}{l}\text { Error during excavation, involving dizging } 100 \text { deeply, in the wrong } \\
\text { location, without proper authorization, or striking an unanticipened object }\end{array}$ \\
\hline $\begin{array}{l}\text { Complex/Accident } \\
\text { Response }\end{array}$ & 30. Diagnosis error & $\begin{array}{l}\text { Failure to correctly diagnose an accident situation or identify the correct } \\
\text { response }\end{array}$ \\
\hline $\begin{array}{l}\text { Complex/Accident } \\
\text { Response }\end{array}$ & 31. Failure of visual inspection & $\begin{array}{l}\text { Failure to observe an abnormal characteristic when looking for such things } \\
\text { (includes looking through cameras, periscopes, etc.)(does not include } \\
\text { detection of fire, which is covered under another human eror) }\end{array}$ \\
\hline $\begin{array}{l}\text { Complex/Accident } \\
\text { Response }\end{array}$ & 32. Failure of manual fire detection & Failure of cocupant to delect fire, when not aided by an avematic system \\
\hline $\begin{array}{l}\text { Complex/Accident } \\
\text { Response }\end{array}$ & $\begin{array}{l}\text { 33. Failure of manual fire suppression by } \\
\text { occupant }\end{array}$ & $\begin{array}{l}\text { Fire is not suppressed by occupant by manual fire suppression means (fire } \\
\text { extinquisher, other) }\end{array}$ \\
\hline
\end{tabular}




\begin{tabular}{|c|c|c|}
\hline Type & Human Error Event & Description \\
\hline $\begin{array}{l}\text { Complex/Accident } \\
\text { Response }\end{array}$ & $\begin{array}{l}\text { 34. Failure of manual fire suppression by non- } \\
\text { occupant }\end{array}$ & $\begin{array}{l}\text { Fire is not suppressed by fire brigade or fire department by manuel fire } \\
\text { suppression means }\end{array}$ \\
\hline $\begin{array}{l}\text { Complex/Accident } \\
\text { Response }\end{array}$ & 35. Failure of long-term accident recovery & $\begin{array}{l}\text { Failure to diagnose situation and identify recovery action when lots of time } \\
\text { (hours or days) is available (assumes equipment required for recovery will be } \\
\text { available) }\end{array}$ \\
\hline
\end{tabular}




\begin{tabular}{|c|c|}
\hline 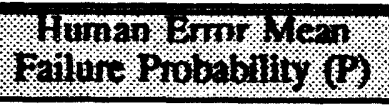 & 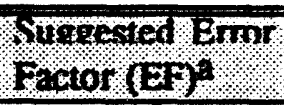 \\
\hline $0.0<\mathrm{P}<0.01$ & 10 \\
\hline $0.01 \Xi P<0.1$ & 5 \\
\hline $0.1 \Xi P \leq 0.3$ & 3 \\
\hline $0.3<P \equiv 0.5$ & 2 \\
\hline $0.5<P \Xi 1.0$ & 1 \\
\hline
\end{tabular}

a. A lognormal distribution is assumed. The EF (error factor) is the 95th percentile divided by the 50 th percentile. 


\begin{tabular}{|c|c|c|c|c|c|c|c|c|c|c|}
\hline \multirow[t]{3}{*}{ Human Error Event } & \multicolumn{9}{|c|}{ Failure Probability or Rate } & \multirow[t]{3}{*}{ Notes } \\
\hline & \multirow[t]{2}{*}{ WP. } & \multicolumn{2}{|c|}{ Gencric iodel. } & \multicolumn{2}{|c|}{ (1. } & \multicolumn{2}{|c|}{ PUSientior. } & \multicolumn{2}{|c|}{ RCreininingids. } & \\
\hline & & Mean & EI & Exem & Benands: & Men & 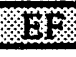 & Wrean & 6 & \\
\hline \multirow{3}{*}{$\begin{array}{l}\text { 1. Failure of } \\
\text { administrative control }\end{array}$} & Nominal & $1.0 \mathrm{E}-2$ & 5 & 6 & 878 & $7.0 \mathrm{E}-3$ & 1.9 & $5.0 \mathrm{E}-3$ & 10 & Three event sets used \\
\hline & High & $1.0 \mathrm{E}-1$ & 3 & & & & & $5.0 \mathrm{E}-2$ & 5 & $\begin{array}{l}\text { Nominal case \% change } \\
\text { applied }\end{array}$ \\
\hline & Low & $1.0 \mathrm{E}-3$ & 10 & & & & & $5.0 \mathrm{E}-4$ & 10 & $\begin{array}{l}\text { Nominal case \% change } \\
\text { applied }\end{array}$ \\
\hline \multirow{3}{*}{$\begin{array}{l}\text { 2. Failure to respond to } \\
\text { compelling signal }\end{array}$} & Nominal & $1.0 \mathrm{E}-2$ & 5 & & & & & $1.0 \mathrm{E}-2$ & 5 & \\
\hline & High & $1.0 \mathrm{E}-1$ & 3 & & & & & $1.0 \mathrm{E}-1$ & 3 & \\
\hline & Low & $3.0 \mathrm{E}-3$ & 10 & & & & & $3.0 \mathrm{E}-3$ & 10 & \\
\hline \multirow{3}{*}{$\begin{array}{l}\text { 3. Failure to verify } \\
\text { within control room }\end{array}$} & Nominal & $1.0 \mathrm{E}-2$ & 5 & & & & & $1.0 \mathrm{E}-2$ & 5 & \\
\hline & High & $5.0 \mathrm{E}-2$ & 5 & & & & & $5.0 \mathrm{E}-2$ & 5 & \\
\hline & Low & $3.0 \mathrm{E}-3$ & 10 & & & & & $3.0 \mathrm{E}-3$ & 10 & \\
\hline \multirow{3}{*}{$\begin{array}{l}\text { 4. Failure to verify } \\
\text { outside control room }\end{array}$} & Nominal & $3.0 \mathrm{E}-2$ & 5 & & & & & $3.0 \mathrm{E}-2$ & 5 & \\
\hline & High & $1.0 \mathrm{E}-1$ & 3 & & & & & $1.0 \mathrm{E}-1$ & 3 & \\
\hline & Low & $1.0 \mathrm{E}-2$ & 5 & & & & & $1.0 \mathrm{E}-2$ & 5 & \\
\hline \multirow{3}{*}{$\begin{array}{l}\text { 5. Error in selecting } \\
\text { control within control } \\
\text { room }\end{array}$} & Nominal & $1.0 \mathrm{E}-2$ & 5 & & & & & $1.0 \mathrm{E}-2$ & 5 & \\
\hline & High & $3.0 \mathrm{E}-2$ & 5 & & & & & $3.0 \mathrm{E}-2$ & 5 & \\
\hline & Low & $1.0 \mathrm{E}-3$ & 10 & & & & & $1.0 \mathrm{E}-3$ & 10 & \\
\hline \multirow{3}{*}{$\begin{array}{l}\text { 6. Error in selecting } \\
\text { control outside control } \\
\text { room }\end{array}$} & Nominal & $1.0 \mathrm{E}-2$ & 5 & & & & & $1.0 \mathrm{E}-2$ & 5 & \\
\hline & High & $5.0 \mathrm{E}-2$ & 5 & & & & & $5.0 \mathrm{E}-2$ & 5 & \\
\hline & Low & $3.0 \mathrm{E}-3$ & 10 & & & & & $3.0 \mathrm{E}-3$ & 10 & \\
\hline \multirow[t]{3}{*}{ 7. Communication error } & Nominal & $5.0 \mathrm{E}-2$ & 5 & & & & & $5.0 \mathrm{E}-2$ & 5 & \\
\hline & High & $5.0 \mathrm{E}-1$ & 2 & & & & & $5.0 \mathrm{E}-1$ & 2 & \\
\hline & Low & $1.0 \mathrm{E}-3$ & 10 & & & & & $1.0 \mathrm{E}-3$ & 10 & \\
\hline
\end{tabular}




\begin{tabular}{|c|c|c|c|c|c|c|c|c|c|c|}
\hline \multirow{3}{*}{ Human Error Event } & \multicolumn{9}{|c|}{ Failure Probability or Rate } & \multirow[t]{3}{*}{ Notes } \\
\hline & \multirow[t]{2}{*}{ Typ } & \multicolumn{2}{|c|}{ Genenc Model } & \multicolumn{2}{|c|}{ ': . } & \multicolumn{2}{|c|}{ (1. Postertior. } & \multicolumn{2}{|c|}{ 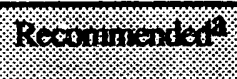 } & \\
\hline & & Mean & $\mathrm{EF}$ & Events. & Bumands & Went: & $\mathrm{Ef}$ & Wresno & $E$ & \\
\hline \multirow{3}{*}{$\begin{array}{l}\text { 8. Checker verification } \\
\text { eror }\end{array}$} & Nominal & $1.0 \mathrm{E}-1$ & 3 & & & & & $1.0 \mathrm{E}-1$ & 3 & \\
\hline & High & $3.0 \mathrm{E}-1$ & 3 & & & & & $3.0 \mathrm{E}-1$ & 3 & \\
\hline & Low & $1.0 \mathrm{E}-2$ & 5 & & & & & $1.0 \mathrm{E}-2$ & 5 & \\
\hline \multirow{3}{*}{$\begin{array}{l}\text { 9. Supervisor verification } \\
\text { emor }\end{array}$} & Nominal & $3.0 \mathrm{E}-1$ & 3 & & & & & $3.0 \mathrm{E}-1$ & 3 & \\
\hline & High & $5.0 \mathrm{E}-1$ & 2 & & & & & $5.0 \mathrm{E}-1$ & 2 & \\
\hline & Low & $1.0 \mathrm{E}-1$ & 3 & & & & & $1.0 \mathrm{E}-1$ & 3 & \\
\hline \multirow{3}{*}{$\begin{array}{l}\text { 10. Incorrect labeling or } \\
\text { tagging }\end{array}$} & Nominal & $5.0 \mathrm{E}-3$ & 10 & & & & & $5.0 \mathrm{E}-3$ & 10 & \\
\hline & High & $3.0 \mathrm{E}-2$ & 5 & & & & & $3.0 \mathrm{E}-2$ & 5 & \\
\hline & Low & $1.0 \mathrm{E}-3$ & 10 & & & & & $1.0 \mathrm{E}-3$ & 10 & \\
\hline \multirow{3}{*}{$\begin{array}{l}\text { 11. Incorrect reading or } \\
\text { recording of data }\end{array}$} & Nominal & $1.0 \mathrm{E}-2$ & 5 & & & & & $1.0 \mathrm{E}-2$ & 5 & \\
\hline & High & $5.0 \mathrm{E}-1$ & 2 & & & & & $5.0 \mathrm{E}-1$ & 2 & \\
\hline & Low & $3.0 \mathrm{E}-3$ & 10 & & & & & $3.0 \mathrm{E}-3$ & 10 & \\
\hline \multirow[t]{3}{*}{ 12. Miscalibration } & Nominal & $1.0 \mathrm{E}-2$ & 5 & 6 & 878 & $7.0 \mathrm{E}-3$ & 1.9 & $5.0 \mathrm{E}-3$ & 10 & Three event sets used \\
\hline & High & $5.0 \mathrm{E}-2$ & 5 & & & & & $3.0 \mathrm{E}-2$ & 5 & $\begin{array}{l}\text { Nominal case \% change } \\
\text { applied }\end{array}$ \\
\hline & Low & $5.0 \mathrm{E}-3$ & 10 & & & & & $3.0 \mathrm{E}-3$ & 10 & $\begin{array}{l}\text { Nominal case \% change } \\
\text { applied }\end{array}$ \\
\hline \multirow{3}{*}{$\begin{array}{l}\text { 13. Failure to restore } \\
\text { following test }\end{array}$} & Nominal & $1.0 \mathrm{E}-2$ & 5 & & & & & $1.0 \mathrm{E}-2$ & 5 & \\
\hline & High & $3.0 \mathrm{E}-2$ & 5 & & & & & $3.0 \mathrm{E}-2$ & 5 & \\
\hline & Low & $5.0 \mathrm{E}-3$ & 10 & & & & & $5.0 \mathrm{E}-3$ & 10 & \\
\hline \multirow{3}{*}{$\begin{array}{l}\text { 14. Failure to restore } \\
\text { following maintenance }\end{array}$} & Nominal & $1.0 \mathrm{E}-2$ & 5 & 14 & 2822 & $5.1 \mathrm{E}-3$ & 1.5 & $5.0 \mathrm{E}-3$ & 10 & Both event sets used \\
\hline & High & $1.0 \mathrm{E}-1$ & 3 & & & & & $5.0 \mathrm{E}-2$ & 5 & $\begin{array}{l}\text { Nominal case \% change } \\
\text { applied }\end{array}$ \\
\hline & Low & $5.0 \mathrm{E}-3$ & 10 & & & & & $3.0 \mathrm{E}-3$ & 10 & $\begin{array}{l}\text { Nominal case \% change } \\
\text { applied }\end{array}$ \\
\hline
\end{tabular}




\begin{tabular}{|c|c|c|c|c|c|c|c|c|c|c|}
\hline \multirow[t]{3}{*}{ Human Error Event } & \multicolumn{9}{|c|}{ Failure Probability or Rate } & \multirow[t]{3}{*}{ Notes } \\
\hline & \multirow[t]{2}{*}{$\pi \%$} & \multicolumn{2}{|c|}{ Gencionodill } & \multicolumn{2}{|c|}{ (2) } & \multicolumn{2}{|c|}{$=9$ Posictior. } & \multicolumn{2}{|c|}{ 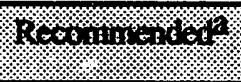 } & \\
\hline & & Mean & $\mathrm{EF}$ & Euens. & Bellands: & Ment & $\mathrm{Ef}$ & Wentas & (1) & \\
\hline \multirow[t]{3}{*}{ 15. Failure to lock out } & Nominal & $3.0 \mathrm{E}-3$ & 10 & 53 & 92,718 & $5.7 \mathrm{E}-4$ & 1.3 & $5.0 \mathrm{E}-4$ & 10 & One event set used \\
\hline & High & $3.0 \mathrm{E}-2$ & 5 & & & & & $5.0 \mathrm{E}-3$ & 10 & $\begin{array}{l}\text { Nominal case \% change } \\
\text { applied }\end{array}$ \\
\hline & Low & $5.0 \mathrm{E}-4$ & 10 & & & & & $1.0 \mathrm{E}-4$ & 10 & $\begin{array}{l}\text { Nominal case \% change } \\
\text { applied }\end{array}$ \\
\hline \multirow[t]{3}{*}{$\begin{array}{l}\text { 16. Chemical addition or } \\
\text { elution error }\end{array}$} & Nominal & $3.0 \mathrm{E}-3$ & 10 & & & & & $3.0 \mathrm{E}-3$ & 10 & \\
\hline & High & $3.0 \mathrm{E}-2$ & 5 & & & & & $3.0 \mathrm{E}-2$ & $\overline{5}$ & \\
\hline & Low & $3.0 \mathrm{E}-4$ & 10 & & & & & $3.0 \mathrm{E}-4$ & 10 & \\
\hline \multirow[t]{3}{*}{ 17. Transfer error } & Nominal & & & 137 & 3.84E7 & & & $\begin{array}{l}\text { 3.0E-6/ } \\
\text { tank-h }\end{array}$ & 10 & See text for rate \\
\hline & High & & & & & & & $\begin{array}{l}3.0 \mathrm{E}-5 / \\
\text { tank-h }\end{array}$ & 10 & $\begin{array}{l}\text { EF adjustment of nominal } \\
\text { case }\end{array}$ \\
\hline & Low & & & & & & & $\begin{array}{l}3.0 \mathrm{E}-71 \\
\text { tank-h }\end{array}$ & 10 & $\begin{array}{l}\text { EF adjustment of nominal } \\
\text { case }\end{array}$ \\
\hline \multirow[t]{3}{*}{ 18. Overfilling of a tank } & Nominal & & & 210 & 4.73E7 & & & $\begin{array}{l}5.0 \mathrm{E}-6 / \\
\text { tank-h }\end{array}$ & 10 & See text for rate \\
\hline & High & $\therefore$ & & & & & & $\begin{array}{l}\text { 5.0E-5/ } \\
\text { tank-h }\end{array}$ & 10 & $\begin{array}{l}\text { EF adjustment of nominal } \\
\text { case }\end{array}$ \\
\hline & Low & & & & & & & $\begin{array}{l}5.0 \mathrm{E}-7 / \\
\text { tank-h }\end{array}$ & 10 & $\begin{array}{l}\text { EF adjustment of nominal } \\
\text { case }\end{array}$ \\
\hline \multirow[t]{3}{*}{$\begin{array}{l}\text { 19. Laboratory analysis } \\
\text { enror }\end{array}$} & Nominal & $5.0 \mathrm{E}-4$ & 10 & 180 & 772,000 & $2.3 \mathrm{E}-4$ & 1.1 & $3.0 \mathrm{E}-4$ & 10 & $\begin{array}{l}\text { Events adjusted (x10) for } \\
\text { "verification" influence }\end{array}$ \\
\hline & High & $3.0 \mathrm{E}-3$ & 10 & & & & & $1.0 \mathrm{E}-3$ & 10 & $\begin{array}{l}\text { Nominal case \% change } \\
\text { applied }\end{array}$ \\
\hline & Low & $5.0 \mathrm{E}-5$ & 10 & & & & & $3.0 \mathrm{E}-5$ & 10 & $\begin{array}{l}\text { Nominal case \% change } \\
\text { applied }\end{array}$ \\
\hline \multirow{3}{*}{$\begin{array}{l}\text { 20. Failure to verify } \\
\text { parameter with } \\
\text { calculation }\end{array}$} & Nominal & $3.0 \mathrm{E}-2$ & 5 & & & & & $3.0 \mathrm{E}-2$ & 5 & \\
\hline & High & $1.0 \mathrm{E}-1$ & 3 & & & & & $1.0 \mathrm{E}-1$ & 3 & \\
\hline & Low & $5.0 \mathrm{E}-3$ & 10 & & & & & $5.0 \mathrm{E}-3$ & 10 & \\
\hline
\end{tabular}




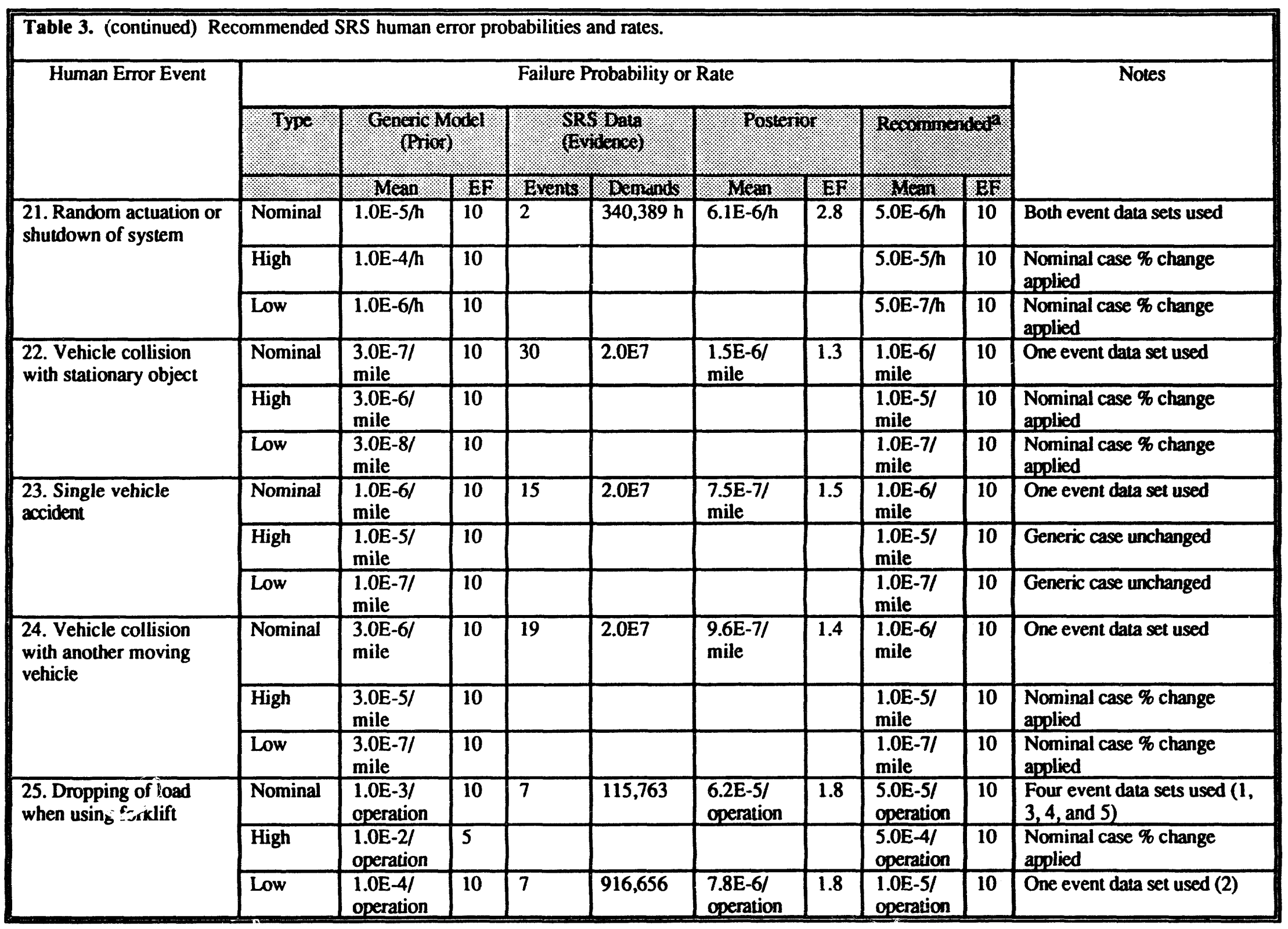


Table 3. (continued) Recommended SRS human error probabilities and rates.

\begin{tabular}{|c|c|c|c|c|c|c|c|c|c|c|}
\hline \multirow[t]{3}{*}{ Human Error Event } & \multicolumn{9}{|c|}{ Failure Probability or Rate } & \multirow[t]{3}{*}{ Notes } \\
\hline & \multirow[t]{2}{*}{ Toro: } & \multicolumn{2}{|c|}{ Generic Model } & \multicolumn{2}{|c|}{ 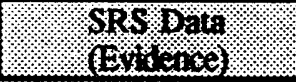 } & \multicolumn{2}{|c|}{ (2. Posterior } & \multicolumn{2}{|c|}{ 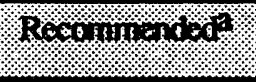 } & \\
\hline & & Mean & EF & Events & Bemands. & Mean & EF & Me:n & $\mathrm{EP}$ & \\
\hline \multirow[t]{3}{*}{$\begin{array}{l}\text { 26. Puncturing of load } \\
\text { when using forklift }\end{array}$} & Nominal & $\begin{array}{l}5.0 \mathrm{E}-5 / \\
\text { operation }\end{array}$ & 10 & $3 / 6^{b}$ & & & & $\begin{array}{l}3.0 \mathrm{E}-5 / \\
\text { operation }\end{array}$ & 10 & $\begin{array}{l}\text { Event } 25 \text { result multiplied by } \\
0.5\end{array}$ \\
\hline & High & $\begin{array}{l}5.0 \mathrm{E}-4 / \\
\text { operation }\end{array}$ & 10 & & & & & $\begin{array}{l}3.0 \mathrm{E}-4 / \\
\text { operation }\end{array}$ & 10 & $\begin{array}{l}\text { Event } 25 \text { result multiplied by } \\
0.5\end{array}$ \\
\hline & Low & $\begin{array}{l}1.0 \mathrm{E}-5 / \\
\text { operation }\end{array}$ & 10 & & & & & $\begin{array}{l}5.0 \mathrm{E}-6 / \\
\text { operation }\end{array}$ & 10 & $\begin{array}{l}\text { Event } 25 \text { result multiplied by } \\
0.5\end{array}$ \\
\hline \multirow[t]{3}{*}{$\begin{array}{l}\text { 27. Dropping of load } \\
\text { when using crane/hoist }\end{array}$} & Nominal & $\begin{array}{l}1.0 \mathrm{E}-4 / \\
\text { operation }\end{array}$ & 10 & 1 & 9,884 & $\begin{array}{l}1.0 \mathrm{E}-4 / \\
\text { operation }\end{array}$ & 3.7 & $\begin{array}{l}1.0 \mathrm{E}-4 / \\
\text { operation }\end{array}$ & 10 & Two data sets used $(3,5)$ \\
\hline & High & $\begin{array}{l}1.0 \mathrm{E}-3 / \\
\text { operation }\end{array}$ & 10 & 1 & 852 & $\begin{array}{l}1.1 \mathrm{E}-3 / \\
\text { nperation }\end{array}$ & 3.7 & $\begin{array}{l}1.0 \mathrm{E}-3 / \\
\text { operation }\end{array}$ & 10 & One data set used (2) \\
\hline & Low & $\begin{array}{l}.0 \mathrm{E}-5 / \\
\text { operation }\end{array}$ & 10 & 2 & 57,750 & $\begin{array}{l}2.9 \mathrm{E}-5 / \\
\text { operation }\end{array}$ & 2.8 & $\begin{array}{l}3.0 \mathrm{E}-5 / \\
\text { operaticn }\end{array}$ & 10 & Two data sets used $(1,4)$ \\
\hline \multirow[t]{3}{*}{$\begin{array}{l}\text { 28. Crane/hoist strikes } \\
\text { stationary object }\end{array}$} & Nominal & $\begin{array}{l}1.0 \mathrm{E}-4 / \\
\text { operation }\end{array}$ & 10 & 2 & 9,450 & $\begin{array}{l}2.0 \mathrm{E}-4 / \\
\text { operation }\end{array}$ & 2.8 & $\begin{array}{l}\text { 3.0E-4/ } \\
\text { operation }\end{array}$ & 10 & One event data set used \\
\hline & High & $\begin{array}{l}1.0 \mathrm{E}-3 / \\
\text { operation }\end{array}$ & 10 & & & & & $\begin{array}{l}3.0 \mathrm{E}-3 / \\
\text { operation }\end{array}$ & 10 & $\begin{array}{l}\text { Nominal case \% change } \\
\text { applied }\end{array}$ \\
\hline & Low & $\begin{array}{l}1.0 \mathrm{E}-5 / \\
\text { operation }\end{array}$ & 10 & & & & & $\begin{array}{l}3.0 \mathrm{E}-5 / \\
\text { operation }\end{array}$ & 10 & $\begin{array}{l}\text { Nominal case \% change } \\
\text { applied }\end{array}$ \\
\hline \multirow[t]{3}{*}{ 29. Excavation error } & Nominal & $\begin{array}{l}1.0 \mathrm{E}-2 / \\
\text { excavation }\end{array}$ & $\overline{5}$ & 5 & 638 & $\begin{array}{l}8.0 \mathrm{E}-3 / \\
\text { excavation }\end{array}$ & 1.9 & $\begin{array}{l}1.0 \mathrm{E}-2 / \\
\text { excavation }\end{array}$ & 5 & Both data sets used \\
\hline & High & $\begin{array}{l}1.0 \mathrm{E}-1 / \\
\text { excavation }\end{array}$ & 3 & & & & & $\begin{array}{l}1.0 \mathrm{E}-1 / \\
\text { excavation }\end{array}$ & 3 & Generic case unchanged \\
\hline & Low & $\begin{array}{l}1.0 \mathrm{E}-3 / \\
\text { excavation }\end{array}$ & 10 & & & & & $\begin{array}{l}1.0 \mathrm{E}-3 / \\
\text { excavation }\end{array}$ & 10 & Generic case unchanged \\
\hline \multirow[t]{3}{*}{ 30. Diagnosis error } & Nominal & $1.0 \mathrm{E}-2$ & 5 & & & & & $1.0 \mathrm{E}-2$ & 5 & \\
\hline & High & $1.0 \mathrm{E}-1$ & 3 & & & & & $1.0 \mathrm{E}-1$ & 3 & \\
\hline & Low & $1.0 \mathrm{E}-3$ & 10 & & & & & $1.0 \mathrm{E}-3$ & 10 & \\
\hline \multirow{3}{*}{$\begin{array}{l}\text { 31. Failure of visual } \\
\text { inspection }\end{array}$} & Nominal & $1.0 \mathrm{E}-1$ & 3 & & & & & $1.0 \mathrm{E}-1$ & 3 & \\
\hline & High & $5.0 \mathrm{E}-1$ & 2 & & & & & $5.0 \mathrm{E}-1$ & 2 & \\
\hline & Low & $1.0 \mathrm{E}-2$ & 5 & & & & & $1.0 \mathrm{E}-2$ & 5 & \\
\hline
\end{tabular}




\begin{tabular}{|c|c|c|c|c|c|c|c|c|c|c|}
\hline \multirow{3}{*}{ Human Error Event } & \multicolumn{9}{|c|}{ Failure Probability or Rate } & \multirow{3}{*}{ Notes } \\
\hline & \multirow[t]{2}{*}{$110 \%$} & \multicolumn{2}{|c|}{ Generiv Modill: } & \multicolumn{2}{|c|}{ 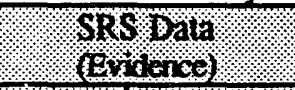 } & \multicolumn{2}{|c|}{ 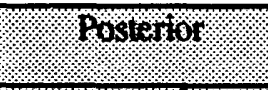 } & \multicolumn{2}{|c|}{ 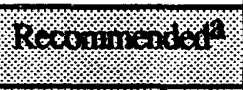 } & \\
\hline & & Mean & EF & Evens: & Donands & Mear & EIX & Wesn & $\mathrm{EF}$ & \\
\hline \multirow{3}{*}{$\begin{array}{l}\text { 32. Failure of manual fire } \\
\text { detection }\end{array}$} & Nominal & $1.0 \mathrm{E}-1$ & 3 & & & $1.0 \mathrm{E}-1^{\mathrm{C}}$ & 3 & $1.0 \mathrm{E}-1$ & 3 & \\
\hline & High & $5.0 \mathrm{E}-1$ & 2 & & & $5.0 \mathrm{E}-1^{\mathrm{C}}$ & 2 & $5.0 \mathrm{E}-1$ & 2 & \\
\hline & Low & $5.0 \mathrm{E}-2$ & 5 & 2 & 225 & $1.1 \mathrm{E}-2^{\mathrm{C}}$ & 2.6 & $1.0 \mathrm{E}-2$ & 5 & \\
\hline \multirow{3}{*}{$\begin{array}{l}\text { 33. Failure of manual fire } \\
\text { suppression by occupant }\end{array}$} & Nominal & $1.0 \mathrm{E}-1$ & 3 & 49 & 166 & $2.8 \mathrm{E}-1$ & 1.2 & $3.0 \mathrm{E}-1$ & 3 & First two data sets used $(1,2)$ \\
\hline & High & $5.0 \mathrm{E}-1$ & 2 & 15 & 20 & $7.1 \mathrm{E}-1$ & 1.2 & $5.0 \mathrm{E}-1$ & 2 & Last two data sets used $(3,4)$ \\
\hline & Low & $5.0 \mathrm{E}-2$ & 5 & & & & & $1.0 \mathrm{E}-1$ & 3 & $\begin{array}{l}\text { Nominal case \% change } \\
\text { applied }\end{array}$ \\
\hline \multirow{3}{*}{$\begin{array}{l}\text { 34. Failure of manual fire } \\
\text { suppression by non- } \\
\text { occupant }\end{array}$} & Nominal & $5.0 \mathrm{E}-1$ & 2 & 9 & 67 & $1.6 \mathrm{E}-1$ & 1.6 & $1.0 \mathrm{E}-1$ & 3 & One event data set used \\
\hline & High & 1.0 & 1 & & & & & $3.0 \mathrm{E}-1$ & 3 & $\begin{array}{l}\text { Nominal case \% change } \\
\text { applied }\end{array}$ \\
\hline & Low & $1.0 \mathrm{E}-1$ & 3 & & & & & $3.0 \mathrm{E}-2$ & 5 & $\begin{array}{l}\text { Nominal case \% change } \\
\text { applied }\end{array}$ \\
\hline \multirow{3}{*}{$\begin{array}{l}\text { 35. Failure of long-term } \\
\text { accident recovery }\end{array}$} & Nominal & $3.0 \mathrm{E}-3$ & 10 & & & & & $3.0 \mathrm{E}-3$ & 10 & \\
\hline & High & $1.0 \mathrm{E}-1$ & 3 & & & & & $1.0 \mathrm{E}-1$ & 3 & \\
\hline & Low & $3.0 \mathrm{E}-5$ & 10 & & & & & $3.0 \mathrm{E}-5$ & 10 & \\
\hline
\end{tabular}

a. Posterior result mean rounded to 1, 3, or 5 times the appropriate power of ten. EFs chosen using guidelines in Table 2.

b. Three puncture events and six drop events.

c. Detection model is $P_{n d}=(X)(0.05)+(1-X)(0.5)$, where $X=$ fraction of time area is occupied, 0.05 is the probability of manual detection given an occupant in the area, and 0.5 is the probability of manual detection given no occupant in the area. The Bayesian update was applied to the probability of manual detection given an occupant in the area ( 0.05 with an assumed EF of five). The Bayesian update posterior is 1.1E-2 with an EF of 2.6. This was rounded to 1.0E-2, with an EF of five. This was then inserted into the model in place of 5.0E-2, and the new results were obtained. 
Table 4. Selection guidelines for recommended human error probabilities and rates

\begin{tabular}{|c|c|c|c|c|}
\hline \multirow[t]{3}{*}{ 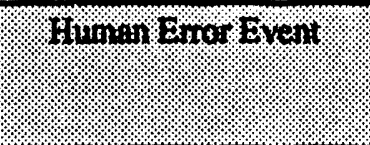 } & \multicolumn{3}{|c|}{ 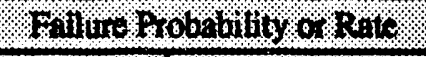 } & \multirow[t]{3}{*}{ Gindelines for Selection of T Tpeb } \\
\hline & \multirow{2}{*}{ 1.Pr: } & \multicolumn{2}{|c|}{ Rocomnendodo: } & \\
\hline & & T. Mears. & GEF: & \\
\hline \multirow{3}{*}{$\begin{array}{l}\text { 1. Failure of } \\
\text { administrative control }\end{array}$} & Nominal & $5.0 \mathrm{E}-3$ & 10 & Typical circumstances \\
\hline & High & $5.0 \mathrm{E}-2$ & 5 & Unusual circumstances \\
\hline & Low & $5.0 \mathrm{E}-4$ & 10 & Routine, repetitive circumstances \\
\hline \multirow{3}{*}{$\begin{array}{l}\text { 2. Failure to respond to } \\
\text { compelling signal }\end{array}$} & Nominal & $1.0 \mathrm{E}-2$ & 5 & Several competing signals \\
\hline & High & $1.0 \mathrm{E}-1$ & $\overline{3}$ & Many competing signals \\
\hline & Low & $3.0 \mathrm{E}-3$ & 10 & Few competing signals \\
\hline \multirow{3}{*}{$\begin{array}{l}\text { 3. Failure to verify within } \\
\text { control room }\end{array}$} & Nominal & $1.0 \mathrm{E}-2$ & 5 & Good layout, procedure-driven \\
\hline & High & $5.0 \mathrm{E}-2$ & 5 & Poor layout, scanning effort \\
\hline & Low & $3.0 \mathrm{E}-3$ & 10 & Excellent layout, procedure-driven \\
\hline \multirow{3}{*}{$\begin{array}{l}\text { 4. Failure to verify } \\
\text { outside control room }\end{array}$} & Nominal & $3.0 \mathrm{E}-2$ & 5 & Good layout, procedure-driven \\
\hline & High & $1.0 \mathrm{E}-1$ & 3 & Poor layout, scanning effort \\
\hline & Low & $1.0 \mathrm{E}-2$ & $\overline{5}$ & Excellent layout procedure-driven \\
\hline \multirow{3}{*}{$\begin{array}{l}\text { 5. Error in selecting } \\
\text { control within control } \\
\text { room }\end{array}$} & Nominal & $1.0 \mathrm{E}-2$ & 5 & Good layout, procedure-driven \\
\hline & High & $3.0 \mathrm{E}-2$ & 5 & Poor layout, scanning effort \\
\hline & Low & $1.0 \mathrm{E}-3$ & 10 & Excellent layout, procedure-driven \\
\hline \multirow{3}{*}{$\begin{array}{l}\text { 6. Error in selecting } \\
\text { control outside control } \\
\text { room }\end{array}$} & Nominal & $1.0 \mathrm{E}-2$ & 5 & Good layout, procedure-driven \\
\hline & High & $5.0 \mathrm{E}-2$ & 5 & Poor layout, scanning effort \\
\hline & Low & $3.0 \mathrm{E}-3$ & 10 & Excellent layout, procedure-driven \\
\hline \multirow[t]{3}{*}{ 7. Communication error } & Nominal & $5.0 \mathrm{E}-2$ & 5 & Moderate information \\
\hline & High & $5.0 \mathrm{E}-1$ & 2 & Complex information \\
\hline & Low & $1.0 \mathrm{E}-3$ & 10 & Simple information \\
\hline \multirow{3}{*}{$\begin{array}{l}\text { 8. Checker verification } \\
\text { error }\end{array}$} & Nominal & $1.0 \mathrm{E}-1$ & 3 & Alerted, but not active participant \\
\hline & High & $3.0 \mathrm{E}-1$ & 3 & Written materials not used \\
\hline & Low & $1.0 \mathrm{E}-2$ & 5 & Checking requires active participation \\
\hline \multirow{3}{*}{$\begin{array}{l}\text { 9. Supervisor verification } \\
\text { error }\end{array}$} & Nominal & $3.0 \mathrm{E}-1$ & 3 & Check-off sheet, medium dependence \\
\hline & High & $5.0 \mathrm{E}-1$ & 2 & No check-off sheet, high dependence, high stress \\
\hline & Low & $1.0 \mathrm{E}-1$ & 3 & Check-off sheet, low dependence \\
\hline \multirow{3}{*}{$\begin{array}{l}\text { 10. Incorrect labeling or } \\
\text { tagging }\end{array}$} & Nominal & $5.0 \mathrm{E}-3$ & 10 & Normal administrative controls \\
\hline & High & $3.0 \mathrm{E}-2$ & 5 & Poor administrative controls \\
\hline & Low & $1.0 \mathrm{E}-3$ & 10 & Excellent administrative controls \\
\hline \multirow{3}{*}{$\begin{array}{l}\text { 11. Incorrect reading or } \\
\text { recording of data }\end{array}$} & Nominal & $1.0 \mathrm{E}-2$ & 5 & Good display (graph) \\
\hline & High & $5.0 \mathrm{E}-1$ & 2 & Poor display \\
\hline & Low & $3.0 \mathrm{E}-3$ & 10 & $\begin{array}{l}\text { Excellent display (digital readout, indicator } \\
\text { lamp) }\end{array}$ \\
\hline
\end{tabular}


Table 4 (continued) Selection guidelines for recommended human error probabilities and rates

\begin{tabular}{|c|c|c|c|c|}
\hline \multirow{3}{*}{ 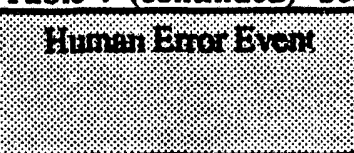 } & \multicolumn{3}{|c|}{ 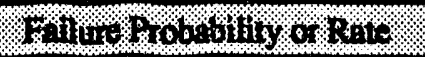 } & \multirow[t]{3}{*}{ Gridelines far Seleciton of Typeb } \\
\hline & \multirow[t]{2}{*}{ 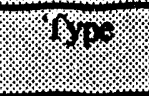 } & \multicolumn{2}{|c|}{ Roconninatiod } & \\
\hline & & 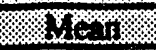 & E⿰⿱亠䒑⿱⺊口灬. & \\
\hline \multirow[t]{3}{*}{ 12. Miscalibration } & Nominal & $5.0 \mathrm{E}-3 \mathrm{C}$ & 10 & Single-person, operator check \\
\hline & High & $3.0 \mathrm{E}-2$ & 5 & Single-person, no checks \\
\hline & Low & $3.0 \mathrm{E}-3 \mathrm{C}$ & 10 & Two-person team, operator check \\
\hline \multirow{3}{*}{$\begin{array}{l}\text { 13. Failure to restore } \\
\text { following test }\end{array}$} & Nominal & $1.0 \mathrm{E}-2 \mathrm{C}$ & 5 & Single person, operator check \\
\hline & High & $3.0 \mathrm{E}-2$ & 5 & Single-person, no checks \\
\hline & Low & $5.0 \mathrm{E}-3 \mathrm{C}$ & 10 & Two-person team, operator check \\
\hline \multirow{3}{*}{$\begin{array}{l}\text { 14. Failure to restore } \\
\text { following maintenance }\end{array}$} & Nominal & $5.0 \mathrm{E}-3 \mathrm{C}$ & 10 & Single-person, operator check \\
\hline & High & $5.0 \mathrm{E}-2$ & 5 & Single-person, no checks \\
\hline & Low & $3.0 \mathrm{E}-3 \mathrm{c}$ & 10 & Two-person team, operator check \\
\hline \multirow{3}{*}{ 15. Failure to lock out } & Nominal & $5.0 \mathrm{E}-4$ & 10 & Typical lockout plan (5 to 10 lockouts) \\
\hline & High & $5.0 \mathrm{E}-3$ & 10 & Complex lockout plan (11 to 100 lockouts) \\
\hline & Low & $1.0 \mathrm{E}-4$ & 10 & Simple lockout plan (1 to 4 lockouts) \\
\hline \multirow{3}{*}{$\begin{array}{l}\text { 16. Chemical addition or } \\
\text { elution error }\end{array}$} & Nominal & $3.0 \mathrm{E}-3$ & 10 & Typical process \\
\hline & High & $3.0 \mathrm{E}-2$ & 5 & Complex process \\
\hline & Low & $3.0 \mathrm{E}-4$ & 10 & Simple process \\
\hline \multirow[t]{3}{*}{ 17. Transfer error } & Nominal & $\begin{array}{l}3.0 \mathrm{E}-6 / \\
\text { tank-h d }\end{array}$ & 10 & Moderate activity (10 potential transfers/year) \\
\hline & High & $\begin{array}{l}3.0 E-5 / \\
\text { tank-h }\end{array}$ & 10 & High activity (100 potential transfers/year) \\
\hline & Low & $\begin{array}{l}3.0 E-7 / \\
\text { tank-h d }\end{array}$ & 10 & Low activity (1 potential transfer/year) \\
\hline \multirow[t]{3}{*}{ 18. Overfilling of a tank } & Nominal & $\begin{array}{l}5.0 E-6 / \\
\text { tank-h } d\end{array}$ & $\overline{10}$ & Moderate activity (10 potential transfers/year) \\
\hline & High & $\begin{array}{l}5.0 E-5 / \\
\text { tank-h d }\end{array}$ & 10 & High activity (100 potential transfers/year) \\
\hline & Low & $\begin{array}{l}5.0 E-7 / \\
\text { tank-h d }\end{array}$ & 10 & Low activity (1 potential transfer/year) \\
\hline \multirow{3}{*}{$\begin{array}{l}\text { 19. Laboratory analysis } \\
\text { emror }\end{array}$} & Nominal & $3.0 \mathrm{E}-4^{\mathrm{C}}$ & 10 & Low dependence check \\
\hline & High & $1.0 \mathrm{E}-3$ & 10 & No check \\
\hline & Low & $3.0 \mathrm{E}-5^{\mathrm{C}}$ & 10 & Zero dependence check \\
\hline \multirow{3}{*}{$\begin{array}{l}\text { 20. Failure to verify } \\
\text { parameter with } \\
\text { calculation }\end{array}$} & Nominal & $3.0 \mathrm{E}-2 \mathrm{c}$ & 5 & Procedure usually used, verification \\
\hline & High & $1.0 \mathrm{E}-1$ & 3 & No verification \\
\hline & Low & $5.0 \mathrm{E}-3 \mathrm{C}$ & 10 & Procedure almost always used, verification \\
\hline
\end{tabular}


Table 4 (continued) Selection guidelines for recommended human error probabilities and rates

\begin{tabular}{|c|c|c|c|c|}
\hline \multirow[t]{3}{*}{ Hin $\%$ *ns $\%$} & \multicolumn{3}{|c|}{ 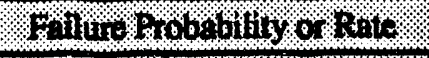 } & \multirow[t]{3}{*}{ 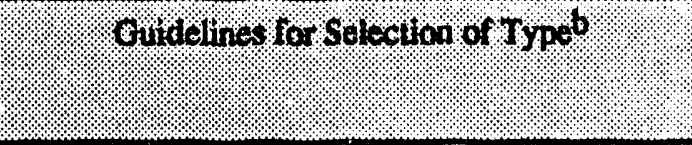 } \\
\hline & $1 \% 0$. & Rooninoin & 86 & \\
\hline & & \%sentin & 3 & \\
\hline \multirow{3}{*}{$\begin{array}{l}\text { 21. Random actuation/ } \\
\text { shutdown of system }\end{array}$} & Nominal & $5.0 \mathrm{E}-6 / \mathrm{h}$ & 10 & Some activities could affect system \\
\hline & High & $5.0 \mathrm{E}-5 / \mathrm{h}$ & 10 & Many activities could affect system \\
\hline & Low & $5.0 \mathrm{E}-7 / \mathrm{h}$ & 10 & Almost no activities could affect system \\
\hline \multirow{3}{*}{$\begin{array}{l}\text { 22. Vehicle collision with } \\
\text { stationary object }\end{array}$} & Nominal & $1 \mathrm{E}-6 / \mathrm{mi}^{\mathrm{d}}$ & 10 & Typical highway environment \\
\hline & High & $1 \mathrm{E}-5 / \mathrm{mi}$ & 10 & $\begin{array}{l}\text { Congested road, many objects close to road, bad } \\
\text { weather }\end{array}$ \\
\hline & Low & $1 \mathrm{E}-7 / \mathrm{mi} \mathrm{d}^{\mathrm{d}}$ & 10 & Freeway environment \\
\hline \multirow{3}{*}{$\begin{array}{l}\text { 23. Single vehicle } \\
\text { accident }\end{array}$} & Nominal & $1 \mathrm{E}-6 / \mathrm{mi} d$ & 10 & Typical highway environment \\
\hline & High & $1 \mathrm{E}-5 / \mathrm{mi}$ & 10 & Congested road, bad weather \\
\hline & Low & $1 \mathrm{E}-7 / \mathrm{mi}^{\mathrm{d}}$ & 10 & Freeway environment \\
\hline \multirow{3}{*}{$\begin{array}{l}\text { 24. Vehicle collision with } \\
\text { another moving vehicle }\end{array}$} & Nominal & $1 \mathrm{E}-6 / \mathrm{mi} d$ & 10 & Typical highway environment \\
\hline & High & $1 \mathrm{E}-5 / \mathrm{mi} \mathrm{d}$ & 10 & Congested road, bad weather \\
\hline & Low & $1 \mathrm{E}-7 / \mathrm{mi} \mathrm{d}$ & 10 & Freeway environment \\
\hline \multirow[t]{3}{*}{$\begin{array}{l}\text { 25. Dropping of load } \\
\text { when using forklift }\end{array}$} & Nominal & $\begin{array}{l}5.0 \mathrm{E}-5 / \\
\text { operation } \\
\mathrm{e}\end{array}$ & 10 & Typical load \\
\hline & High & $\begin{array}{l}5.0 \mathrm{E}-4 / \\
\text { operation e }\end{array}$ & 10 & Unusual, unevenly balanced load \\
\hline & Low & $\begin{array}{l}1.0 \mathrm{E}-5 / \\
\text { operation } \mathrm{e}\end{array}$ & 10 & Standardized load, spotter present \\
\hline \multirow[t]{3}{*}{$\begin{array}{l}\text { 26. Puncturing of load } \\
\text { when using forklift }\end{array}$} & Nominal & $\begin{array}{l}3.0 \mathrm{E}-5 / \\
\text { oreration }\end{array}$ & 10 & Typical load \\
\hline & High & $\begin{array}{l}3.0 \mathrm{E}-4 / \\
\text { operation } \mathrm{e}\end{array}$ & 10 & Unusual, unevenly balanced load \\
\hline & Low & $\begin{array}{l}5.0 \mathrm{E}-6 / \\
\text { operation e }\end{array}$ & 10 & Standardized load, spotter present \\
\hline \multirow[t]{3}{*}{$\begin{array}{l}\text { 27. Dropping of load } \\
\text { when using crane/hoist }\end{array}$} & Nominal & $\begin{array}{l}1.0 \mathrm{E}-4 / \\
\text { operation } \mathrm{e}\end{array}$ & 10 & Typical load \\
\hline & High & $\begin{array}{l}1.0 \mathrm{E}-3 / \\
\text { operation } \mathrm{e}\end{array}$ & 10 & $\begin{array}{l}\text { Unusual, unevenly balanced load or remotely } \\
\text { operated crane/hoists }\end{array}$ \\
\hline & Low & $\begin{array}{l}\text { 3.0E-5/ } \\
\text { operation e }\end{array}$ & 10 & Standardized load, spotter present \\
\hline \multirow[t]{3}{*}{$\begin{array}{l}\text { 28. Crane/hoist strikes } \\
\text { stationary object }\end{array}$} & Nominal & $\begin{array}{l}3.0 \mathrm{E}-4 / \\
\text { operation } \mathrm{e}\end{array}$ & 10 & Typical visibility \\
\hline & High & $\begin{array}{l}.0 \mathrm{E}-3 / \\
\text { operation } \mathrm{e}\end{array}$ & 10 & No spotter, low visibility \\
\hline & Low & $\begin{array}{l}3.0 \mathrm{E}-5 / \\
\text { operation } \mathrm{e} \\
\end{array}$ & 10 & Spotter present \\
\hline
\end{tabular}




\begin{tabular}{|c|c|c|c|c|}
\hline \multirow[t]{2}{*}{ 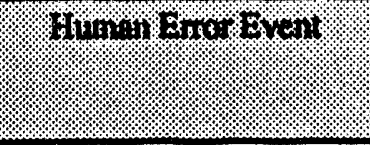 } & \multicolumn{3}{|c|}{ Fillinu ro obability o k karo } & \multirow[t]{2}{*}{ Citidelines for Selection of Type b } \\
\hline & $1 \% \%$. & \multicolumn{2}{|c|}{ Rocommended /9. } & \\
\hline \multirow[t]{3}{*}{ 29. Excavation error } & Nominal & $\begin{array}{l}1.0 \mathrm{E}-2 / \\
\text { excavation }\end{array}$ & 5 & Good review of area \\
\hline & High & $\begin{array}{l}1.0 \mathrm{E}-1 / \\
\text { excavation }\end{array}$ & 3 & Poor review of area \\
\hline & Low & $\begin{array}{l}1.0 \mathrm{E}-3 / \\
\text { excavation }\end{array}$ & 10 & $\begin{array}{l}\text { Excellent review of area (survey for } \\
\text { underground objects) }\end{array}$ \\
\hline \multirow[t]{3}{*}{ 30. Diagnosis error } & Nominal & $1.0 \mathrm{E}-2$ & 5 & Knowledge-based, 30 to 120 minutes \\
\hline & High & $1.0 \mathrm{E}-1$ & 3 & Knowledge-based, 10 to 30 minutes \\
\hline & Low & $1.0 \mathrm{E}-3$ & 10 & Knowledge-based, greater than 120 minutes \\
\hline \multirow[t]{3}{*}{$\begin{array}{l}\text { 31. Failure of visual } \\
\text { inspection }\end{array}$} & Nominal & $1.0 \mathrm{E}-1$ & 3 & $\begin{array}{l}\text { Procedure usually followed, event easy to } \\
\text { observe }\end{array}$ \\
\hline & High & $5.0 \mathrm{E}-1$ & 2 & Event difficult to observe \\
\hline & Low & $1.0 \mathrm{E}-2$ & 5 & $\begin{array}{l}\text { Procedure followed, event easy to observe } \\
\text { (damage very prominent) }\end{array}$ \\
\hline \multirow{3}{*}{$\begin{array}{l}\text { 32. Failure of manual fire } \\
\text { detection }\end{array}$} & Nominal & $1.0 \mathrm{E}-1$ & 3 & Area occupied $80 \%$ of time \\
\hline & High & $5.0 \mathrm{E}-1$ & 2 & Area unoccupied \\
\hline & Low & $1.0 \mathrm{E}-2$ & 5 & Area occupied $100 \%$ of time \\
\hline \multirow[t]{3}{*}{$\begin{array}{l}\text { 33. Failure of manual fire } \\
\text { suppression by occupant }\end{array}$} & Nominal & $3.0 \mathrm{E}-1$ & 3 & $\begin{array}{l}\text { Typical fire extinguisher } \\
\text { installation/maintenance }\end{array}$ \\
\hline & High & $5.0 \mathrm{E}-1$ & 2 & Poor fire extinguisher installation/maintenance \\
\hline & Low & $1.0 \mathrm{E}-1$ & 3 & $\begin{array}{l}\text { Excellent fire extinguisher } \\
\text { installation/maintenance }\end{array}$ \\
\hline \multirow{3}{*}{$\begin{array}{l}\text { 34. Failure of manual fire } \\
\text { suppression by non- } \\
\text { occupant }\end{array}$} & Nominal & $1.0 \mathrm{E}-1$ & 3 & Response by 10 minutes, typical fire \\
\hline & High & $3.0 \mathrm{E}-1$ & 3 & $\begin{array}{l}\text { Response much longer than } 10 \text { minutes, difficult } \\
\text { fire }\end{array}$ \\
\hline & Low & $3.0 \mathrm{E}-2^{\mathrm{f}}$ & 5 & Response less than 10 minutes, simple fire \\
\hline \multirow[t]{3}{*}{$\begin{array}{l}\text { 35. Failure of long-term } \\
\text { accident recovery }\end{array}$} & Nominal & $3.0 \mathrm{E}-3$ & 10 & $\begin{array}{l}24-48 \text { hours for recovery, simple recovery } \\
\text { actions }\end{array}$ \\
\hline & High & $1.0 \mathrm{E}-1$ & 3 & Less than 24 hours for recovery \\
\hline & Low & $3.0 \mathrm{E}-5$ & 10 & 3. 7 days for recovery, simple recovery actions \\
\hline
\end{tabular}

a. A lognormal distribution is assumed. The EF (error factor) is the 95th percentile/50th percentile (median). To convert a mean value to a median, multiply the mean by the following:

\begin{tabular}{cc} 
EF & Mean-10-Median Multiplier \\
\hline 1 & 1.00 \\
2 & 0.92 \\
3 & 0.80 \\
5 & 0.62 \\
10 & 0.38
\end{tabular}

b. For most human error events, the nominal case value implies good procedures, training, experience, and environment; the high value implies poor procedures, training, experience, and environment; and the low value implies excellent procedures, training, experience, and cnvironment.

c. These values already include recoveries.

d. Values presented include contributions from mechanical failures.

e. An operation was defined as a lift, move, and setting down of a load.

f. Not recommended for fires in unoccupied buildings. 


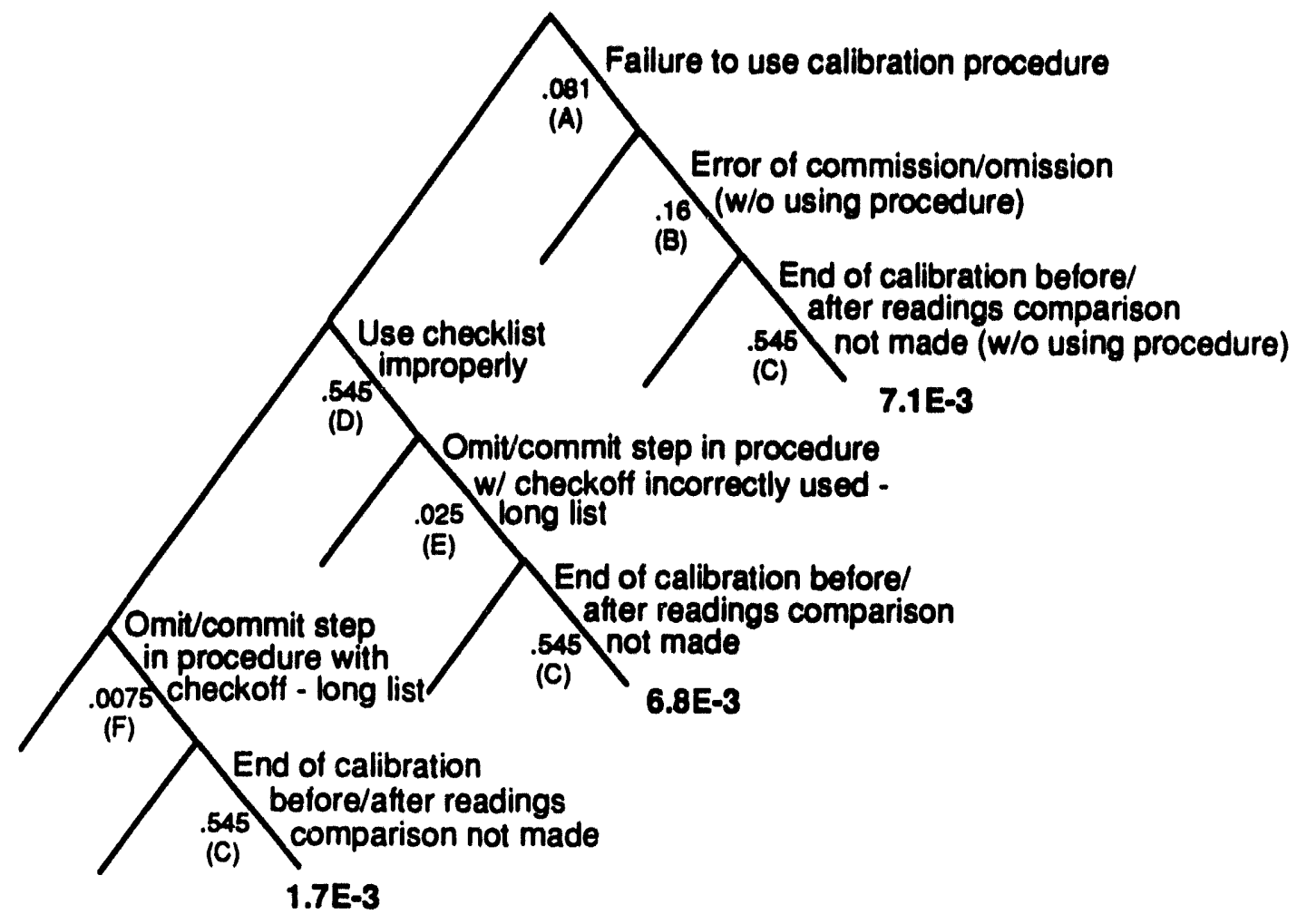

Sum of failure path probabilities

$$
\begin{aligned}
\text { Nominal } & =7.1 \mathrm{E}-3+6.8 \mathrm{E}-3+1.7 \mathrm{E}-3=1.6 \mathrm{E}-2 \\
\text { High } & =6.4 \mathrm{E}-2+8.2 \mathrm{E}-3+2.0 \mathrm{E}-3=7.4 \mathrm{E}-2 \\
\text { Low } & =7.6 \mathrm{E}-4+3.9 \mathrm{E}-3+9.9 \mathrm{E}-4=5.7 \mathrm{E}-3
\end{aligned}
$$

NOTE HANDBOOK SOURCE

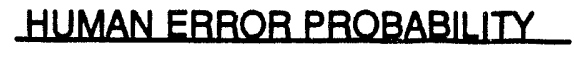
A. Table 20-6, Item 6
B. Table 20-7, Item 5
.081
5
.05
C. Table 20-22, Item 8
.16
5
$.1 *$
.545
5
(reduced to 2)
.5
D. Table 20-6, Item 8
.545
5
(reduced to 2)
.5
E. Table 20-7, Item 4
.025
3
$.02 *$
F. Table 20-7, Item 2
.0075
3
$.006^{*}$

Mean

EF

Median

Median doubled to cover both types of errors.

Figure 1. Nominal Case THERP tree for Miscalibration. 


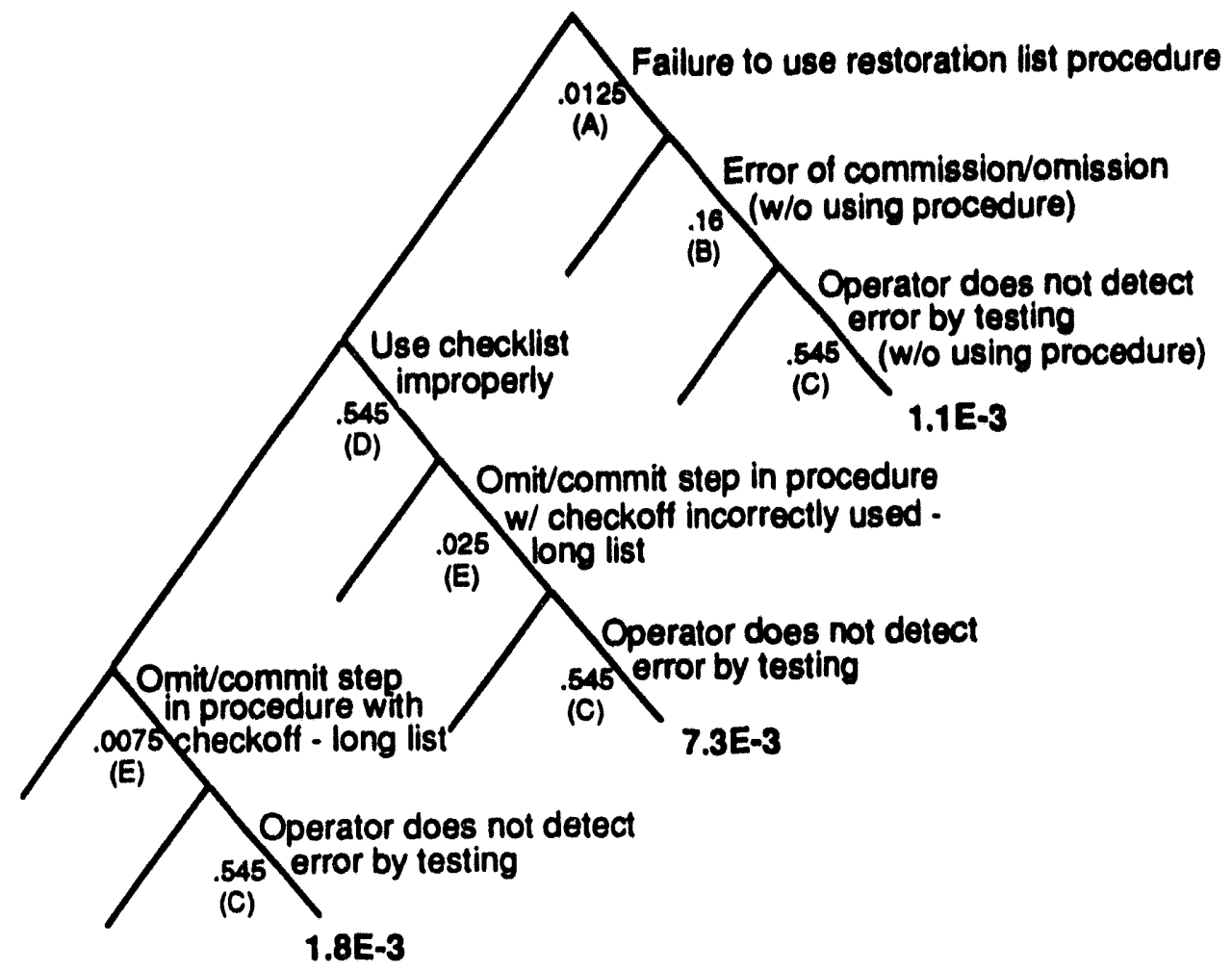

Sum of failure path probabilities

$$
\begin{aligned}
\text { Nominal } & =1.1 \mathrm{E}-3+7.3 \mathrm{E}-3+1.8 \mathrm{E}-3=1.0 \mathrm{E}-2 \\
\text { High } & =6.0 \mathrm{E}-3+1.3 \mathrm{E}-2+3.3 \mathrm{E}-3=2.2 \mathrm{E}-2 \\
\text { Low } & =2.0 \mathrm{E}-4+4.0 \mathrm{E}-3+1.0 \mathrm{E}-3=5.3 \mathrm{E}-3
\end{aligned}
$$

NOTE HANDBOOK SOURCE

HUMAN ERROR PROBABILITY
A. Table 20-6, Item 5
B. Table $20-7$, ltem 5
.0125
3
.01
C. Table 20-22, ltem 8
.16
5
$.1^{*}$
.545
5
.5
D. Table 20-6, Item 8
.545
(reduced to 2)
E. Table 20-7, Item 4
.025
5 (reduced to 2)
.5
F. Table 20-7, ltem 2
.0075
3
$.02^{*}$

Mean

EF

Median

* Median doubled to cover both types of errors.

Figure 2. Nominal Case THERP tree for failure to restore following test. 


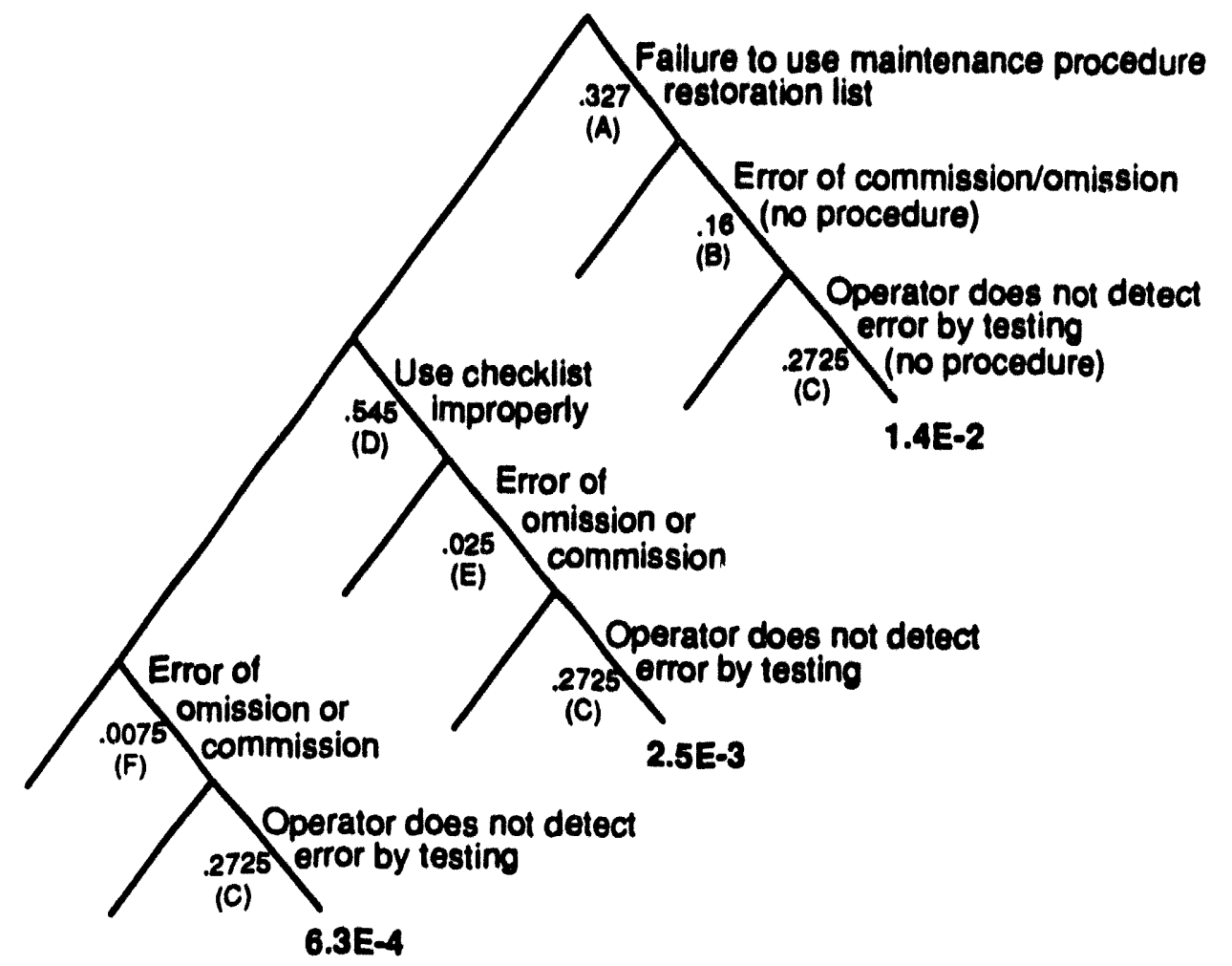

Sum of failure path probabilities

Nominal $=1.4 \mathrm{E}-2+2.5 \mathrm{E}-3+6.3 \mathrm{E}-4=1.7 \mathrm{E}-2$

High $=1.0 \mathrm{E}-1+4.8 \mathrm{E}-3+1.2 \mathrm{E}-3=1.1 \mathrm{E}-1$

Low $=2.3 E-3+1.8 \mathrm{E}-3+4.6 \mathrm{E}-4=4.6 \mathrm{E}-3$

\section{HUMANERROR PROBABILITY}

NOTE HANDBOOK SOURCE Mean EF Median
A. Table 20-6, Item 7
.327
$\stackrel{5}{\text { (reduced to 2) }}$
.3
B. Table 20-7, Item 5
.16
5
$.1 *$
C. Table 20-22, Item 8 \& 10
.2725
5
(reduced to 2) $\quad .5 / 2$
D. Table 20-6, Item 8
.545
5
(reduced to 2)
E. Table 20-7, Item 4
.025
3
$.02^{*}$
F. Table 20-7, Item 2
.0075
3
$.006^{*}$

* Mediar trubled to cover both types of errors.

Figure 3. Nominal case THERP tree for failure to restore following maintenance. 


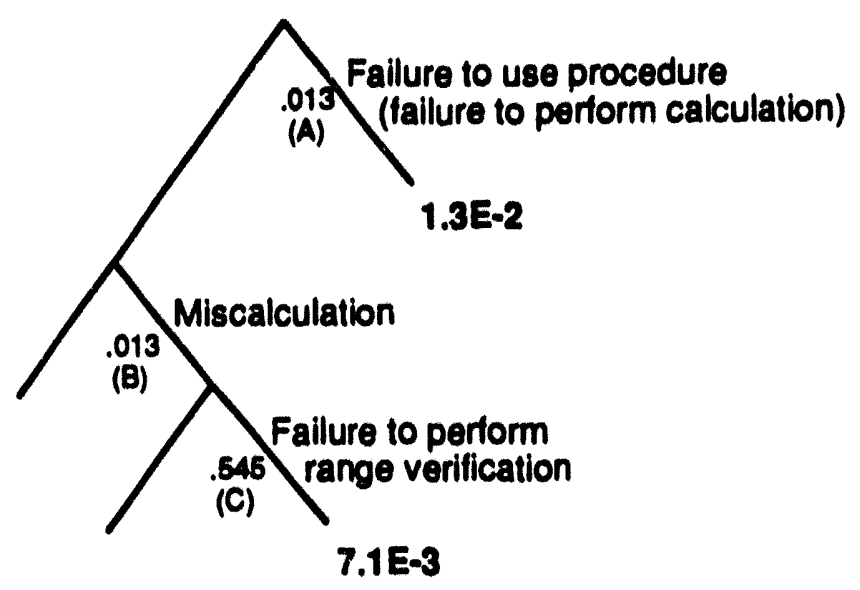

Sum of failure path probabilities $\mathbf{=} 2.0 \mathrm{E}-2$

HUMANERROR PROBABILITY

NOTE HANDBOOK SOURCE MEaD EF
A. Table 20-6, Item 3
.013
3
.01
B. Table 20-10, Item 10
.013

$3 \quad .01$
C. Table $20-21$, Item $4 a$
.545
2
.5

Figure 4. Nominal Case THERP tree for failure to verify parameter with calculation. 

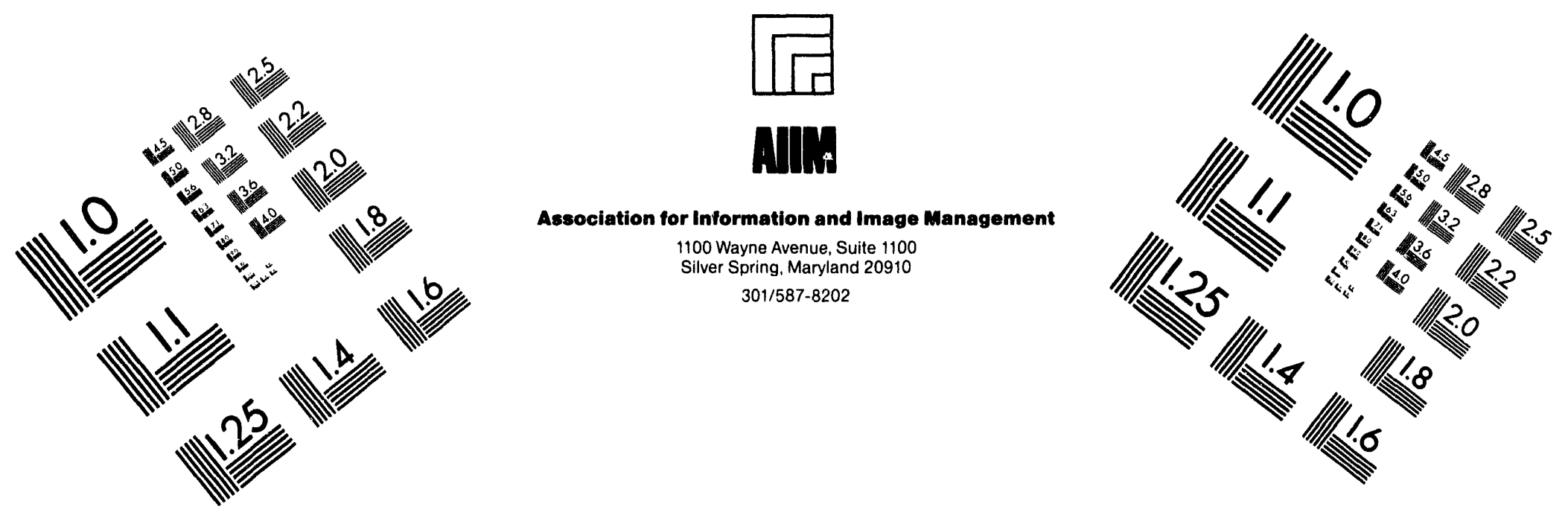

\section{Centimeter}

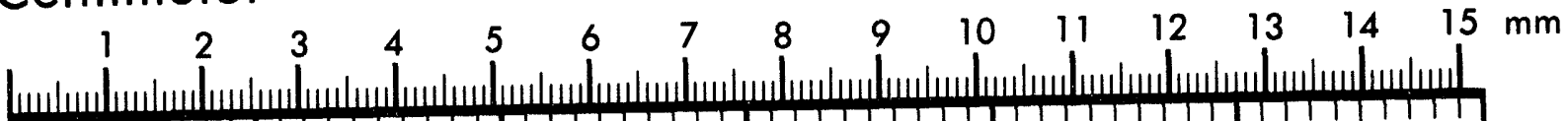

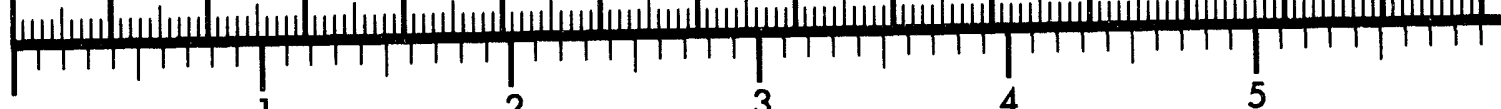
Inches

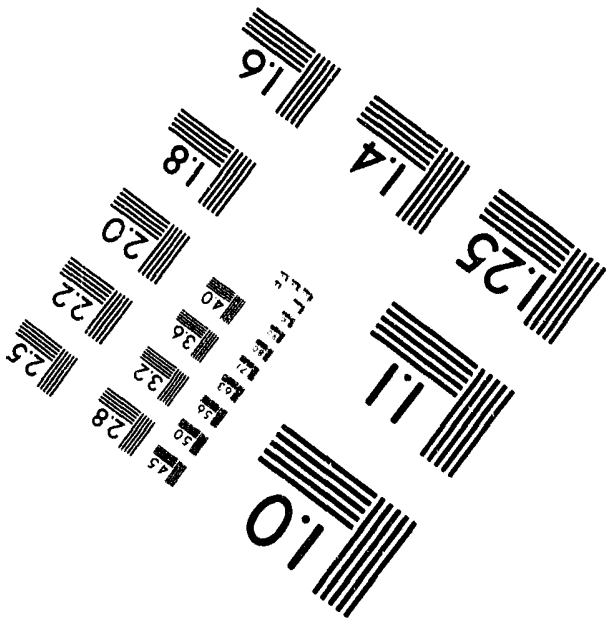

MANUFACTURED TO AIIM STANDARDS BY APPLIED IMAGE, INC.

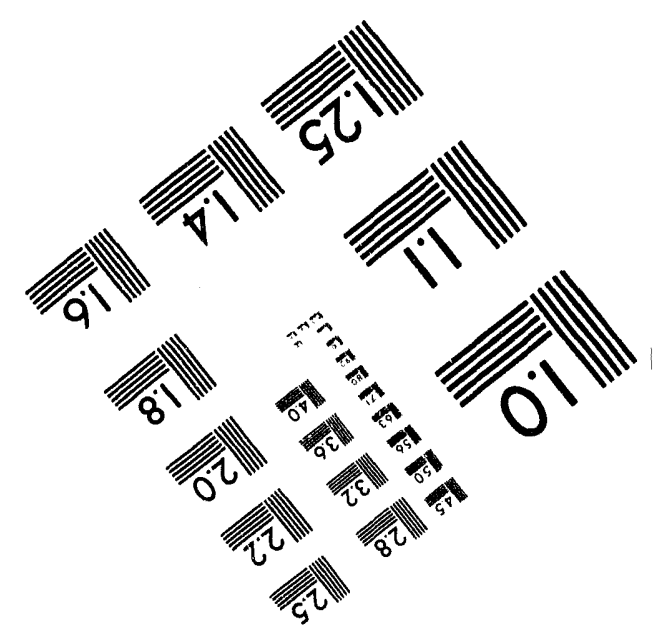



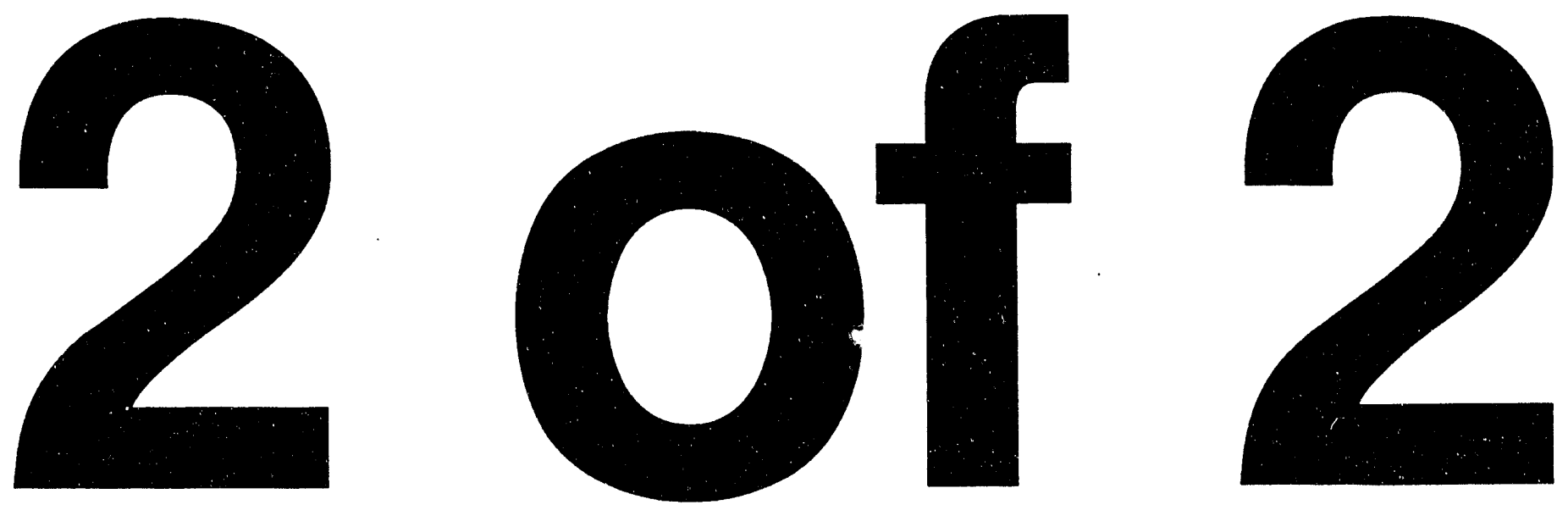


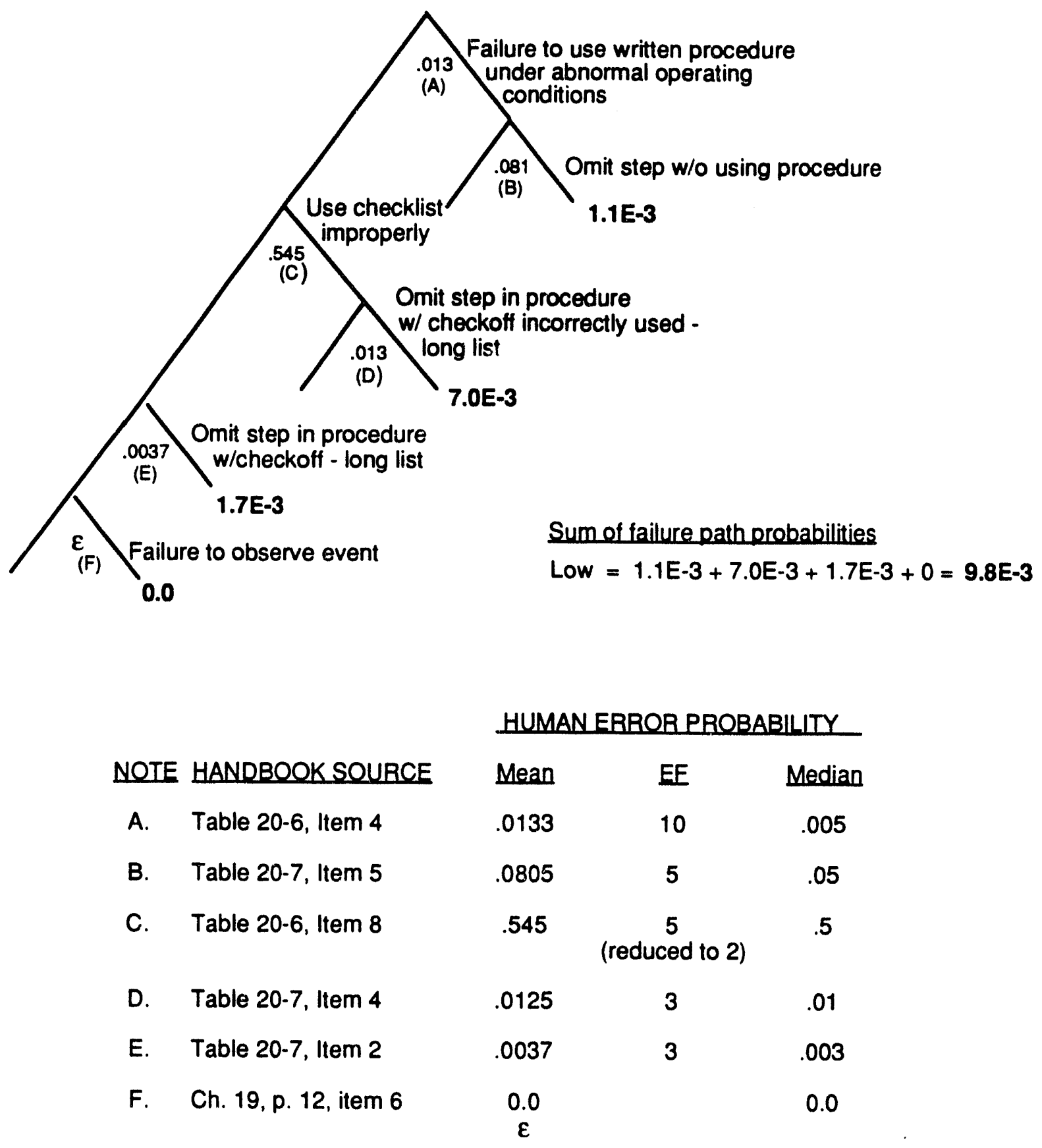

Figure 5. Low Case THERP tree for failure of visual inspection. 
WSRC-TR-93-581

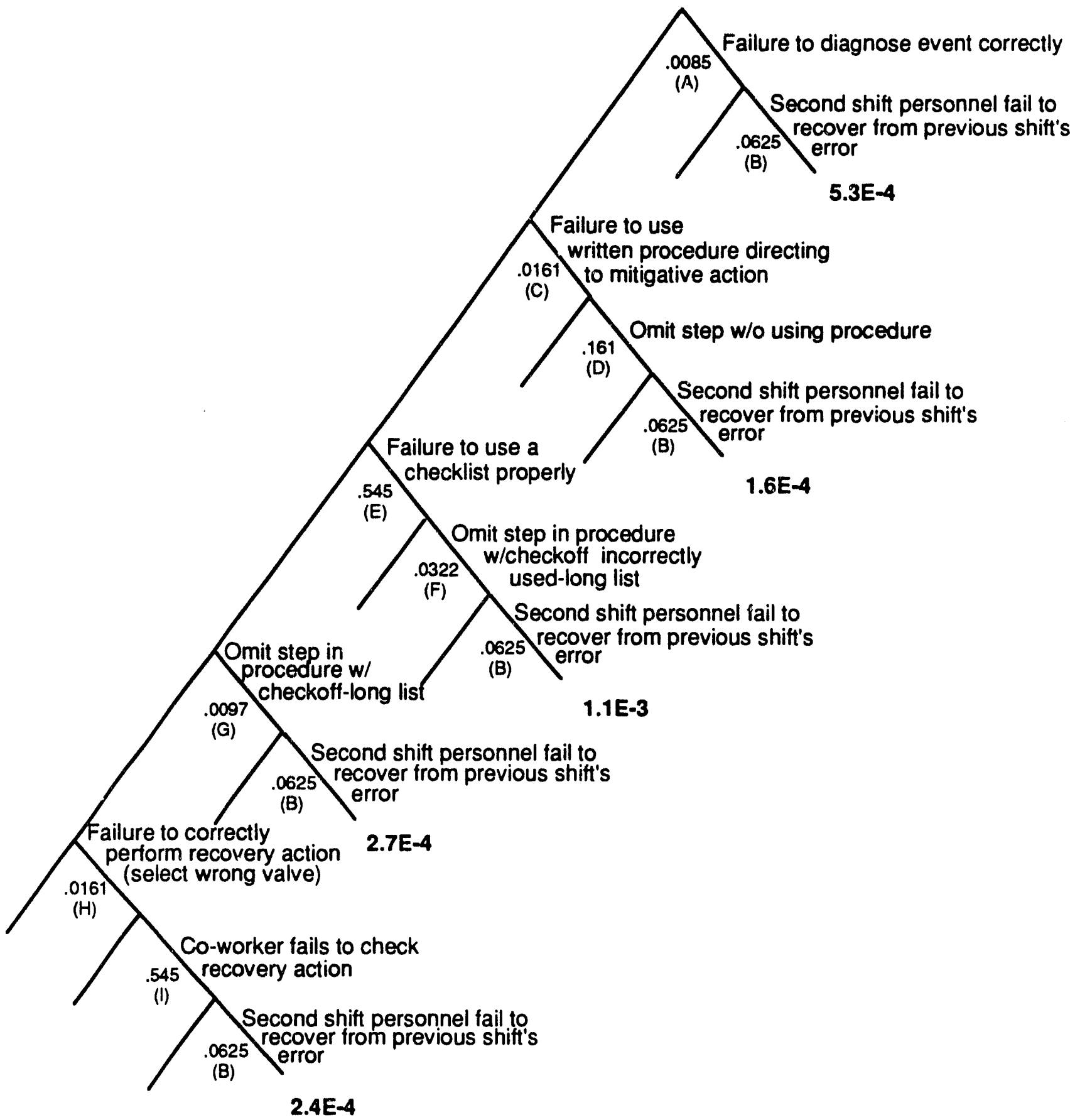

Sum of failure path probabilities $=2.3 \mathrm{E}-3$

Figure 6. Nominal Case THERP tree for long-term accident recovery. 


\section{HUMAN ERROR PROBABILITY}

\begin{tabular}{|c|c|c|c|c|}
\hline NOTE & HANDBOOK SOURCE & Mean & EE & Median \\
\hline A. & $\begin{array}{l}\text { Figure } 12-4 \text {, Time } T \\
=240 \text { min., upper bound }\end{array}$ & .0085 & 30 & .001 \\
\hline B. & Table 20-21, Item 2a & .0625 & 3 & .05 \\
\hline c. & $\begin{array}{l}\text { Table 20-6, Item } 4 \\
\text { Table 20-16, Item 4a } \\
\text { Table 20-20, Item } 5\end{array}$ & .0161 & 5 & .01 \\
\hline D & $\begin{array}{l}\text { Table 20-7, Item } 5 \\
\text { Table 20-16, Item 4a } \\
\text { Table 20-20, Item } 5\end{array}$ & .161 & 5 & .1 \\
\hline E. & Table 20-6, item 8 & .545 & $\begin{array}{c}5 \\
\text { (reduced to 2) }\end{array}$ & .5 \\
\hline F. & $\begin{array}{l}\text { Table 20-7, Item 4 } \\
\text { Table 20-16, Item 4a } \\
\text { Table 20-20, Item } 5\end{array}$ & .0322 & 5 & .02 \\
\hline G. & $\begin{array}{l}\text { Table 20-7, Item } 2 \\
\text { Table 20-16, Item 4a } \\
\text { Table 20-20, Item } 5\end{array}$ & .0097 & 5 & .006 \\
\hline $\mathrm{H}$. & $\begin{array}{l}\text { Table 20-13, Item } 3 \\
\text { Table 20-16, Item 4a } \\
\text { Table 20-20, Item } 5\end{array}$ & .0161 & 5 & .01 \\
\hline I. & Table 20-21, Item 4a & .545 & 2 & .5 \\
\hline
\end{tabular}

Figure 6. Nominal Case THERP tree for long-term accident recovery. 

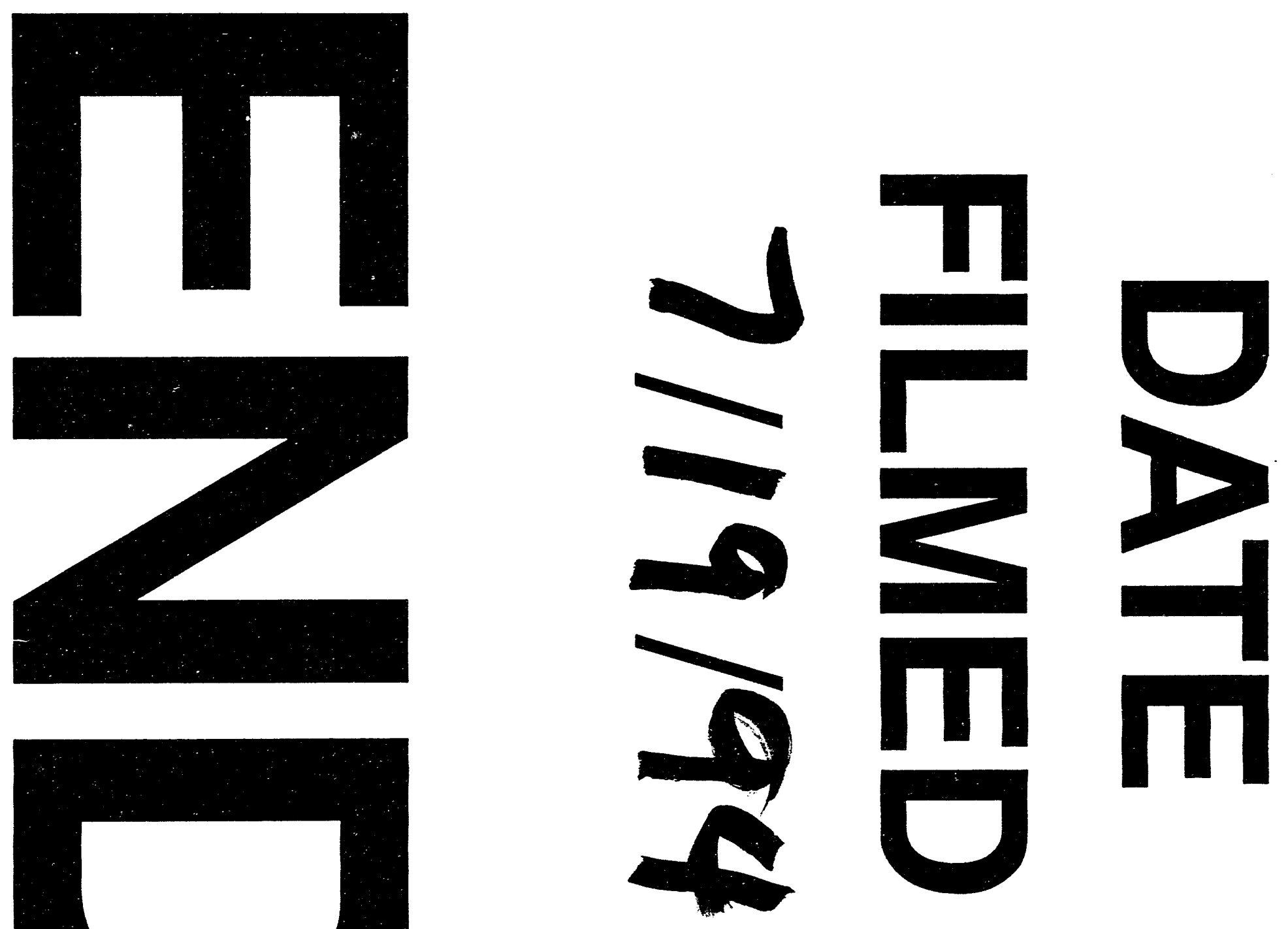


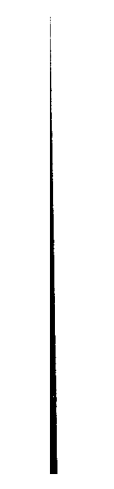

